Prepared for the U.S. Department of Energy

under Contract DE-AC05-76RL01830

\title{
Federally Funded Programs Related to Building Energy Use: Overlaps, Challenges, and Opportunities for Collaboration
}

KA Cort

RS Butner

DJ Hostick

October 2010

Pacific Northwest

NATIONAL LABORATORY

Proudly Operated by Battelle Since 1965 


\title{
DISCLAIMER
}

This report was prepared as an account of work sponsored by an agency of the United States Government. Neither the United States Government nor any agency thereof, nor Battelle Memorial Institute, nor any of their employees, makes any warranty, express or implied, or assumes any legal liability or responsibility for the accuracy, completeness, or usefulness of any information, apparatus, product, or process disclosed, or represents that its use would not infringe privately owned rights. Reference herein to any specific commercial product, process, or service by trade name, trademark, manufacturer, or otherwise does not necessarily constitute or imply its endorsement, recommendation, or favoring by the United States Government or any agency thereof, or Battelle Memorial Institute. The views and opinions of authors expressed herein do not necessarily state or reflect those of the United States Government or any agency thereof.

\author{
PACIFIC NORTHWEST NATIONAL LABORATORY \\ operated by \\ BATTELLE \\ for the \\ UNITED STATES DEPARTMENT OF ENERGY \\ under Contract DE-AC05-76RL01830
}

Printed in the United States of America
Available to DOE and DOE contractors from the Office of Scientific and Technical Information,
P.O. Box 62, Oak Ridge, TN 37831-0062;
ph: (865) 576-8401
fax: $(865) 576-5728$
email: reports $(\boldsymbol{a})$ donis.osti.gov

Available to the public from the National Technical Information Service

5301 Shawnee Rd., Alexandria, VA 22312

ph: (800) 553-NTIS (6847)

email: orders@ntis.gov $<$ http://www.ntis.gov/about/form.aspx $>$

Online ordering: http://www.ntis.gov

This document was printed on recycled paper. 


\section{Federally Funded Programs Related to Building Energy Use: Overlaps, Challenges, and Opportunities for Collaboration}

KA Cort

RS Butner

DJ Hostick

October 2010

Prepared for

the U.S. Department of Energy

under Contract DE-AC05-76RL01830

Pacific Northwest National Laboratory

Richland, Washington 99352 



\section{Executive Summary}

As energy efficiency in buildings continues to move from discrete technology development to an integrated systems approach, the need to understand and integrate complementary goals and targets becomes more pronounced. Whether within the U.S. Department of Energy's (DOE) Building Technologies Program (BTP), across the Office of Energy Efficiency and Renewable Energy (EERE), or throughout DOE and the federal government, mutual gains and collaborative synergies exist that are not easily capitalized upon because of organizational and time constraints. There also are cases where federal agencies may be addressing similar issues, but with different (and sometimes conflicting) goals in mind.

This report conducts a comprehensive inventory across all EERE and other relevant federal agencies of building-related energy efficiency programs and identifies potential activities that hold promise for collaboration and synergistic benefits. The study identifies four primary channels by which the federal government influences building energy use: internal government activities, regulatory activities, research and development (R\&D) funding, and targeted demonstration and deployment. These "channels of influence" and the activities associated with them are characterized in terms of the collaborations currently taking place, the collaborative challenges, and the opportunities for further collaboration. A taxonomy of activities with potential interdependencies is presented.

The report identifies a number of federal program objectives, products, and plans related to building energy efficiency and characterizes the current structures of and interactions between these plans and programs. Overlapping areas and the challenges of addressing issues related to overlapping goals and programs are identified. Based on the input gathered from various sources, including 20 separate interviews with federal agency staff and contractor staff supporting buildings programs, this study identifies characteristics of effective collaboration. A review of these successful collaborations revealed three key factors in common that have facilitated beneficial collaborations, including:

- Clear mission. The program and/or activities are guided by a clear, well-defined mission.

- Collaboration is intentional. The collaboration and coordination among various players is deliberate and part of the program plan. In other words, it does not just happen by coincidence.

- Transparent, documented process. The program is supported by a transparent and welldocumented process accessible to a large contingency.

While many collaborations related to building energy research, development, demonstration, and deployment (RDD\&D) are clearly taking place, there appears to be room for improvement and an opportunity to establish new collaborative efforts. Synergistic opportunities include the expansion of efforts outside of the agencies' traditional "channels of influence" such as making greater use of federal building stock and information from internal agency programs to assist in the various RDD\&D activities. In addition, there are potential synergistic benefits from uniting energy efficiency, air quality, and grid stability goals in pursuit of carbon reduction goals. The effective implementation of building energy efficiency technologies, systems, designs, and programs can be enhanced by interagency efforts to understand and integrate complementary goals and targets while minimizing any detrimental effects of potentially conflicting missions. With a deliberate, thoughtful approach that includes regular and open communication, opportunities for mutual gains through collaborative efforts can be brought to fruition. Appendix A summarizes the work in a presentation format. 



\section{Acknowledgments}

The authors express their appreciation to David M. Hunt (PNNL) and Sean C. McDonald (PNNL) who assisted with interviews and in the preparation of this document by providing comments and suggestions on the report.

The authors also express their appreciation to staff who took time from their schedules to be interviewed for this report. These include staff members from the Department of Energy (DOE) Building Technologies Program, DOE Office of Electricity Delivery and Energy Reliability, DOE Federal Energy Management Program, the Department of Housing and Urban Development, the Environmental Protection Agency, the National Institute of Standards and Technology, Pacific Northwest National Laboratory, and Oak Ridge National Laboratory. 



\section{Acronyms and Abbreviations}

ANSI

ARPA-E

ARRA

ASHRAE

BASE

BEES

BLCC

BPA

BTP

BTRD

CBI

CEC

$\mathrm{CH}_{4}$

CIAQ

$\mathrm{CO}$

$\mathrm{CO}_{2}$

DARPA

DOD

DOE

DOE-OS

DOJ

EERE

EISA

EO

EPA

EPAct

FEMP

GAO

GSA

HFC

HUD

HVAC

HVAC\&R

IAQ

IAQI\&V

ICC
American National Standards Institute

Advanced Research Projects Agency-Energy

American Reinvestment and Recovery Act

American Society of Heating, Refrigerating, and Air-Conditioning

Building Assessment Survey and Evaluation

Building Environmental and Economic Sustainability

Building Life-Cycle Cost

Bonneville Power Administration

Buildings Technologies Program

Buildings Technology Research and Development Subcommittee

Commercial Buildings Integration

California Energy Commission

methane

Committee on Indoor Air Quality

carbon monoxide

carbon dioxide

Defense Advanced Research Projects Agency

U.S. Department of Defense

U.S. Department of Energy

Department of Energy's Office of Science

U.S. Department of Justice

Office of Energy Efficiency and Renewable Energy

Energy Independence and Security Act

Executive Order

Environmental Protection Agency

Energy Policy Act

Federal Energy Management Program

Government Accountability Office

General Services Administration

hydrofluorocarbon

U.S. Department of Housing and Urban Development

heating, ventilation, and air-conditioning

HVAC and refrigeration

indoor air quality

indoor air quality, infiltration, and ventilation

International Code Council 


\begin{tabular}{|c|c|}
\hline IESNA & Illuminating Engineering Society of North America \\
\hline ISO & International Organization for Standardization \\
\hline ISWG & Interagency Sustainability Working Group \\
\hline LIHEAP & Low-Income Home Energy Assistance Program \\
\hline MELS & Miscellaneous Electric Loads \\
\hline MOU & Memorandum of Understanding \\
\hline $\mathrm{N}_{2} \mathrm{O}$ & nitrous oxide \\
\hline NASA & National Aeronautical and Space Administration \\
\hline NIST & National Institute of Standards and Technology \\
\hline $\mathrm{NO}_{2}$ & nitrogen dioxide \\
\hline NOPR & notice of a proposed rulemaking \\
\hline NREL & National Renewable Energy Laboratory \\
\hline NSF & National Science Foundation \\
\hline NSTC & National Science and Technology Council \\
\hline NYSERDA & New York State Energy Research and Development Authority \\
\hline NZEB & Net Zero Energy Building \\
\hline $\mathrm{O}_{3}$ & ozone \\
\hline $\mathrm{OE}$ & Office of Electricity Delivery and Energy Reliability \\
\hline OMB & Office of Management and Budget \\
\hline OS & Office of Science \\
\hline PFC & perfluorocarbon \\
\hline PM & particulate matter \\
\hline PNNL & Pacific Northwest National Laboratory \\
\hline $\mathrm{R} \& \mathrm{D}$ & research and development \\
\hline RDD\&D & research, development, demonstration, and deployment \\
\hline $\mathrm{SF}_{6}$ & sulfur hexafluoride \\
\hline $\mathrm{SO}_{2}$ & sulfur dioxide \\
\hline SSL & solid-state lighting \\
\hline TVA & Tennessee Valley Authority \\
\hline WAP & Weatherization Assistance Program \\
\hline WIP & Weatherization and Intergovernmental Program \\
\hline
\end{tabular}




\section{Contents}

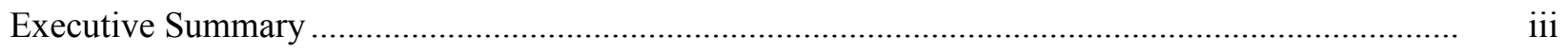

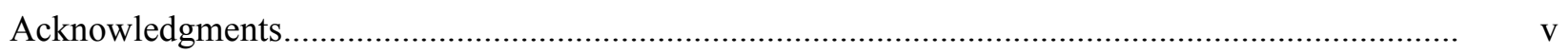

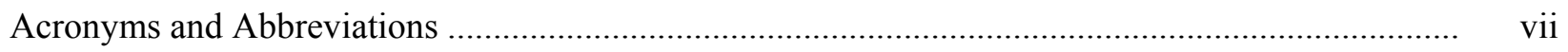

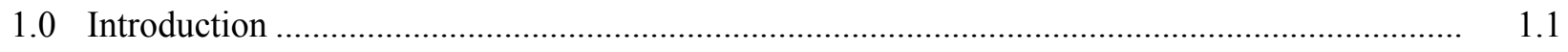

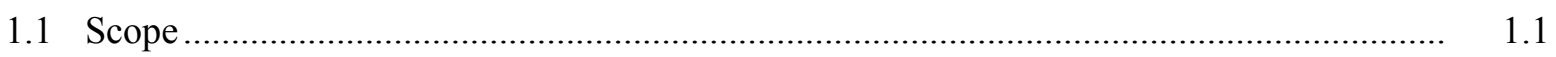

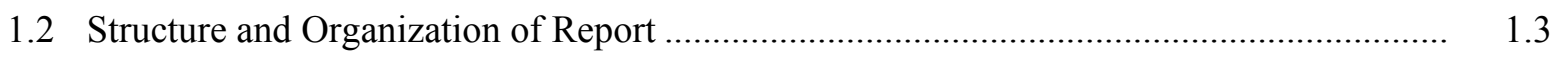

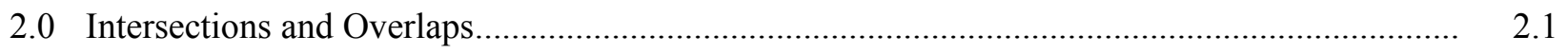

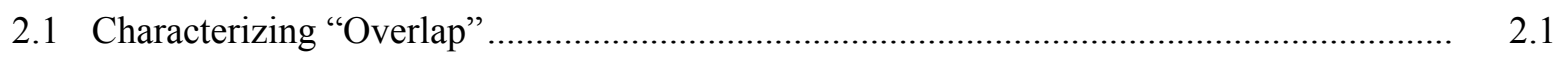

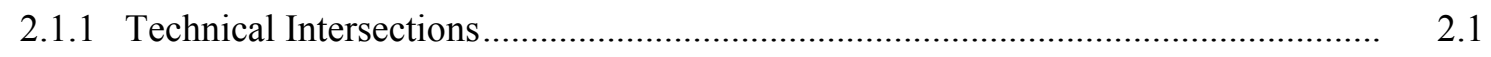

2.1.2 Organizational Intersections ......................................................................... 2.4

3.0 Characterizing Federal Government Influence on Building Energy Use ............................... 3.1

3.1 Influencing Building Energy Through Internal Federal Government Efforts .................... 3.2

3.1.1 Activities Related to Internal Federal Government Efforts ................................... 3.2

3.1.2 Interactions Related to Internal Federal Government Efforts ............................... 3.3

3.2 Influencing Building Energy Through Regulation........................................................ 3.4

3.2.1 Activities Related to Regulation of the Building Sector ....................................... 3.4

3.2.2 Interactions Related to Regulatory Efforts .................................................... 3.5

3.3 Influencing Building Energy Through R\&D.............................................................. 3.6

3.3.1 Activities and Interactions Related to R\&D Programs.......................................... 3.6

3.3.2 Summary of Interactions Related to R\&D Programs .......................................... 3.12

3.4 Influencing Building Energy Through Deployment Programs ......................................... 3.13

3.4.1 Activities Related to Building Deployment Programs ........................................ 3.14

3.4.2 Interactions Related to Building Deployment Programs...................................... 3.15

3.5 Summary Characterization of Interactions and Overlaps.............................................. 3.18

4.0 Collaboration Challenges, Solutions, and Synergistic Opportunities .................................... 4.1

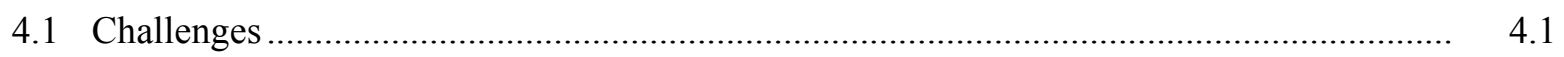

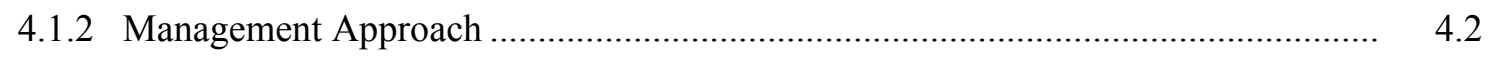

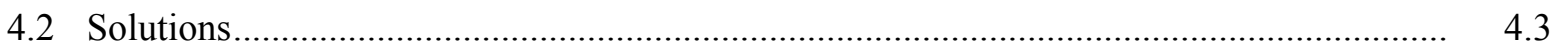

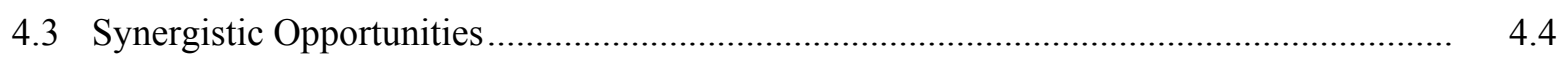

4.3.1 Thinking Outside the "Channel of Influence" ..................................................... 4.5

4.3.2 Coming Together under Carbon-Reduction Goals .............................................. 4.5

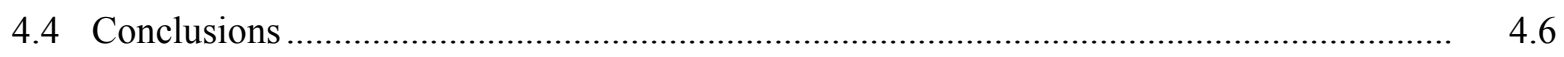

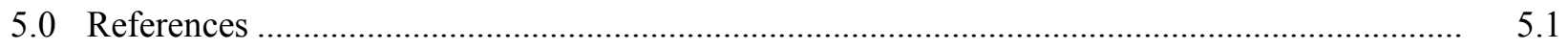

Appendix A - Summary Presentation of Study Results …..................................................... A.1

Appendix B - Contacts and Interviews........................................................................... B... B

Appendix C - List of Federal Programs and Projects Related to Buildings ................................... C.1 


\section{Figures}

2.1 Building Energy Supply and Demand Results in Many Intersections Between Building Systems, Building Envelope, Lighting, Appliances, and Generation ....................................... 2.2

2.2 Overlap Potential Related to Federal Building Activities...................................................... 2.2

2.3 R\&D, Demonstration, and Deployment Activities over the Development Timeline ................. 2.4

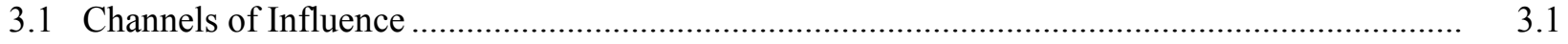

3.2 Building Energy Supply and Demand Results in Many Intersections Between Building Systems, Building Envelope, Lighting, Appliances, and Generation ........................................ $\quad 3.7$

\section{Tables}

2.1 Taxonomy of Federal Agency Activities by Topic Area ..................................................... 2.3

2.2 Taxonomy of Federal Agency Activities by Stage of "Research" ........................................... 2.5

3.1 Collaborative Interactions Related to Internal Federal Government Activities......................... 3.4

3.2 Collaborative Interactions Related to Regulatory Activities ................................................... 3.6

3.3 Federal RD\&D Programs Related to HVAC ................................................................ 3.10

3.4 Collaborative Interactions Related to R\&D Activities ...................................................... 3.13

3.5 Collaborative Interactions Related to Deployment Activities ................................................ 3.18 


\subsection{Introduction}

The U.S. Department of Energy's (DOE's) Building Technologies Program (BTP) funds research and technology development to reduce commercial and residential building energy use. BTP falls under the purview of DOE's Office of Energy Efficiency and Renewable Energy (EERE) and, although it takes the lead in directing DOE's building energy research, it is not the only program within EERE that focuses on building energy use - the Weatherization and Intergovernmental Program (WIP) and Federal Energy Management Program (FEMP) also address building energy use. In addition, the research that is conducted under EERE programs focusing on distributed energy sources (e.g., Solar Energy Technologies Program) is applicable to buildings. A number of other federal agencies outside of DOE/EERE also have programs and policies that affect building energy use. Although each of these offices and agencies is working in the same general field, each has its own missions and goals. It is therefore important for all parties involved in building energy efficiency programs to understand how all of these programs, their policies, and offices interact with one another in order to properly plan and implement effective research, development, demonstration, and deployment (RDD\&D) programs.

A lack of understanding or awareness of others' goals and needs may result in missed opportunities to advance a common objective. BTP commissioned the Pacific Northwest National Laboratory (PNNL) to conduct a comprehensive inventory of the potential building-related activities of all DOE and other relevant federal agencies. The goal of this data-gathering effort is to characterize current interactions and identify areas where further collaboration would be beneficial to more effectively achieve both individual and collective goals of energy-efficiency programs. This report summarizes the outcomes of the datagathering effort along with the input received from 20 separate interviews ${ }^{1}$ of federal agency staff and contract researchers who have supported a number of different building-related programs sponsored by the federal government.

\subsection{Scope}

PNNL researchers conducted a comprehensive inventory of all building-related activities (including research, deployment, policies and efforts, etc.) sponsored by the federal government. Although all federal agencies were originally included in the scope of the study, after a cursory search of the agencies a number of them were identified as having major efforts that related to building energy use. These agencies and their corresponding activities are summarized in Appendix B of this report. The agencies with significant efforts related to building energy use include the following:

- U.S. Department of Energy (DOE)

- Office of Energy Efficiency and Renewable Energy (EERE)

- Building Technologies Program (BTP)

- Federal Energy Management Program (FEMP)

- Geothermal Technologies Program (Geothermal)

○ Solar Energy Technologies Program (Solar)

\footnotetext{
${ }^{1}$ See Appendix B for a comprehensive list of agencies that were interviewed.
} 
- Weatherization and Intergovernmental Program (WIP)

$\circ$ Wind \& Water Power Programs (Small Wind)

- Office of Electricity Delivery and Energy Reliability (OE)

- Office of Science (OS)

- Advanced Research Projects Agency-Energy (ARPA-E)

- U.S. Department of Defense (DOD)

- Facilities

- $\quad$ The Defense Advanced Research Projects Agency (DARPA)

- U.S. Environmental Protection Agency (EPA)

- General Services Administration (GSA)

- U.S. Department of Housing and Urban Development (HUD)

- National Institute of Standards and Technology (NIST) (Within the U.S. Department of Commerce)

- Other agencies supporting basic research include the National Science Foundation (NSF) and National Aeronautical and Space Administration (NASA).

In addition to the agencies listed above, to assess the depth and breadth of government-supported building energy programs, this study included a summary review of the activities taking place at two federal government utilities, the Tennessee Valley Authority (TVA) and Bonneville Power Administration (BPA), as well as at two large state organizations involved in energy research, the New York State Energy Research and Development Authority (NYSERDA) and the California Energy Commission (CEC). The summaries of these programs are found in Appendix C.

After reviewing information about an assortment of programs and activities related to building energy from all agencies, two patterns emerged that influenced the scope and organization of the study and this report. First, it was noted that most of the federal agencies had at least some sort of programs and policies to reduce energy in their own offices/facilities. These are referred to as "internal government efforts" in this report. The leaders in this area appeared to be FEMP, whose mission it is to facilitate the Federal Government's implementation of energy management and investment policies, and also GSA and DOD, who act as "landlords" for a substantial portion of the government building stock. It should be noted, however, that others were heavily involved in these efforts, notably the U.S. Postal Service and the Department of Justice, which are also responsible for significant numbers of federal buildings. These internal efforts are discussed in Section 3.1 of this report, however, the overall characterizations of these efforts is primarily represented by our characterization of FEMP, because it plays a primary role in coordinating internal government efforts in this area.

A second pattern that emerged during this review was that a number of the agencies and offices were primarily involved in basic research. These included DARPA, ARPA-E, NSF, DOE-OS, and NASA. A brief individual assessment of these individual offices and the basic research they each support is found in Section 3.3 of this report. However, no interviews were conducted with representatives from these agencies, because the nature of basic research is to address the creation of broad new knowledge and competencies and its specific application to building energy may not necessarily be known or well- 
specified at the outset of the research. The general characterization of the activities supported by these offices/agencies is referred to collectively as "basic research" efforts throughout this report.

After reviewing information and descriptions of program activities, the scope of the more detailed review was narrowed to include the following agencies and offices:

- DOE

- Office of Energy Efficiency and Renewable Energy (EERE)

- Buildings Technology Program (BTP)

- Federal Energy Management Program (FEMP)

- Distributed Renewable (e.g., Solar and Wind)

- Office of Electricity Delivery and Energy Reliability (OE)

- U.S. Environmental Protection Agency (EPA)

- U.S. Department of Housing and Urban Development (HUD)

- National Institute of Standards and Technology (NIST).

Interviews were conducted with federal staff representing these agencies and with contractor staff supporting programs funded by these agencies to gather additional information regarding the program structure, the interactions currently taking place, the implementation challenges, and where opportunities for further collaboration might exist.

\subsection{Structure and Organization of Report}

Section 2.0 of this report defines the nature of the intersecting building technologies, systems, and issues related to building energy use. Section 3.0 characterizes federally funded programs related to building energy and identifies where intersections and overlaps throughout the federal government exist, based on information gathered from reports, program websites, and interviews with relevant staff. Although every effort has been made to accurately represent the thoughts and ideas expressed by those who were interviewed, this information has been generalized and paraphrased by the authors of this report. It should also be noted that the information gathered to write this report represents a snapshot of current activities, while the actual activities, plans, and goals that are characterized for this report are all part of a dynamic process. To reflect the more dynamic nature of these research activities and goals, we try to capture the essence of the programs, missions, and interactions, without delving into specific details, which are likely to change over the course of a given planning cycle. 



\subsection{Intersections and Overlaps}

Building energy usage is dependent on a complicated set of interactions between building equipment, components, and systems coupled with the complexities associated with the needs and behaviors of the building occupants. Multiple intersections and overlapping issues inherently exist when dealing with the energy needs in the built environment. To set the context for this study, we first examine the types of intersections and interactions that occur within the built environment.

\subsection{Characterizing "Overlap"}

Overlapping issues are inevitable when dealing with energy efficiency and energy use in the built environment. To be clear, overlapping programs or goals are not necessarily "bad" in and of themselves, but it is important to recognize where overlap occurs in order to efficiently and effectively implement programs addressing building energy use. Obviously program managers would want to avoid programs overlapping in a manner such that there is a significant resource efficiency loss that drives costs up without commensurate increases in benefits. Negative effects from overlap could occur when duplicative or conflicting efforts are undertaken or when excessive "coordination costs" (due to overlap) are imposed to organize the effort. On the other hand, having staff from multiple agencies or areas working on the same problem can have positive outcomes as well. These outcomes could include the "typical" benefits that come from a healthy team environment, including the possibility of generating a wider range of ideas and innovations. The larger community of researchers can bounce ideas off of each other, share and divide the effort, take more risks to achieve outcomes, create greater momentum, and provide mentoring and institutional knowledge on a wide range of topics. To identify where overlap occurs, we first identify the nature of the intersections and interactions related to building energy use and building energy programs.

\subsubsection{Technical Intersections}

Numerous technical intersections exist related to energy use in the built environment due to the nature of how energy is used in a building. Electricity used in the building is typically generated offsite and then distributed to the building through a series of transmission and distribution lines and transformers. Natural gas or petroleum-based fuels may also be combusted onsite to power furnaces and boilers. A building site may also be equipped with distributed energy sources, such as solar power or diesel generators. All energy sources feed an intricate set of heating, cooling, lighting, water heating, and other miscellaneous electric end-uses through an internal distribution system. The building envelope and insulation are in place to help reduce heating gains or losses (see Figure 2.1).

DOE and other federal agencies have long recognized the complex interactions that occur within the building and between the grid and distributed energy sources. A primary focus of recent research and development (R\&D) efforts coming from both DOE and NIST has been directed toward "integrations research" in order to optimize these interactions in an effort to more efficiently use energy. The sheer number of energy-related building features, however, lends itself to numerous technical interactions and overlaps in the sense that multiple players will be working on the same topic area for various reasons. Figure 2.2 provides a visual demonstration and how complicated the issues of overlap becomes when related to buildings. Table 2.1 provides a summary taxonomy of the federal agency activities by topic area. 


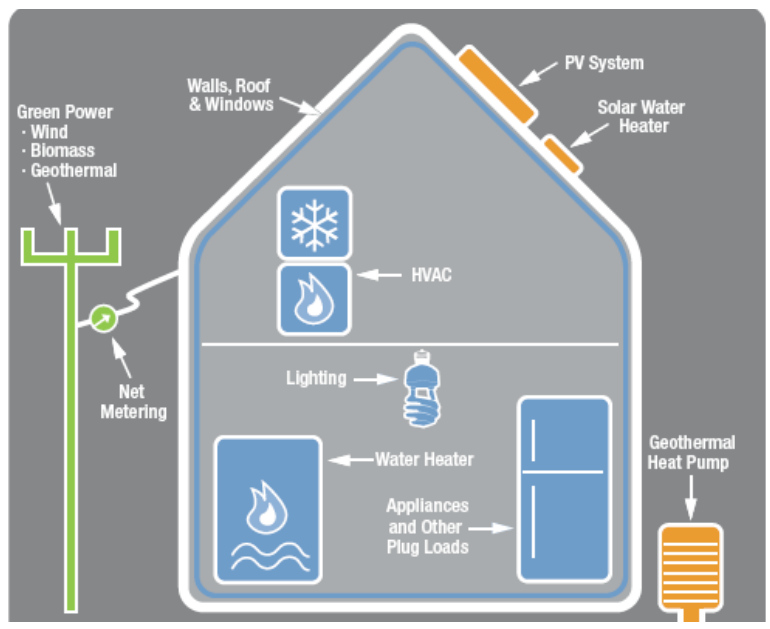

Figure 2.1. Building Energy Supply and Demand Results in Many Intersections Between Building Systems, Building Envelope, Lighting, Appliances, and Generation (Source of Graphic: MYPP: $\mathrm{RBI}^{1}$ )

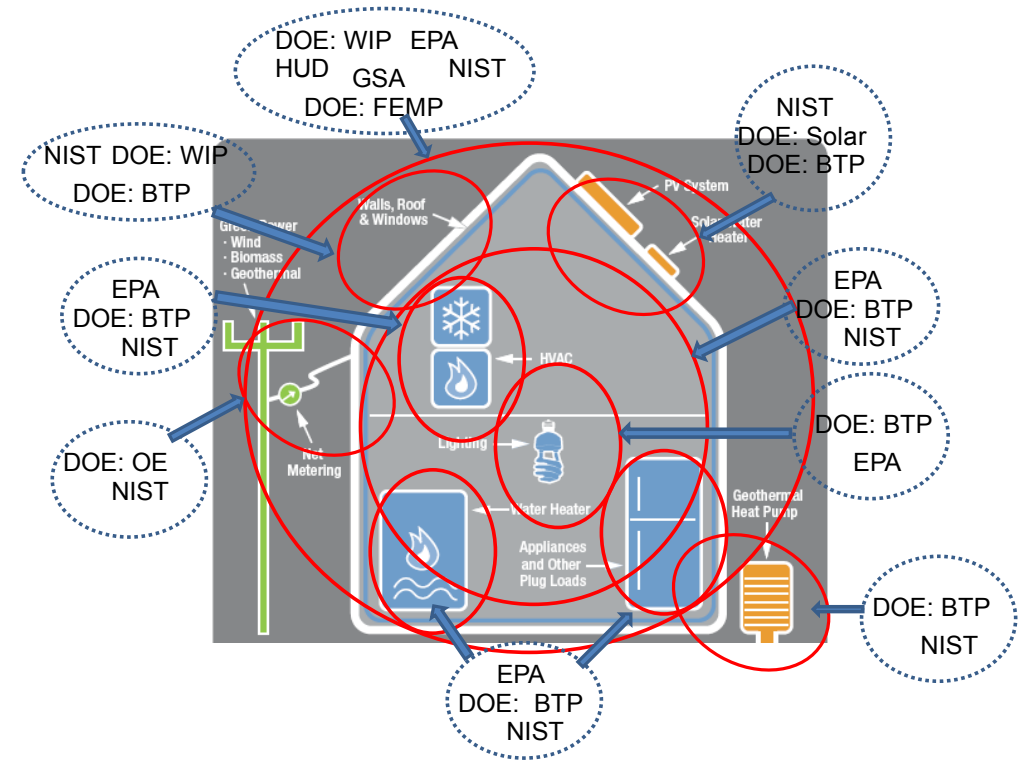

Figure 2.2. Overlap Potential Related to Federal Building Activities

Topic areas where relatively more "overlap" occurs include heating, ventilation, and air-conditioning (HVAC), refrigeration, lighting, whole building systems, and onsite generation RD\&D. The taxonomy presented in Table 2.1 also includes a non-specific topic, "Generic Energy-Reduction Goal," which represents a more generic deployment focus on reducing energy where any variety of energy-reduction approaches may be taken to achieve these goals. In general, FEMP, WIP, DOD, and GSA all fall into this category and a more detailed discussion of these activities is found in Section 3.1 of this report. With the more technology-specific topic areas, DOE, NIST, and EPA all have major efforts directed toward HVAC, lighting, refrigeration, and whole-building activities. Specific interactions are discussed more thoroughly in Sections 3.3 and 3.4 of this report.

\footnotetext{
${ }^{1}$ BTP's Multi-Year Program Planning (MYPP) meeting presentation, December 2009, presentation on Residential Buildings Integration.
} 
Table 2.1. Taxonomy of Federal Agency Activities by Topic Area

\begin{tabular}{|l|c|}
\hline \multicolumn{1}{|c|}{ KEY } & \multicolumn{1}{|c|}{} \\
\hline Major Focus Area & $\bullet$ \\
\hline Significant Effort & $\bullet$ \\
\hline Effort & $\bigcirc$ \\
\hline Addressed & blank \\
\hline Not Addressed &
\end{tabular}

The following is a qualitative assessment of the building energy related activities (whether it be research, development, deployment, analysis, or internal efforts) for 15 different offices or agencies within the federal government. The assessment is based on data collected and presented in Appendix B of this report.

TOPIC

Generic Energy-Reduction Goal

(i.e., specific topic, approach, and/or building type not specified)

Whole-Building Systems/Building Design Integration

\section{HVAC}

Thermal Distribution

Lighting Equipment

Day-Lighting

Water Heating

Refrigeration

Other Equipment \& Appliances

Windows

Opaque Envelope/Insulating Materials

Sensors and Controls (lighting, supervisory, etc.)

Miscellaneous Electric Plug Loads (MELS)

Distributed Renewable Generation

Building Commissioning and Audits

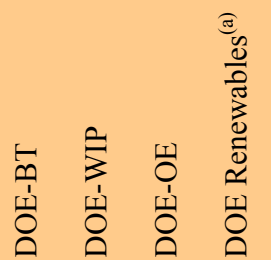

$\sum_{\substack{1 \\ 1 \\ 1 \\ 1 \\ 0}}^{2}$

○

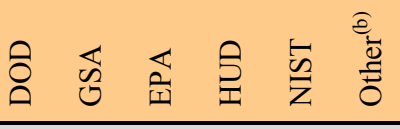

- $\odot \circ \circ$

(a) Renewable energy programs reviewed include applicable distributed generation programs such as solar.

(b) "Other" includes federal agencies conducting basic research potentially applicable to building energy include ARPA-E and DOE- OS (both part of DOE), DARPA (under DOD), NASA, and NSF. 


\subsubsection{Organizational Intersections}

Different federal agencies sponsoring building energy programs will often target specific building sectors or types of buildings in accordance with their organizational structure and mission. For example, HUD targets low-income public housing, which is directly related to its mission to provide affordable housing to all. FEMP targets the federal building stock in accordance with its mission. Intersections in program influence may occur when agencies target similar building types or use similar technologies, systems, and approaches to achieve energy-reduction goals.

Intersections in building-related activities also occur between the approaches and stages of research emphasized by a given office or agency. The stages of research and technology development are generally thought of in terms of research, development, demonstration, and then deployment of a given technology or system, where research occurs at the beginning of the cycle and "deployment" activities are predominantly implemented at the downstream phase of the technology-development cycle. Basic or fundamental research, by its very nature would occur at the very beginning of any research process, because the direct application of the research to a given technology may not even be known. Beyond basic research, however, the lines between these various stages of RD\&D are often blurred because some deployment activities will take place in the "R\&D Phase" of the program and some R\&D types of activities may also occur in support of the implementation of specific building technologies, systems, and designs (see 3).

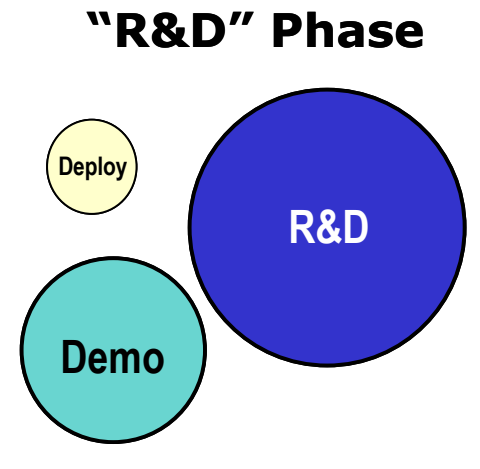

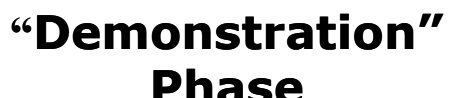

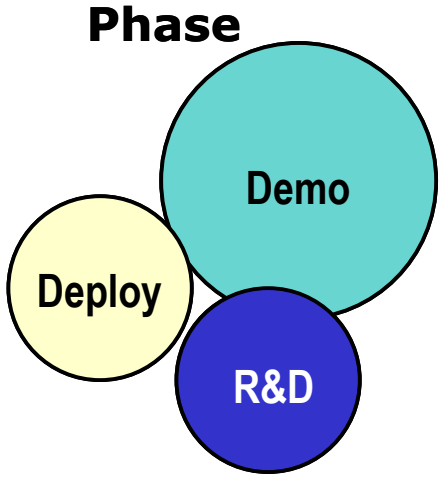

TIME
"Deployment" Phase

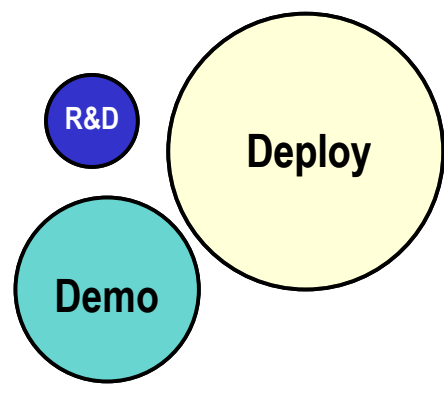

Figure 2.3. R\&D, Demonstration, and Deployment Activities over the Development Timeline

Although some offices and agencies may focus on specific stages of research, these stages and approaches will often overlap with one another. Table 2.2 provides a qualitative assessment of the analytical approaches or stages of research emphasized by the 15 different offices or agencies assessed with regard to their building activities. 
Table 2.2. Taxonomy of Federal Agency Activities by Stage of "Research"

\begin{tabular}{|c|c|}
\hline KEY & \\
\hline Major Focus Area & $\bullet$ \\
\hline Significant Effort & 0 \\
\hline Effort & $\odot$ \\
\hline Addressed & $\mathrm{O}$ \\
\hline Not Addressed & Blank \\
\hline
\end{tabular}

The following is a qualitative assessment of the activities related to building energy (whether it be research, development, deployment, analysis, or internal efforts) for different stages of research.

\begin{tabular}{|c|c|c|c|c|c|c|c|c|c|c|c|}
\hline Stage of Research (related to building energy use) & 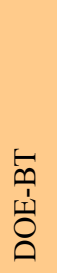 & 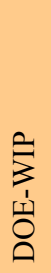 & $\begin{array}{l}1 \text { 1 } \\
0 \\
1 \\
0 \\
0 \\
0\end{array}$ & 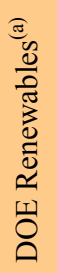 & 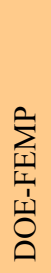 & Оิ & $\underset{\mathscr{J}}{\mathbb{J}}$ & 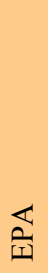 & 尽 & $\stackrel{\bullet}{\mathscr{Z}}$ & $\begin{array}{l}\hat{0} \\
\stackrel{\overline{0}}{0} \\
\stackrel{0}{0}\end{array}$ \\
\hline Analysis & $\mathbf{0}$ & O & $\mathbf{0}$ & $\mathbf{0}$ & $\odot$ & O & 0 & $\odot$ & O & $\mathbf{0}$ & $\odot$ \\
\hline \multicolumn{11}{|l|}{ Basic research } & $\bullet$ \\
\hline Applied Research \& Technology Development & $\mathbf{0}$ & & $\odot$ & $\mathbf{0}$ & & & & & & $\mathbf{0}$ & O \\
\hline Applications Guidance & $\mathbf{0}$ & O & O & $\odot$ & O & O & O & O & O & $\bullet$ & \\
\hline Field Testing \& Demonstration & - & & $\odot$ & $\mathbf{0}$ & & & & & & $\odot$ & \\
\hline Market Transformation \& Deployment & $\mathbf{0}$ & $\mathbf{0}$ & $\odot$ & 0 & 0 & 0 & 0 & $\bullet$ & $\odot$ & O & \\
\hline Training & $\odot$ & 0 & & 0 & 0 & 0 & 0 & $\odot$ & 0 & 0 & \\
\hline
\end{tabular}

(a) Renewable energy programs reviewed include applicable distributed generation programs such as solar.

(b) "Other" includes federal agencies conducting basic research potentially applicable to building energy include ARPA-E and DOE OS (both part of DOE), DARPA (under DOD), NASA, and NSF. 



\subsection{Characterizing Federal Government Influence on Building Energy Use}

There are four primary channels that the federal government can take to influence building energy use: internal government efforts, regulatory efforts, $\mathrm{R} \& \mathrm{D}$ investments, or targeted deployment activities. These four "channels of influence," or paths by which the federal government can influence building energy use, are characterized as follows:

- Internal Federal Agency Efforts. The federal government is the nation's single largest energy consumer and single largest landlord. Although many internal federal agency efforts focus on implementation and deployment of energyefficiency measures and practices, they are often supported with analysis, testing, case studies, and demonstration efforts to support the planning and deployment of certain measures.

- Regulation. Another channel of influence is regulations. When Congress passes laws related to building energy, building equipment, or any products that potentially serve the building sector, federal agencies are directed to write rules to implement the laws. DOE-BTP's Building Energy Standards and Codes program likely has the most direct regulatory influence over the building sector. The EPA also has

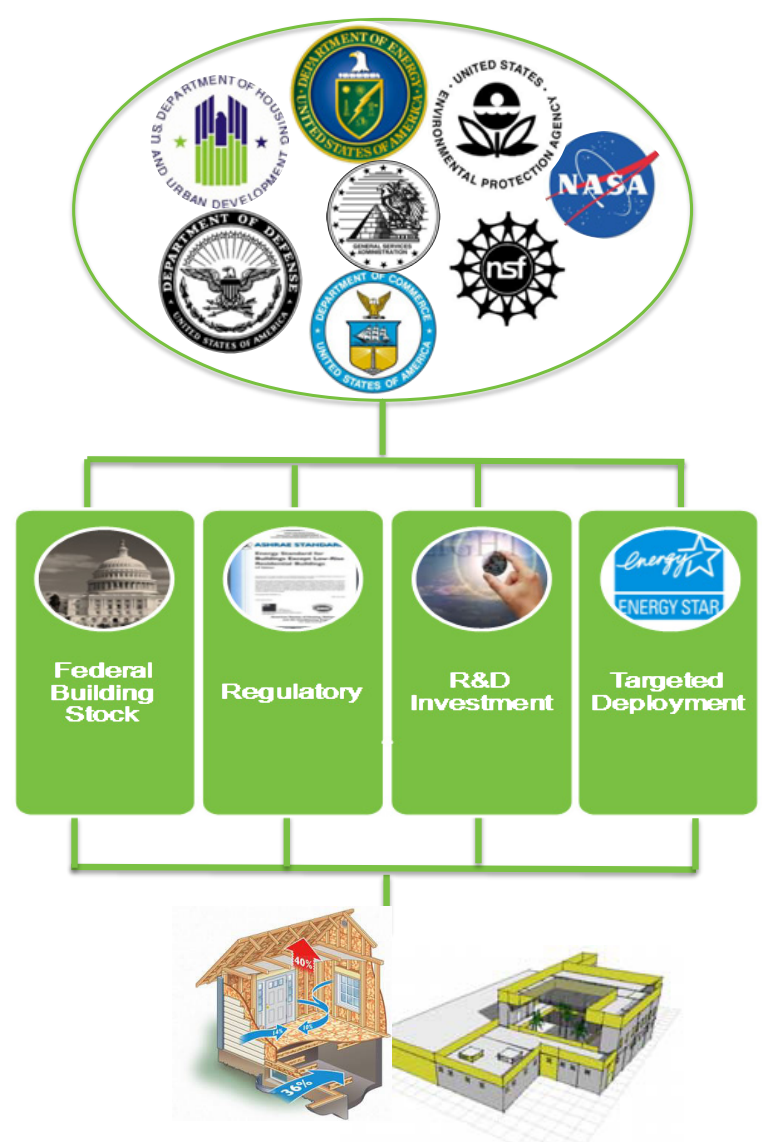

Figure 3.1. Channels of Influence regulatory influence over the building sector, although its influence over energy-efficiency is more indirect. Rule-making, deployment, and enforcement of regulatory measures are often supported with analysis, training measures, and deployment programs focused on information dissemination.

- R\&D. The federal government has historically played a significant role in funding and conducting $\mathrm{R} \& \mathrm{D}$, both at the basic research level and the more applied level, for buildings and building-related materials, technologies, designs, and systems. Although DOE has played a leading role in applied research, other agencies, such as NIST, have also been involved in building-related R\&D. In addition, a number of other agencies (NSF, DARPA, and even NASA) have been involved in more basic research questions that have potential applications in the building sector.

- Targeted Deployment Programs. A number of federally supported programs focus on building energy at a number of different levels, whether it be applied analysis, testing, and development of certain products or technologies or more focused deployment programs, which could include voluntary partnerships (i.e., federal-local government or government-private partnerships), targeted subsidies and grants, technical assistance, training, or information dissemination programs. 


\subsection{Influencing Building Energy Through Internal Federal Government Efforts}

In an effort to reduce energy consumption in the federal sector, which is the nation's single largest energy consumer, a number of laws and executive orders have been enacted over the years to establish requirements for and direct the reduction of energy and water consumption in federal facilities. Because buildings account for about 35 percent of the government's total energy usage, these laws and orders specifically address the building sector, as follows ${ }^{1}$ :

- The Energy Policy Act of 2005 (EPAct 2005) directs federal buildings to be metered “. . .for the purposes of efficient use of energy and reduction in the cost of electricity used in such buildings. .."

- The Federal Leadership in High-Performance and Sustainable Buildings Memorandum of Understanding (MOU) establishes guiding principles and goals to improve energy efficiency and water conservation in federal buildings (2006).

- Executive Order (EO) 13423 issued in January 2007 increases energy intensity reduction goals and directs that all new construction and major renovations in agency buildings comply with the guiding principles established in the 2006 MOU.

- Title IV, Subtitle C of the Energy Independence and Security Act (EISA) of 2007 builds off of previous laws and executive orders and establishes new energy- and water-management requirements and standards for federal buildings and for the agencies that oversee them.

- EO 13514 issued in October 2009 directs agencies to establish reduction targets for certain greenhouse gas emissions.

Federal agencies must report their progress toward achieving EISA goals to Congress. This report to Congress is coordinated through FEMP and the Office of Management and Budget (OMB), which issues a semiannual Executive Branch Management Scorecard to track goals.

\subsubsection{Activities Related to Internal Federal Government Efforts}

The mission of DOE's FEMP (in the EERE) is to facilitate the Federal Government's implementation of sound, cost-effective energy management and investment practices to enhance the nation's energy security and environmental stewardship. FEMP often takes the lead coordinating role to implement many of the laws and EOs that affect building energy in the federal sector. In addition, three other agencies were designated as the "implementing agencies," helping the federal government carry out EISA goals: GSA, OMB, and EPA. The GSA, which currently has management responsibilities for approximately 8,300 buildings, is directed by EISA Section 436 to establish an Office of Federal High-Performance Green Buildings and is tasked to coordinate "green" building activities across the federal government. The OMB is charged with tracking agencies' progress toward achieving various federal goals and requirements. The EPA provides energy benchmark tools and expertise to assist in the implementation of EISA and other EO mandates. NIST is also an active participant in many of the working groups and cochairs the Buildings Technology Research and Development Subcommittee (BTRD) with DOE.

\footnotetext{
${ }^{1}$ Government Accountability Office (GAO), Federal Energy Management: GSA's Recovery Act Program Is on Track, but Opportunities Exist to Improve Transparency, Performance Criteria, and Risk Management. June 2010.
} 


\subsubsection{Interactions Related to Internal Federal Government Efforts}

The many internal efforts to reduce energy in the federal building stock require coordination. Coordination is facilitated by formal organizational systems and structures, including reporting requirements, web-based tracking systems, guidelines, and benchmarking tools. A number of interagency working groups also facilitate the implementation of these goals, including the BTRD and Interagency Sustainability Working Group (ISWG), formed in 2001 in response to EO 13423. Collaborative successes derived come from these formal working groups include the coordination and consolidation of agency policies and development of best practices for implementing sustainable design and construction practices. As a result of the ISWG collaborative efforts, for example, over 189 Federal buildings located in 21 different federal agencies have been certified through the Leadership in Energy and Environmental Design (LEED) certification process. ${ }^{1}$

Most of the staff interviewed for this study reported that collaborative working groups function fairly well. A number of synergistic successes were noted to have come from these internal government collaborations, including the Labs 21 partnerships, ${ }^{2}$ which is a voluntary partnership program dedicated to improving the environmental performance of U.S. laboratories. Labs 21 is currently sponsored by DOE and EPA, and it was conceived and started from a multi-agency working group. Tools developed in support of many of these efforts include the Building Life-Cycle Cost (BLCC) and Building Environmental and Economic Sustainability (BEES) software tools developed by NIST.

Certainly some collaborative efforts work better than others. Many who were interviewed indicated that for these more "in-the-field" types of efforts a lot of the efficiency comes down to who is working with whom and the level of motivation. A number of contractors who have worked on these internal government efforts praised FEMP's collaborative style noting that it was not overly dogmatic or rigid, allowing for more autonomy by individual agencies and flexibility in the implementation of some of these measures. The primary issue that has hampered most of these efforts is that most of the associated legislative and EO requirements are not specifically funded. Therefore, the implementation of these energy-efficient efforts must be fit into the daily business of the agency. Although FEMP has the collaborative lead for most of these efforts, it does not necessarily have the funding to implement measures - just provide assistance. As a result, FEMP has to prioritize where its funding and resources are spent. All staff interviewed reported that the American Reinvestment and Recovery Act (ARRA) of 2009 stimulus funding has greatly strengthened many of these internal efforts such that implementation could take place. Table 3.1 summarizes the collaborative interactions related to internal government efforts.

\footnotetext{
${ }^{1}$ FEMP website: http://www1.eere.energy.gov/femp/program/sustainable casestudies.html .

${ }^{2}$ For further information about Labs21 Partnerships, see website: http:/www.labs21 century.gov/.
} 
Table 3.1. Collaborative Interactions Related to Internal Federal Government Activities

\begin{tabular}{|c|c|c|}
\hline Interactions that Work Well & Interaction/Collaboration Challenges & Synergistic Opportunities Identified \\
\hline $\begin{array}{l}\text { Voluntary multi-agency working } \\
\text { groups appear to work well, } \\
\text { although there seem to be more } \\
\text { and more working groups, } \\
\text { which increases the amount of } \\
\text { time spent in meetings. } \\
\text { - Having FEMP dedicated to } \\
\text { energy management and } \\
\text { collaborative role is beneficial. } \\
\text { - ARRA funding is useful } \\
\text { (although more for } \\
\text { implementation rather than } \\
\text { specific to collaboration) }\end{array}$ & $\begin{array}{l}\text { - Unfunded nature of legislation } \\
\text { and EOs. } \\
\text { - Discontinuity in program } \\
\text { implementation and shifting } \\
\text { responsibilities among staff }\end{array}$ & $\begin{array}{l}\text { Identifying more areas where } \\
\text { government building stock can } \\
\text { be used to aid development and } \\
\text { testing of new energy-efficient } \\
\text { technologies and tools and case } \\
\text { studies. } \\
\text { - Providing more collective } \\
\text { feedback (e.g., lessons learned) } \\
\text { related to energy-efficient } \\
\text { deployment concerns to RD\&D } \\
\text { programs. }\end{array}$ \\
\hline
\end{tabular}

\subsection{Influencing Building Energy Through Regulation}

When Congress passes laws related to building energy, building equipment, or any products that potentially serve the building sector, federal agencies are directed to write rules to implement the laws. EPA and DOE are the primary federal agencies with regulatory influence over the building sector. Rulemaking, deployment, and enforcement of regulatory measures are often supported with analysis, training measures, and deployment programs focused on information dissemination.

\subsubsection{Activities Related to Regulation of the Building Sector}

The Energy Policy Act (EPAct) of 1992 requires states to establish building energy codes and also establishes minimum efficiency standards for certain commercial and residential building equipment and appliances (e.g., HVAC and refrigeration equipment). DOE-BTP participates in the model national energy codes development process in coordination with the American National Standards Institute (ANSI), the American Society of Heating, Refrigerating and Air-Conditioning Engineers (ASHRAE), the Illuminating Engineering Society of North America (IESNA), and the International Code Council (ICC). DOE issues "determinations" after the issuance of updated building energy standards, determining whether or not the new standard will save energy. DOE has 1 year to publish the determination after the newest edition of the code is approved. If DOE finds that the newest version of the building energy standard is more energy efficient than the previous version, states are required by the EPAct to certify that their building energy codes meet or exceed the requirements of the new standard within 2 years. DOE also writes the rules for all building equipment and appliance efficiency standards. By law, DOE must upgrade standards to the maximum level of energy efficiency that is technically feasible and economically justified.

By an act of Congress in 1974, HUD was designated as the government agency to oversee the Federal Manufactured Housing Program designed to protect the health and safety of the owners of manufactured (mobile) homes through the enforcement of the federal standards for manufactured home construction and safety. HUD standards cover body and frame requirements, thermal protection, plumbing, electrical, fire safety, and other aspects of the home. ${ }^{1}$ Section 413 of EISA (2007) requires the DOE to establish "standards for energy efficiency in manufactured housing" within 4 years (by December 2011), which

\footnotetext{
${ }^{1}$ Manufactured home standards are published in the Code of Federal Regulations at 24 CFR 3280.
} 
would be in addition to the current HUD regulations. Eventually the EISA mandated standards would replace the energy-efficiency standards in the current HUD regulations (24 CFR Part 3280).

NIST has the mission of promoting U.S. innovation and competitiveness by anticipating and meeting the measurement needs, standards needs, and technology needs of the U.S. building and fire safety industries in ways that enhance economic security and improve the quality of life. NIST influences regulatory efforts through its development of building-related standards, as well as measurement, testing, and rating procedures. NIST does not regulate any building-related materials or processes, but it develops test procedures for various types of building appliances and equipment and develops rating procedures for voluntary accreditation programs. NIST has worked with DOE-BTP in consensus standards organizations such as ASHRAE and ASTM to develop standards, including ASHRAE 90.1, ASHRAE 62.1, ASHRAE 62.2, ASTM E917. NIST also assists HUD in the development of Manufactured Housing standards.

The EPA develops and enforces regulations any time Congress passes an environmental law. It has the primary responsibility for setting and enforcing national standards, but it sometimes delegates permitting, monitoring, and enforcement responsibility to states and Native American tribes. EPA currently regulates the following air pollutants that affect human health: sulfur dioxide $\left(\mathrm{SO}_{2}\right)$, particulate matter $(\mathrm{PM})$, ozone $\left(\mathrm{O}_{3}\right)$, carbon monoxide $(\mathrm{CO})$, and nitrogen dioxide $\left(\mathrm{NO}_{2}\right)$. The EPA also regulates six greenhouse gas emissions: carbon dioxide $\left(\mathrm{CO}_{2}\right)$, methane $\left(\mathrm{CH}_{4}\right)$, nitrous oxide $\left(\mathrm{N}_{2} \mathrm{O}\right)$, hydrofluorocarbons (HFCs), perfluorocarbons ( $\mathrm{PFCs}$ ), and sulfur hexafluoride $\left(\mathrm{SF}_{6}\right)$. This regulatory influence carries over to building energy efficiency in that some buildings and building equipment will use and emit these regulated pollutants. EPA regulates the usage of a number of other building-related materials and chemicals (e.g., asbestos, some refrigerants) and has rules that pertain to usage and disposal of water and solid waste that potentially have relevance to buildings.

\subsubsection{Interactions Related to Regulatory Efforts}

Many of the interactions and collaborations that take place between federal offices and agencies with regard to regulatory matters are prescribed by an official process. For example, the process for developing appliance and equipment energy standards (led by DOE-BTP) involves analysis, public notice, and consultation with interested parties, or "stakeholders," which include state and federal agencies and any other groups or individuals with an interest in the standards. Each stage of the rulemaking process involves Federal Register notices to place information in the public domain. DOE invites both oral and written comments at each of the first three stages. Also, DOE may directly consult with stakeholders to clarify an issue or request information. When DOE publishes a notice of a proposed rulemaking (NOPR), it must provide the U.S. Department of Justice (DOJ), the EPA, and the OMB with a copy of the NOPR and technical support documents associated with the rule. DOJ reviews the standard levels for any lessening of competition likely to result from the imposition of standards (42 USC $6295(\mathrm{o})(2)(\mathrm{B})(\mathrm{i})(\mathrm{V})$ and (ii)). Before the final rule is issued, DOE considers any comments from DOJ, EPA, OMB, and the Small Business Administration on the impacts of the proposed standard levels on competition to determine whether changes to these standard levels are needed. The publication of the NOPR is followed by a public comment period that includes a public meeting (PNNL 2010).

Although much of this process is prescribed and interactions occur on a formal and regular basis, information derived from our interviews with federal agency staff suggests that some of these interactions could improve if supplemented with more informal communication. For example, HUD has an interest in 
knowing as soon as possible in the regulatory process about any regulatory changes in the pipeline that may potentially affect low-income households and the affordability of residential housing. Because HUD deals with low-income housing, any increases in building component costs could disproportionately affect the cost of low-income housing, and as such HUD seeks to be a part of the regulatory process. Collaborative interactions are prescribed by the regulatory process, which sometimes acts as a barrier to more informal communication and collaborative efforts. Table 3.2 summarizes the collaborative interactions related to the federal regulatory influence on building energy.

Table 3.2. Collaborative Interactions Related to Regulatory Activities

\begin{tabular}{|c|c|c|}
\hline Interactions that Work Well & Interaction/Collaboration Challenges & Synergistic Opportunities Identified \\
\hline $\begin{array}{l}\text { - Interactions and collaborations } \\
\text { occur and are often mandated } \\
\text { through a formal process. }\end{array}$ & $\begin{array}{l}\text { - Interactions can sometimes be } \\
\text { quite "formal"-driven by the } \\
\text { legal system and not enough by a } \\
\text { collaborative spirit and purpose. }\end{array}$ & $\begin{array}{l}\text { - More informal interactions and } \\
\text { open communication could be } \\
\text { beneficial. }\end{array}$ \\
\hline
\end{tabular}

\subsection{Influencing Building Energy Through R\&D}

Federal Government R\&D programs related to energy efficiency have been in place since the early 1970s. Building energy performance has benefited from early research focused on heating, lighting, and refrigeration. DOE has played a leading role in this $\mathrm{R} \& \mathrm{D}$ effort and much of the research has been carried out in partnership with the building supply industry and other agencies. More recently, DOE-BTP building $R \& D$ has focused on building design and systems integration, with $R \& D$ focused on developing designs, processes, and tools to ensure optimal energy performance in buildings. Other agencies have also contributed R\&D efforts to building energy use; e.g., NIST has collaborated with DOE-EERE to tackle the R\&D needs under the 2008 Federal R\&D Agenda focusing on net zero energy, highperformance green buildings. Some other agencies that focus more on fundamental/basic research efforts have also played a role in buildings energy use, although due to the nature of basic research, the intent of the research is not always directly tied to solving building research needs. For example, NASA's research that led to the development of radiation insulation for space travel was also widely applicable to developing more effective insulating materials for homes and commercial buildings.

\subsubsection{Activities and Interactions Related to R\&D Programs}

Within the federal sector, a number of programs contain R\&D agendas that directly or indirectly target building energy use. As illustrated in Table 2.2, applied research programs include those found in DOE-EERE, DOE-OE, and NIST, while other agencies/offices such as ARPA-E, DOE-OS, DARPA, NASA, and NSF primarily focus their efforts on basic research that may affect building energy use. Other research programs not identified in this report may also produce technologies that are applicable to buildings in the future.

\subsubsection{DOE-EERE R\&D Programs Impacting Building Energy Use}

EERE supports both energy-efficiency and renewable R\&D investments that affect buildings. BTP takes a leading role in building energy-efficiency R\&D. The Solar Energy Technologies (Solar) program promotes the development of solar photovoltaics and solar water heating, which also directly affect building energy use. The Wind Program is investing in the development of "small" distributed wind 
generation, which would potentially be located onsite at the building level. There is also some cross-over analysis and testing directly related to buildings (that potentially supports R\&D efforts) that occur within WIP (residential focus) and FEMP (government buildings).

Design integration has been at the heart of BTP's commercial and residential integration and deployment programs in recent years although the focus is shifting more towards deployment, particularly towards existing buildings. As component research is the purview of other parts of BTP, much of the research for these programs has been directed toward the "technical interactions" of the building, as identified in Figure 2.1. In order to optimize the energy performance of buildings, careful integration of HVAC, lighting, and envelope materials is required. More recently, there has been added emphasis on characterizing the miscellaneous electric loads in the building. Figure 3.2 illustrates the technical interactions addressed as part of the BTP R\&D agenda. BTP's Emerging Technologies program supports solid-state lighting (SSL) R\&D, HVAC, water heat (including solar), and high-performance windows and insulating materials.

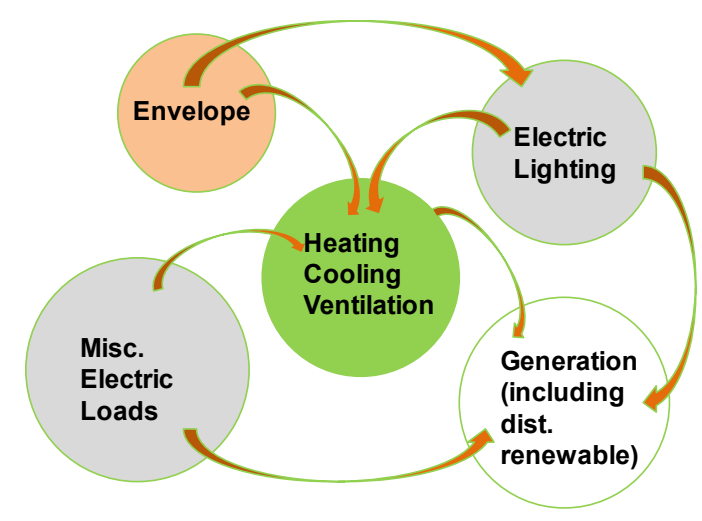

Figure 3.2. Building Energy Supply and Demand Results in Many Intersections Between Building Systems, Building Envelope, Lighting, Appliances, and Generation

To facilitate interactions between programs within BTP, an annual integration meeting has traditionally brought together researchers and program managers from emerging technologies, envelope research, and whole-building research areas. Broader research goals are addressed during this type of meeting, but the meeting does not necessarily focus on integration throughout DOE or with agencies outside of DOE. Multi-year plans are developed throughout EERE, which facilitates some coordination between offices, and these plans are occasionally coordinated with agencies outside of EERE or DOE. There has also been a great deal of planning and coordination centered around developing a research agenda for net-zero energy, high-performance green buildings ${ }^{1}$ in recent years, including multi-agency workshops and reports on the topic. In addition, the Emerging Technologies program within BTP is currently co-sponsoring a number of HVAC and refrigeration (HVAC\&R) R\&D projects with NIST.

\footnotetext{
${ }^{1}$ In 2008, the National Science and Technology Council (NSTC) established the Net Zero Energy Building (NZEB) and green buildings research agenda, which included goals for advancing technologies to transform energy, water, and materials use in buildings to achieve high-performance green buildings on a large scale.
} 
It was noted that there was not necessarily an overall BTP formal process to bring together information from different stages of research. A number of different planning tools and processes have been considered and used throughout EERE to deal with this issue. Most recently, BTP examined the Stage Gate ${ }^{1}$ process, which was being used by EERE's Biomass Program and Industrial Technologies Program. ${ }^{2}$ Although benefits of this process were identified, it has some drawbacks and to date it has not been formally adopted as a planning tool. It should be noted, however, that several of the programs include a mechanism to collect and distribute "lessons learned" and other deployment-oriented feedback into the technology development. As part of the Commercial Buildings Partnerships and Alliance programs, for example, working groups collectively identify areas where targeted technical assistance is needed and multi-lab teams focus on these "problem areas" and systematically distribute information back to alliance members through summit meetings and webinars. Similarly, the Lighting R\&D program uses systematic feedback between different stages of the research within its planning process, which is updated annually.

The staff interviewed suggested that, in general, although collaboration takes place quite regularly, these efforts are often limited by time and budget and there are not necessarily incentives in place to invest heavily in collaborative processes or interactions. In addition, some noted that although collaborative efforts may be beneficial, the benefits are often difficult to quantify, and therefore difficult to justify. Some noted a trend in more multi-laboratory (i.e., DOE laboratories) R\&D efforts and noted several pluses and minuses of these arrangements. On the plus side, when multi-laboratory efforts are well-organized and roles and responsibilities are well-defined, these efforts produce robust research and collaborative benefits; however, if roles are not well-defined, they can produce confusion and reduce the overall efficiency of a program.

\subsubsection{DOE-OE R\&D Programs}

Approximately half of the energy consumed in buildings is delivered to the buildings by the electric grid. DOE-OE is charged with leading national efforts to modernize the electric grid, enhance security and reliability of the energy infrastructure, and facilitate recovery from disruptions to energy supply. As part of this mission, OE has invested heavily in "Smart Grid" R\&D. The Smart Grid encompasses a system of technologies designed to make the electricity grid more efficient, reliable, and capable. Smart Grid technologies aim to reduce operating costs for both utilities and consumers by easing congestion and increasing capacity use through transmission corridors to accommodate the demand for electricity. In addition, Smart Grid technologies reduce the environmental impact of electricity production by reducing load during peak demand and making it easier to integrate clean energy sources into the grid. Specific investments address digital control technologies, advancing onsite energy storage technologies, deploying intelligent appliances, and developing new communication standards for appliance and grid-connected equipment. All of these technological advances would have at least some impact on buildings and building energy use.

\footnotetext{
${ }^{1}$ Stage-Gate is a process that uses a risk-management approach to improve the success rate of new products. The approach is designed to help R\&D managers make difficult decisions, first in selecting appropriate projects to pursue and then managing scarce resources by continually assessing each stage for all projects in the portfolio throughout the life of their development.

${ }^{2}$ A report examining the "Lessons Learned from Stage-Gate" was published in February 2010 by DOE-BTP.
} 
To date the goals of OE and EERE have not necessarily been well aligned. OE has been traditionally focused on the reliability of the grid and low-cost energy delivery, while EERE has focused on energyefficiency and promoting renewable energy. The intermittent nature of some renewable sources of energy and the promotion of net zero buildings does not necessarily help grid stability, which results in potentially conflicting missions between EERE and OE. To address some of these issues the Wind and Solar programs have been examining the implications of renewable generation connections to the larger grid in addition to the development and deployment of the respective generation technologies. It was noted that some of the EERE's previous efforts that focused on the vast deployment of net zero energy buildings are not necessarily conducive to grid stability on the whole. With increasing interest focused on reducing $\mathrm{CO}_{2}$ impacts, there is more possibility for OE and EERE to come together under a unifying goal because Smart Grid technologies can have measurable impacts on reducing carbon emissions by improving grid efficiency and reducing peak demands ${ }^{1}$ on the system. Achieving these goals, however, will have to be done in coordination with the building sector, which must receive and respond to the signals sent through the smart grid. Several staff indicated that the coordination and collaboration between grid research and buildings research held important synergistic benefits if appropriately implemented.

\subsubsection{NIST R\&D Programs}

NIST participates in building R\&D through its Building and Fire Research Laboratory. NIST is charged with promoting U.S. innovation and competitiveness by anticipating and meeting the measurement science, standards, and technology needs of the U.S. building and fire safety industries in ways that enhance economic security and improve the quality of life. NIST R\&D related to building energy focuses on measurement science and methods, and standards and rating development, which are applied in several different building topic areas, including whole-building performance, building commissioning, HVAC, refrigeration, solar photovoltaics, and sensors/controls. The focus of NIST's measurement science effort includes developing performance metrics and measurement methods, predictive tools, calibration methods, evaluation technologies/systems/practices, and technical guidelines and basis for standards.

As indicated in the Figure 2.1 taxonomy of topics, NIST has a number of topic areas that overlap with other agencies, including HVAC\&R and distributed renewable generation. The current set of HVAC programs is listed in Table 3.3. In terms of these technology-specific efforts, it should be noted that NIST collaborates with a number of different agencies and national laboratories. For example the Nanolubricants for Refrigerant Pool Boiling Heat Transfer and Optimization of HVAC\&R Equipment projects are co-sponsored with DOE-BTP. R\&D projects addressing photovoltaic research are in cooperation with DOE's national laboratories: Sandia National Laboratories and the National Renewable Energy Laboratory (NREL). Programs that address indoor air-quality have multiple agency sponsors including HUD, DOD, and the Department of Health and Human Services.

\footnotetext{
${ }^{1}$ Some estimates state that 10 to 20 percent of the overall electricity costs (as well as a disproportionate amount of carbon emissions) in the United States come from the top 100 hours on the electricity system. (Source: NPR Interview with Dan Delurey of the Demand Response and Smart Grid Coalition, July 7, 2010 : http://www.npr.org/templates/story/story.php?storyId=128365808)
} 
Table 3.3. Federal RD\&D Programs Related to HVAC

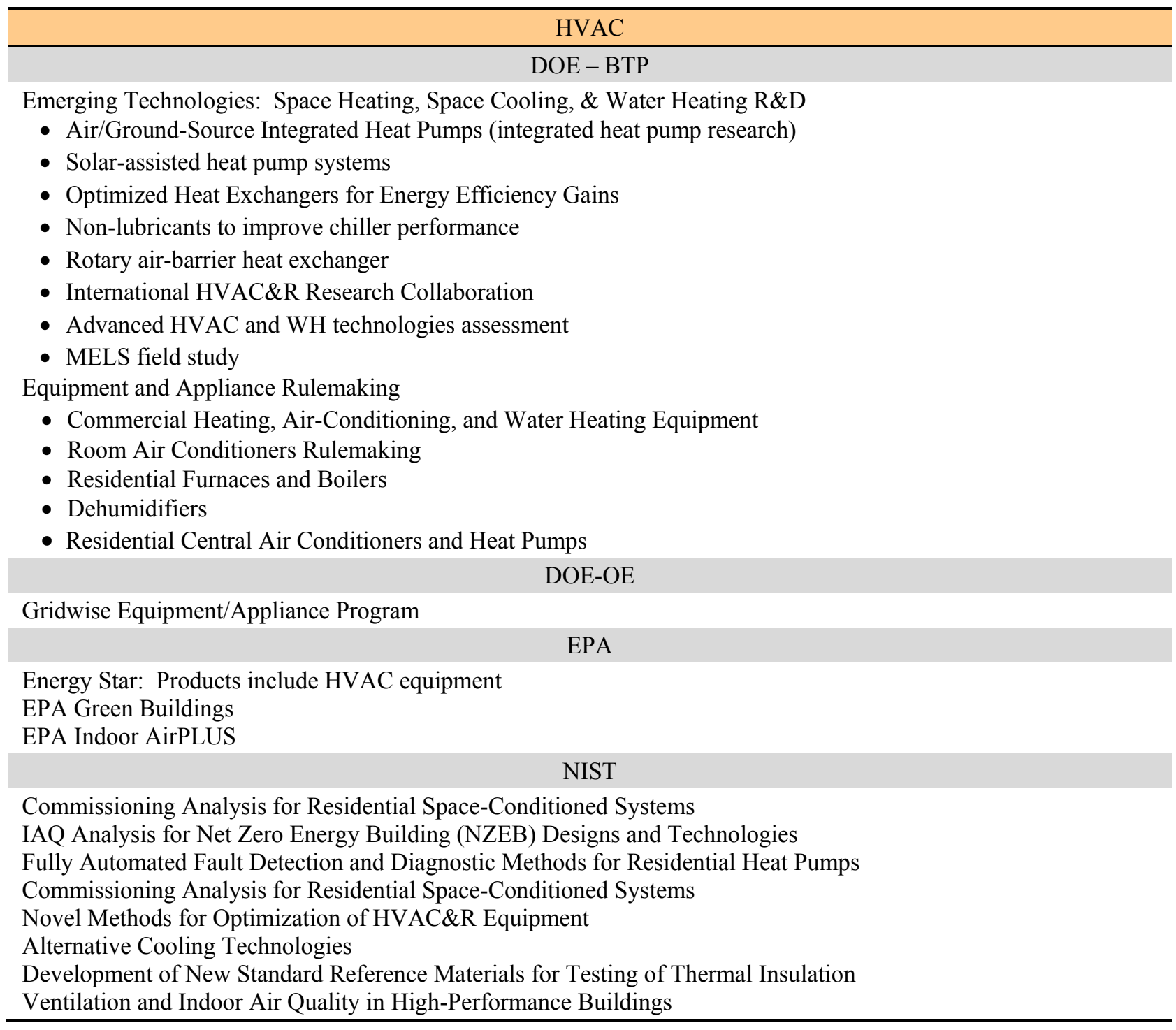

Of all the agencies reviewed as part of this study, NIST has the most deliberate collaborative approach. NIST often works in coordination with other agencies to address R\&D needs. In 2008, NIST helped establish and co-chaired (with DOE) the NSTC ${ }^{1}$ Subcommittee on Buildings Technology R\&D, which collaboratively developed a national research agenda focused on green buildings and energy efficiency. In response to the national research agenda, NIST sponsored a multi-disciplinary and multiagency workshop directed toward defining NIST's role in developing adequate "measurement science" to meet the needs of national R\&D goals. ${ }^{2}$

\footnotetext{
${ }^{1}$ The National Science and Technology Council, which was established by Executive Order 12881 (1993), is a Cabinet-level council within the executive branch, that is charged with coordinating science and technology policy across the entities that make up the federal research and development enterprise.

${ }^{2}$ NIST. March 2010. Measurement Science Roadmap for Net-Zero Energy Buildings. Available online at: http://www.nist.gov/customcf/get_pdf.cfm?pub_id=905024
} 
NIST's more collaborative approach to R\&D may stem in part from its mission to focus on measurement science and standards. These goals are often linked to larger R\&D goals and technology development efforts. In addition, the development of measurements, standards, and ratings is often most effective if it is completed in a collaborative manner. For example, one of NIST's most impactful R\&D successes was leading the development of communication protocols for Building Automation and Control, or BACnet. BACnet is now an ASHRAE, ANSI, and International Organization for Standardization (ISO) standard protocol and has been adopted in over 30 countries. Its adoption enables communication of building automation and control systems for applications such as HVAC control, lighting control, access control, and fire detection systems to exchange information, regardless of the particular building service they perform. These types of standards and guidelines cannot be developed in isolation.

NIST also works with agencies that do not have in-house R\&D capabilities or structures to meet their measurement and standards R\&D needs. For example, HUD recently commissioned NIST to develop measurement methods to measure the longevity of various weatherization materials that are frequently deployed in HUD buildings. NIST has also developed a consumer information handbook (with ZIP software tools) for WIP. Most recently, OE has funded NIST to lead the development of interoperability standards for smart meters installed at a building or facility. Systematic interaction and collaboration with outside agencies appears to be the norm rather than the exception for most NIST R\&D.

\subsubsection{Basic Research}

Because basic research often produces discoveries that are relevant to a broad range of applied uses and further application development, an effort was made to characterize programs that may potentially influence building energy efficiency in the future. Several agencies (DARPA, ARPA-E, NSF, DOE-OE, and NASA) were identified as influencing building energy needs primarily through basic research pathways. While agencies identified in this section are not necessarily focused exclusively on improving energy efficiency or answering questions directly associated with building energy efficiency in the near future, their research was identified as holding the potential to materialize into more directly impactful work in the intermediate to long-term. These activities are summarized collectively in Table 2.1 and Table 2.2 as "basic research."

DARPA focuses on funding advanced research efforts for DOD and ensures U.S. technological superiority on the battlefield. Though DARPA is focused on the development and deployment of new technologies to the battlefield, it is currently working on a number of projects that have potential applications to buildings as the technologies mature. In general, the programs fall under the "distributed generation" product focus, which reflects the agency's interest in developing deployable technologies that increase the reliability and availability of electricity on the battlefield. These include programs to develop advanced capacitors and batteries, minimizing transmission losses, or power sources that are otherwise readily transported. Other projects included in the survey include those that might one day enhance sensor and control automation.

ARPA-E, a civilian counterpart to DARPA operated by DOE, focuses on the advancement of "risky" research programs that have the potential for significant progress. Among all the basic research-oriented agencies identified, ARPA-E is the most focused on building energy efficiency, with many of its programs directly aimed at shaping new technologies to reduce energy consumption. In particular, programs under ARPA-E are focused on developing or improving elements of the Smart Grid (namely 
transmission and electricity storage), heating and cooling technologies, and overall grid stability and renewable generation integration.

The NSF acts as a funding source for basic research activities performed by American universities though grants in specific areas of work. Funding for research is distributed across seven directorates, each of which supports the advancement of science and engineering. The NSF, while covering a very large number of fields, may possibly influence building energy efficiency principally through its basic research in information and networking technology, power generation and storage, and sensors and controls. It is possible, however, that research efforts in a number of other directorates may also produce technologies that influence building energy usage. It should be noted that NSF also supports some policy research that extends into building energy area. A 2009 NSF-funded report provided guidance on how to increase the government research emphasis on innovation in sustainable energy technologies and education, including recommendations for the building sector. ${ }^{1}$

The DOE-OS is the largest source of funding for basic research in physical, chemical, and materials sciences. As such, the OS works in a broad range of disciplines to advance the understanding and production of energy and electricity across 6 program offices, in addition to managing 10 national laboratories. Many of the programs examined focused upon the manipulation of materials at a molecular level to enhance electrical storage and generation. Other areas included the development of superconductive materials, biofuels, and fuel cells. Because of these areas of focus, technologies developed under these programs are likely to be directly applicable to buildings in the intermediate to long-term future.

NASA has an established history of developing technologies specifically suited to its space-mission needs that later become applied to a variety of other civilian uses. Current research programs that may become applicable to buildings in the intermediate to distant future include aero gel insulation and ultra thin photovoltaic panels.

The overlaps of these efforts related to building energy use are categorized in Table 2.1 (taxonomy by topic) and Table 2.2 (summary by stage of research). The basic research community primarily uses refereed journal articles and specialized conferences to interact with one another and communicate findings. Depending on the topic, it may also be common practice to conduct research in larger consortiums that are made up of researchers from multiple universities, laboratories, and research institutions.

\subsubsection{Summary of Interactions Related to R\&D Programs}

Although quite a number of agencies and offices address distributed generation (see Table 2.1), no significant overlapping intersections in research or conflicts were identified by these interviews. The primary intersection challenge identified for distributed generation was between the grid and the generation unit, particularly when generation occurs on an intermittent basis. At a federal agency level, these interactions occur between the EERE's Solar/Wind programs and OE, and there are currently a number of programs focusing on the interactions between renewable generation and the grid. A major

\footnotetext{
${ }^{1}$ Building a Sustainable Energy Future: U.S. Action for an Effective Energy Economy Transformation, August 3, 2009. Available online: http://www.nsf.gov/nsb/publications/pub_summ.jsp?ods_key=nsb0955.
} 
research effort has focused on developing reliable energy storage to address the intermittency issues of associated with renewable energy.

There were a number of areas identified where collaboration works well within a given office or agency. Collaborations between agencies are less frequent, but do occur, particularly between NIST and DOE with regard to HVAC\&R development. Most staff interviewed reported that good communication facilitates useful collaborations and that communication is most effective when it is deliberate and systematic (rather than casual and adhoc in nature). Although there is disagreement about whether the previous green building and net-zero energy research agenda should be emphasized and implemented, many agreed that comprehensive roadmaps and planning efforts help to focus multiple programs toward a clearly enunciated goal, which helps multiple parties come together in a more collaborative manner. Table 3.4 summarizes the collaborative interactions related to the federal building R\&D activities.

Table 3.4. Collaborative Interactions Related to R\&D Activities

\begin{tabular}{|c|c|c|}
\hline $\begin{array}{c}\text { Interactions/Collaborations that } \\
\text { Work Well }\end{array}$ & Interaction/Collaboration Challenges & $\begin{array}{l}\text { Synergistic Opportunities } \\
\text { Identified }\end{array}$ \\
\hline $\begin{array}{l}\text { Program-specific } \\
\text { collaborations: A number of } \\
\text { programs within BTP and other } \\
\text { agencies had feedback } \\
\text { processes that worked well. } \\
\text { - Multi-agency and multi-lab } \\
\text { R\&D efforts work well when } \\
\text { roles are well defined. } \\
\text { - Roadmap efforts work well to } \\
\text { define needs and roles. }\end{array}$ & $\begin{array}{l}\text { - Budget and incentives are not in } \\
\text { place to collaborate. } \\
\text { - OE and EERE goals are not } \\
\text { traditionally well aligned and } \\
\text { sometimes conflict. } \\
\text { - Inter-agency dialogue happens on } \\
\text { an adhoc basis and is dependent } \\
\text { on the personnel involved. } \\
\text { - Discontinuity in program } \\
\text { implementation and shifting } \\
\text { responsibilities among staff }\end{array}$ & $\begin{array}{l}\text { Development of a new and/or } \\
\text { updated high-level R\&D } \\
\text { agenda (equivalent to the } \\
\text { recent NSTC-sponsored } \\
\text { NZEB agenda) to help guide } \\
\text { R\&D roles and } \\
\text { responsibilities. } \\
\text { - Overall carbon-reduction goals } \\
\text { can unify and potentially } \\
\text { facilitate needed } \\
\text { collaborations. } \\
\text { - Office-wide process such as } \\
\text { Stage-Gate may be beneficial } \\
\text { if not associated with overly } \\
\text { burdensome reporting } \\
\text { requirements. }\end{array}$ \\
\hline
\end{tabular}

\subsection{Influencing Building Energy Through Deployment Programs}

The federal government sponsors a number of deployment-oriented programs that potentially affect building energy use. These programs include a wide range of activities, from voluntary partnerships, targeted subsidies and grants, technical assistance, and training, to information dissemination programs. They also could include some forms of analysis, testing, and development of certain products or tools that directly apply to more focused deployment and marketing efforts, and, thus, fall outside of the range of the R\&D programs described in Section 3.3. In addition, FEMP, GSA, DOD, and NIST all have active deployment programs to meet the energy-reduction goals within their own building stock and facilities. These activities are addressed and characterized as "internal government efforts" in Section 3.1 of this report. 


\subsubsection{Activities Related to Building Deployment Programs}

\subsubsection{DOE Deployment Programs}

DOE's EERE has supported a number of deployment efforts that affect the energy performance of commercial and residential buildings. These efforts have included building appliance labeling, partnerships, technical assistance, information tools, tax credits for energy-efficient building improvements, retrofit grants for schools, hospitals and low-income housing, and building energy performance guidelines and standards. Within EERE, the Wind and Solar programs have also implemented deployment programs that affect building energy use with information dissemination and evaluation tools that promote the deployment of small wind and solar units at the building site.

BTP deployment activities have been organized in a number of different ways and have included programs such as EnergySmart Schools, which focuses on offering targeted technical assistance in an effort to build and renovate buildings with energy-efficient designs and technologies. Most of the BTP deployment programs are directly linked with a more R\&D-focused component of the program. For example, the Commercial Building Integration program has an R\&D effort to develop high-performance design guidelines for constructing commercial buildings that reduce energy costs by 30 percent to 50 percent over the ASHRAE standard 90.1 (ASHRAE 90.1). It also supports deployment-focused programs to deploy these high-performance designs and practices, such as Commercial Building Alliances (e.g., retail alliances, hospital alliances) and Commercial Building Partnerships, which partners DOE with building owners and operators to explore energy-saving ideas and strategies in retrofit and new construction projects. Similarly, the Building America program has an R\&D component to develop design guidelines for high-performance homes and has a deployment component to work with residential builders and developers to deploy these practices. There are also deployment programs associated with regulatory programs that include training, workshops, software, and tools to assist in energy code deployment at the state and regional level. DOE has jointly managed the Energy Star program, which promotes the market for high-efficiency appliances, windows, and lighting products through consumer education and voluntary testing and labeling of products.

Within WIP, the Weatherization Assistance Program (WAP) pays to weatherize low-income households, thereby reducing energy costs by increasing the energy efficiency of the homes and ensuring occupants' health and safety. WIP also includes the State Energy Program, which provides grants to states to enable the design and implementation of renewable energy and energy-efficiency programs. WAP-funded offices receive a portion of their funding from the Department of Health and Human Service's Low-Income Home Energy Assistance Program (LIHEAP), which is a federally funded program that provides financial assistance to low-income households to help pay their home heating and cooling bills.

\subsubsection{EPA Deployment Programs}

EPA sponsors a number of deployment-oriented programs that affect buildings. These programs sometimes directly address building energy efficiency, for example, through programs such as the Energy Star program, and they also may have more indirect impacts on building energy by targeting refrigerant use, emissions reduction, pollution prevention, water and air-quality, and waste disposal practices. The energy-efficiency programs (primarily Energy Star) are organized into three branches that address energy 
efficiency as a way to prevent greenhouse gas emissions - through products, homes, and buildings/plants. To be labeled as an "Energy Star product," the product must meet the energy-efficiency guidelines, set by EPA and DOE, which will vary by product. Homes and businesses can also earn an Energy Star rating if their building meets the performance requirements specified by the Energy Star program. The commercial building rating system is on a scale of 1 to 100 , which provides a means for benchmarking the energy efficiency of specific buildings and industrial plants against the energy performance of similar facilities. Buildings that score a 75 or greater may qualify for the Energy Star label, and EPA provides an online tool (Portfolio Manager) that will calculate the score.

In addition to the EPA's most direct influence over building energy efficiency through the Energy Star program, other agency programmatic areas may also create indirect channels through which to influence efficiency by overlapping with different components or appliances. For example, the EPA's GreenChill Advanced Refrigeration Partnership program under the Ozone Layer Protection group promotes the use of environmentally benign refrigerants through manufacturer and owner alliances, principally targeting larger units owned or operated by food retailers. While not directly focused on the energy consumption of the units, the program's emphasis on the chemical refrigerants likely affects the energy performance of the refrigeration units to varying degrees, creating an indirect channel through which agency efforts can affect energy consumption.

Other programs that may indirectly affect building energy consumption range from design guidance and contractor educational materials for home and appliance designers (such as the Target Finder tool set offered by Energy Star), to Indoor airPLUS, which promotes efficient HVAC system designs and components with the ultimate goal of improving air quality through a labeling program similar to that of Energy Star. In addition, numerous waste disposal programs exist with possible implications for buildings in the form of waste-reduction alliances and partnerships. Among these programs, the EPA is engaged with manufacturers and retailers through its Mercury-Containing Light Bulb Recycling, Safe Mercury Management, and E-cycling (i.e., recycling of electronic waste) programs.

\subsubsection{HUD Deployment Programs}

As part of HUD's mission to provide quality affordable housing for all, it manages 3500 public housing authorities in all 50 states. HUD has an internal goal to reduce the energy use in the public housing stock, but until recently it has had very little budget to implement these goals. Recently, HUD received a significant amount of money through ARRA funding to advocate the deployment of energyefficient technologies and practices promoted by DOE and EPA. One of the programs includes making bulk purchases of some of the Energy Star-rated appliances and equipment to replace aging equipment in the HUD housing stock. FEMP has assisted HUD in measuring whether or not HUD is achieving its energy-saving goals.

\subsubsection{Interactions Related to Building Deployment Programs}

Although WAP and HUD both target low-income housing, HUD targets public housing units (primarily multi-family units), which have not traditionally been a priority target for WAP. In the spring of 2009, however, HUD and DOE signed an MOU promising greater cooperation in weatherizing the 
multi-family housing stock. To that end, a revised set of guidelines was issued by WIP, ${ }^{1}$ that make it easier to weatherize HUD housing by assuming that certain HUD units would be deemed qualified for weatherization. These guidelines are intended to relieve the verification burden for these buildings. HUD also administers Section 8 housing, ${ }^{2}$ which includes all types of housing. Because "Section 8 " tenants typically qualify for weatherization assistance through WAP, HUD is currently working with regional public housing authorities to streamline the weatherization process by getting "pre-approval" for some of the Section 8 housing stock. In addition to the HUD-WAP connections, HUD has developed some links with BTP's Building America program, although interactions between HUD and BTP programs occur primarily on an intermittent basis. HUD also interacts with NIST on a fairly regular basis, because they have worked cooperatively to develop the HUD Code for mobile homes and they periodically commission NIST to address certain research areas of concern to HUD, such as the testing of sealant degradation.

For many years the Energy Star program has been run jointly by EPA and DOE, because its current structure reflects the merging of two similar programs, Energy Saver (originated at DOE) and Energy Star (originated at EPA). Management of the program was shared by DOE and EPA and divided by products such that DOE had responsibility for certain technologies and EPA had responsibility for other types of products plus the overall building in its entirety. All of the staff interviewed who have supported the Energy Star program in one capacity or another agreed that there have been overlap issues with regard to shared management of this program from its inception. As one staff member put it, "sharing is hard." Although there were differing opinions with regard to how to best resolve some of these issues, all agreed that there were problems with how the roles and responsibilities were defined and distributed. On September 30, 2009, an MOU was signed between DOE and EPA to address the management of the Energy Star program and to address coordination efforts to enhance the National Building Rating Program. ${ }^{3}$ With regard to Energy Star, the agreement calls for EPA to be the brand manager for the Energy Star product label, which includes marketing, outreach, monitoring and verification, and setting the performance level, while DOE will lead the effort to develop the testing and monitoring procedures for these products. Similarly for buildings, DOE will develop the benchmarking and testing procedures, while EPA manages the Energy Star brand and coordinates outreach, monitoring, and verification of performance. The details of this agreement are still being coordinated and implemented and many staff members interviewed felt that is was too soon to comment on the effectiveness of this new arrangement; however, several were hopeful that the changes would improve the management of this program.

With regard to the connections and intersections between R\&D and deployment efforts, several staff members involved in the deployment programs indicated that there are R\&D gaps related to developing simpler pragmatic tools to aid deployment efforts. Examples include the need for a "user-friendly" ductsealing test, methods for whole-system/building testing, and benchmarking "rules of thumb." Some expressed frustration that these potentially valuable tools are dismissed by those in the research

\footnotetext{
${ }^{1}$ WIP Memo addressing: Final Rule on Amending Eligibility Provisions to Multi-Family Buildings for Weatherization Assistance Program, March 2, 2010. Accessed online (9/14/10): http://www.waptac.org/data/files/website docs/government/guidance/2010/wpn\%2010-15\%20revised.pdf

${ }^{2}$ Section 8, or the Housing Choice Voucher Program, is a federal housing program that provides housing assistance to low-income renters and homeowners.

${ }^{3}$ The MOU can be found at: http://www1.eere.energy.gov/office eere/pdfs/epa doe agreement.pdf. A summary of the agreement as well as Frequently Asked Questions can be found online at (09/28/2010):

http://www.energystar.gov/index.cfm?c=partners.mou.
} 
community because they are imperfect. However, some headway has been made in terms of indoor air quality standards and testing and many successful collaborations have come out of this field.

Another area identified as having overlaps was the general area of benchmarking. Almost all activities dealing with benchmarking and metrics/measurement end up being a source of overlap and duplication, because each program tends to develop its own measurements instead of working collaboratively to develop a mutually effective and agreed-upon benchmark. There are some valid reasons for these distinct benchmarks, because different agencies and programs have different perspectives and goals; however, the existence of multiple metrics and benchmarks leads to duplication and confusion for those who are trying to deploy the measures. The September 30th DOE/EPA MOU was designed to address some of these benchmarking issues as part of the collaborative implementation of the National Building Rating Program, which is a joint DOE/EPA effort to establish a national energy rating and labeling program for all homes and commercial buildings. ${ }^{1}$

Another potential source of overlap and possible conflict arises with regard to air-quality, pollutionprevention, and stratospheric-protection efforts (headed by EPA) and energy-efficient equipment R\&D and deployment efforts. As previously specified, when an EPA program promotes the use of certain refrigerants as part of its pollution-prevention or stratospheric-protection program, these programs may indirectly affect energy-efficiency programs that may be promoting different kinds of refrigerants for energy-efficiency purposes. Conversely, some of the energy-efficient insulation and ventilation measures have potentially negative effects on indoor air quality. The potential for conflict in these areas has been recognized for some time and there have been a number of efforts to resolve these differences, including some MOUs signed on the topic. In fact, DOE, NIST, EPA, and other non-governmental organizations have successfully collaborated to solve a number of issues with regard to indoor air quality (IAQ) and energy-efficiency and they continue to do so while developing new building energy code standards (see IAQ Lessons Learned sidebar). NIST and EPA also worked together to develop the Building Assessment Survey and Evaluation (BASE) tool for IAQ research.

Other successful collaborations that were noted include the recent work by FEMP and EPA to revise the Portfolio Manager database that supports Energy Star for commercial buildings and facilities. To make appropriate revisions to this database, EPA has been using data gathered by FEMP to inform the development of benchmarks. FEMP has also been working with BTP to help with the product testing and evaluation of solid-state lighting technologies (i.e., CALiPER program) by identifying appropriate government facilities and using these facilities to perform testing and evaluation of new technologies.

One area identified as needing more coordination and possible deployment collaboration was OE's Gridwise appliance program. The Gridwise appliance program promotes the deployment of grid-friendly appliances into the residential market. Considering that BTP and EPA also have market transformation and standards programs addressing the same equipment, some coordination between these programs seems warranted.

Table 3.5 summarizes the collaborative interactions related to the federal agency deployment activities concerning building energy.

\footnotetext{
${ }^{1}$ Because this program was just being launched, no feedback was gathered regarding this collaborative effort.
} 
Table 3.5. Collaborative Interactions Related to Deployment Activities

\begin{tabular}{|c|c|c|}
\hline $\begin{array}{l}\text { Interactions/Collaborations that } \\
\text { Work Well }\end{array}$ & Interaction/Collaboration Challenges & $\begin{array}{c}\text { Synergistic Opportunities } \\
\text { Identified }\end{array}$ \\
\hline $\begin{array}{l}\text { - IAQ model - deliberate and } \\
\text { planned coordination to address } \\
\text { potential conflicts on an } \\
\text { ongoing basis. } \\
\text { - FEMP data and building stock } \\
\text { have enabled beneficial } \\
\text { collaborations between } \\
\text { BTP/FEMP and EPA/FEMP. } \\
\text { - Internal efforts (coordinated by } \\
\text { FEMP) have led to tool } \\
\text { development and lessons } \\
\text { learned for deployment } \\
\text { programs. }\end{array}$ & $\begin{array}{l}\text { - "Sharing" programs without clear } \\
\text { delineation of roles and } \\
\text { responsibilities sets up "turf war" } \\
\text { environment. } \\
\text { - Too many differing benchmarks } \\
\text { and metrics addressing similar } \\
\text { problems and products. } \\
\text { - Inter-agency dialogue happens on } \\
\text { adhoc basis and is dependent on } \\
\text { the personnel involved } \\
\text { - More simple tools and "rules of } \\
\text { thumb" are needed from RD\&D } \\
\text { efforts to facilitate deployment of } \\
\text { energy-efficient technologies and } \\
\text { measures. }\end{array}$ & $\begin{array}{l}\text { - Gridwise product development } \\
\text { and labeling could be } \\
\text { coordinated with other } \\
\text { HVAC-development and } \\
\text { labeling efforts. } \\
\text { - More FEMP and RD\&D } \\
\text { collaborations similar to } \\
\text { CALiPER. } \\
\text { - More data exchange between } \\
\text { deployment programs } \\
\text { (e.g., Portfolio Manager, } \\
\text { FEMP data, and BTP high- } \\
\text { performance building data } \\
\text { exchanges) } \\
\text { - Consideration should be given } \\
\text { to sharing platforms for } \\
\text { deployment as similar } \\
\text { programs are developed by } \\
\text { various agencies. }\end{array}$ \\
\hline
\end{tabular}

\subsection{Summary Characterization of Interactions and Overlaps}

There are four primary "channels" that the federal government can use to influence building energy use: internal government efforts, regulatory measures, R\&D activities, and targeted deployment efforts. With regard to the internal government efforts, a number of agencies are currently implementing a series of similar measures to reduce energy use in their own facilities. Many of these measures are undertaken in response to EOs and legislative mandates. To coordinate these efforts and share "lessons learned" from one agency to another, these agencies have formed a number of multi-agency implementation working groups. Most staff involved in these efforts reported that this deliberate coordination has worked fairly well and that it helps facilitate collaboration where needed.

Regulatory channels provide an effective means for the federal government to influence building energy use. For many of the regulatory activities, explicit requirements for consultation and coordination between various agencies are built into the process. Some of the staff interviewed felt that although the regulatory process facilitated the necessary exchange of information between various agencies, the quality of the communication could be improved if it were supplemented by less formal means of communication. The process is often driven by legal measures and rules and there is limited ability to modify the way rules and regulations are implemented.

There are multiple intersections that occur with regard to $R \& D$ programs that address building energy use. Over the years these intersections have been identified and addressed for a number of different areas - sometimes with formal R\&D roadmapping and planning efforts, and sometimes with more informal exchanges between personnel involved with these activities. As the R\&D agenda addressing building energy-efficiency evolves, many of the staff interviewed indicated that this deliberate planning 
and exchange of information must continue to occur in order to avoid duplications, conflicts, and misunderstandings, and to facilitate effective, efficient R\&D programs.

With deployment programs, many similar activities often take place under different programs and platforms. This is inherent in programs that involve on-the-ground implementation types of efforts, because one central body cannot reach all target markets at all times. However, a number of duplicative types of problems can arise when many players are working on similar issues. Multiple benchmarks, metrics, titles, and data sets can end up confusing the deployment efforts. The September 30th MOU (DOE-EPA) on this topic addresses some of these issues, but the eventual coordination of efforts comes down to the staff managing these various programs. Several staff indicated that some simple communication measures (rather than top-down, mandated, rigid measures) could help facilitate coordination and exchange of information-something along the lines of working groups or periodic conference calls. 



\subsection{Collaboration Challenges, Solutions, and Synergistic Opportunities}

Both complementary and conflicting issues can yield collaborative opportunities (see IAQ Lessons Learned sidebar below). Before an effective collaboration can take place, the obstacles that prevent a cohesive teamwork environment should be identified and addressed. This section describes some of the more prevalent challenges to beneficial collaborations and possible solutions to these challenges.

\subsection{Challenges}

The challenges to successful identification and implementation of collaborative opportunities are similar to those that hinder successful program implementation: not enough time or budget, personnel changes, lack of interest, inertia, and organizational structure. A number of staff interviewed mentioned that there is not necessarily an incentive to collaborate, in part, because there is not necessarily an easily quantifiable benefit to doing so. There is no metric, for example, for working well together, even though most would agree that working in a congenial collaborative environment has a positive impact on productivity and output. Some mentioned that the emphasis on measured results and performance metrics can work against collaboration, because the investment in collaborating is difficult to assess. With regard to the structure of a given program or agency, two overall collaborative challenges surfaced during the interviews. One involved situations where multiple programs in a similar field suffer from vague or conflicting

\section{IAQ Lessons Learned}

The indoor air quality, infiltration, and ventilation (IAQI\&V) program is a good example of multiple agencies working together to solve a problem through multiple channels of influence (e.g., research and regulatory). This collaborative effort began with the challenging issue of resolving two conflicting building goals: ensuring indoor air-quality and making building envelopes and insulation more air-tight to improve energy efficiency. In 1978, a major research effort was put in place to address indoor air quality (IAQ) caused, in part, by the design and retrofit of buildings to save energy. DOE worked with EPA and NIST, all of which have different missions and research agendas, to produce quality research that eventually informed sound regulatory changes in the area of IAQ. One of the primary lessons learned from this effort was that even the slightest perception of negative health consequences from increased energy efficiency can damage the credibility of DOE's mission to reduce energy use in buildings. Therefore, it is essential that DOE work on these matters in coordination with EPA, which has regulatory jurisdiction over air quality and whose mission is to protect human health and safeguard the natural environment. Energy efficiency, health, safety, affordable housing, and productivity are not mutually exclusive issues. DOE and other agencies should remain cognizant of other consequences of energyefficient technologies and practices and should work with other federal agencies on basic and applied research to enhance technologies with these various concerns in mind (NRC 2001). 
agendas. The other pervasive challenge has to do with how programs and agencies are managed and the overall organization of an agency, office or program.

\subsubsection{Conflicting or Vague Agendas}

The IAQ situation (see IAQ Lessons Learned sidebar) began as a conflict between agendas that was resolved through collaboration. Similarly, conflicting agendas between some of EPA's pollutionprevention programs and energy-efficiency programs pose collaboration challenges and collaboration opportunities. In both cases it is in the best interest of all parties to work together to achieve their goals. There is some concern that some goals set forth by DOE's EERE with regard to deployment of renewable energy sources and energy-efficient technologies could also conflict with some of DOE-OE's Smart Grid efficiency, stability and reliability goals. As previously mentioned, the intermittency of renewable technologies and the consequences of the vast deployment of NZEBs can work against grid stability. Although it may be challenging to bring these two agendas together, there appear to be many advantages to collaborative teaming to resolve issues as details of the Smart Grid initiative materialize.

Vague agendas can also lead to communication challenges that pose collaborative challenges as well as collaboration opportunities. In the past 10 years a number of "sustainable" and "green" initiatives and EOs have focused on buildings. Energy-efficiency is one component of a sustainable building; ${ }^{1}$ but specific guidance and details regarding how to achieve sustainable practices and sustainable building operations are not always well-defined. In some cases, the rather vague sustainability goals would lead to struggles between the management of water use, energy-efficiency, and materials and disposal, pitting one effort against another. Through the collaboration of various agencies, primarily through the internal government efforts (e.g., working groups), the specific agendas for some of these efforts have become more well defined and refined and, as a result, the implementation of some of these measures has become more efficient and effective.

\subsubsection{Management Approach}

The overall management approach of a given program can either enable or pose challenges to effective collaboration. Several interviewed staff mentioned that if "management," at any given level, does not recognize or value the potential benefits of collaboration or understand how effective collaboration takes place, then it is obviously difficult to justify or implement useful collaborations with outside parties. The staff interviewed did not, however, see any need for additional management tools or systems to facilitate more collaboration (see Open Government Directive sidebar text). Instead, many favored traditional communication channels to facilitate the exchange of information. Management and staff continuity also appear to play a role in facilitating collaborative efforts. When program managers are changed frequently and program agendas shift from one focus to another, it is very difficult to pick up any collaborative momentum on any given topic. The organizational structure can also be set up in a manner that works against collaboration. For example, programs that compete with each other for limited funding will often result in turf battles and secrecy rather than a collaborative atmosphere and practices.

\footnotetext{
${ }^{1}$ A "sustainable" building could generally be thought of as one that is designed and operated based on the principles of resource efficiency, health, and productivity such that a building's total economic and environmental impact and performance (from material extraction and product manufacture to product transportation and construction), operations and maintenance, and building reuse or disposal are all considered and optimized (USGBC 1996).
} 


\subsection{Solutions}

As part of the series of interviews conducted for this study, each interviewee was asked to provide examples of "good" inter-agency collaborative efforts and to discuss why these efforts worked well. Out of the many examples, there were four areas that we will highlight because they collectively provide insight into how to make collaboration an effective tool to get things done. These include the IAQ effort (throughout the past 30 years), the NIST Advanced Building Energy Technologies research, BTP Lighting $\mathrm{R} \& \mathrm{D}$, and various FEMP efforts. All four of these efforts have three primary factors in common that have facilitated beneficial collaborations:

- Clear mission. The program and/or activities are guided by a clear, well-defined mission.

- Collaboration is intentional. The collaboration and coordination among various players is deliberate and part of the program plan. In other words, it does not just happen by coincidence.

- Transparent, documented process.

The program is supported by a transparent and welldocumented process accessible to a large contingency.

A number of staff interviewed who support programs in different agencies called out IAQ research and guidelines as an example of multiple agencies working well together to solve a problem through several channels of influence (e.g., research and regulatory). This effort has matured to point where collaboration is somewhat prescribed through a series of standards upgrades and processes. The Federal Interagency Committee on Indoor Air Quality (CIAQ) has the mission to coordinate federal IAQ research while facilitating the

Open Government Directive - Can building energy program management learn from any of the measures taken in response to this directive?

In December 2009, the White House issued its Open Government Directive and launched an ambitious program to make government data available to all, to make its processes transparent, and to make its culture collaborative. In response to this directive a number of collaborative tools and platforms have been developed to aid collaborative efforts. As part of the interview process, we provided descriptions of some of these tools and platforms (e.g., internal wikipedias and data exchanges) to gauge interest. In general, most of the federal staff interviewed implied that they actually had most of the tools they needed and that additional tools and more requirements to move data online would not necessarily facilitate greater collaboration. Instead, many favored simple approaches (see Section 4.2) and traditional communication channels to facilitate the exchange of information. Nevertheless, a number of useful observations have been made regarding the Open Government Directive, and examples of some of the solutions have been highlighted in GSA's Intergovernmental Solutions Newsletter: Government by Collaboration (Spring 2010). In particular, John Kemensky's article on "Preconditions for Successful Collaboration," and Theresa Pardo's article, “A Core Capability for 21st Century Government," are useful reading for all program managers.

exchange of information among federal agencies, state and local governments, the research community, the private sector, and the general public. The CIAQ is co-chaired by EPA, DOE, the Consumer Product 
Safety Commission, the National Institute for Occupational Safety and Health, and the Occupational Safety and Health Administration. Other federal departments and agencies also participate as members.

The mission of NIST's emerging technologies research is to provide measurement science that will advance building energy technologies and enable their deployment. Most of the efforts within this research area are completed in collaboration with other parties. In fact, with most of the research efforts sponsored by NIST, collaboration appears to be more the rule than the exception, suggesting that collaboration is intentional. NIST is very conscientious about carving out its role and mission as part of the overall R\&D mission. The details of all NIST HVAC programs are documented and available online and in published annual reports.

Interviews with a number of staff representing multiple agencies highlighted some of BTP's Emerging Technology R\&D efforts as having collaborative components. The BTP Solid-State Lighting R\&D was often highlighted as having a healthy collaborative component to it, although most of the collaboration that takes place within this program is between BTP and industrial partners rather than between federal agencies. It was noted that one of the reasons staff felt this program stood out is that it had a very clear mission (in part due a legislative mandate) and that it had continuity of R\&D activities, mission, and budget over the course of a number of years, which does not typically occur with some of the building R\&D and deployment programs. The processes were also very open, transparent, and well documented in an annual strategic planning report.

Some staff pointed out that FEMPs existence as a coordinating body serves as a source of good collaboration amongst federal agencies. FEMP also provided continuity and coordination to many of the internal efforts and, because FEMP has the responsibility for coordinating energy-savings results and reporting them to Congress, its processes are well documented and transparent. Many of the internal government efforts have resulted in beneficial tools and processes that could potentially benefit other deployment efforts.

\subsection{Synergistic Opportunities}

In addition to observing some of the challenges that must be overcome to effectively conduct collaborative efforts, several synergistic opportunities were identified that could potentially benefit from additional collaboration. Several collaborative efforts had just begun, including the National Building Rating Program stemming from the September 30th MOU. Because of the early stage of this effort, no feedback about it was solicited during the interviews. Some other opportunities also "in the works" include newer retrofit-focused programs within BTP, such as the Better Buildings program. Several staff pointed out that there would likely be synergistic opportunities for some of these newer initiatives working with other programs that have targeted existing stock, such as Energy Star Home Performance and weatherization programs within WIP. At the time of the interviews, discussions were taking place between some of these programs, but it was too soon to assess the collaborative potential and processes associated with these programs. Two overall synergistic opportunities were repeatedly identified during the interview process and are discussed in the following sections. 


\subsubsection{Thinking Outside the "Channel of Influence"}

The programs addressed in this report were characterized through their "channels of influence" (internal government efforts, regulatory, $\mathrm{R} \& \mathrm{D}$, and deployment) not only for the sake of providing context and categories, but primarily because activities are typically carried out within a given channel with little interaction outside of that channel of influence. However, a number of cases involved beneficial collaboration outside of the channel of influence. FEMP provided two examples where it collaborated both with BTP R\&D (Solid-State Lighting) and EPA. Recent FEMP and BTP collaboration to use strategic government buildings and facilities to conduct testing for the Lighting R\&D program produced beneficial results. FEMP also collaborated with EPA to improve its Portfolio Manager database with data collected for FEMP reporting requirements. NIST provided examples of tools developed for internal government efforts that would have useful applications to deployment efforts. More opportunities and collaborations of this nature should be pursued and implemented.

Interviewees identified sensors and controls as cross-cutting technologies that enable collaboration across various technologies and channels of influence. However, some staff felt that sensors and controls were underfunded in part because it is difficult to quantify the collaborative benefit of this enabling technology. Sensors and controls have the ability to bring together various research efforts, in particular, Smart Grid (OE-led) and "smart buildings" (led by DOE and outside organizations including utilities). Sensors and controls research will often overlap with some of the NIST efforts related to interoperability standards and measurements. Sensors and controls hold promise for bringing low-cost energy savings to retrofits, which may also affect HUD, BTP (Better Buildings), and EPA's Commercial Energy Star and Home Energy Performance programs.

\subsubsection{Coming Together under Carbon-Reduction Goals}

As previously mentioned, the deployment of renewable energy sources and energy-efficient technologies promoted by EERE will not necessarily be helpful to OE's mission to make the electric grid stable and reliable. On the other hand, many of the carbon-reduction benefits touted by OE's Smart Grid initiative are dependent on the responsiveness of the building (demand-response) to signals from smart meters. If the Smart Grid and the building sector are not working well together, these benefits may not be realized. There appears to be a significant need for DOE-EERE, DOE-OE, EPA, and NIST to collaborate under the overarching goal of reducing carbon dioxide emissions. The Smart Grid could significantly reduce peak demand, which could significantly reduce carbon emissions; however, none of this will be possible without the building sector's "cooperation" through demand-side management measures. Although these demand-side measures may not necessarily call for a federal role, there are a number of linkages between the considerable amounts of RD\&D taking place in building energy and Smart Grid efforts that should be examined and understood in order to develop a comprehensive plan to address carbon reductions in this area. In addition to strategic demand response, OE and EERE will need to work together to prepare for the potentially vast deployment of plug-in hybrid electric vehicles, which could dramatically affect both building energy usage and the electric grid. Some interviewees suggested that a collaborative R\&D agenda on this topic, equivalent to that sponsored by the NSTC for high-performance green buildings (2008) should be initiated to clearly state the mission and goals and delineate the roles responsibilities to various relevant agencies. 


\subsection{Conclusions}

A number of federal agencies are currently funding activities that focus on improving energy efficiency in buildings. Energy efficiency in buildings is dependent on a complicated set of technical and organizational factors. The effective implementation of building energy efficiency technologies, systems, designs, and programs can be enhanced by interagency efforts to understand and integrate complementary goals and targets while minimizing any detrimental effects of potentially conflicting missions.

Successful collaborations require a clear mission, intentional collaboration, and a transparent, documented, accessible process. While there are some ongoing collaborative efforts between the agencies including several successful collaborations highlighted in this report, there appears to be both room for improvement as well as the opportunity to establish new collaborative efforts. Synergistic opportunities include the expansion of efforts outside the agencies' traditional "channels of influence," making greater use of federal buildings as an aid in the various RDD\&D activities, and the potential to come together in pursuit of carbon reduction goals by uniting energy efficiency, air quality, and grid stability goals. Enhanced collaboration can also lead to an increase in ideas and innovation while leveraging the risk to individual agencies. However, these mutual gains and synergies are not easily achieved without a deliberate, thoughtful approach within and between Federal agencies and programs. 


\subsection{References}

24 CFR Part 3280. Code of Federal Regulation, Title 24, Part 3280.

42 USC6295. Title 42 of U.S. Code, Section 6295.

American Society of Heating, Refrigerating and Air-Conditioning Engineers (ASHRAE 90.1). 2004. ASHRAE Standard Energy Standard for Buildings Except Low-Rise Residential Buildings. ANSI/ASHRAE/IESNA Standard 90.1-2004. Atlanta, Georgia.

Buildings Technology Program (BTP). 2009. "White Paper: Lessons Learned from Stage-Gate®.” May 2009, Version 1 DRAFT, Department of Energy, Washington D.C.

Energy Efficiency and Renewable Energy (EERE). 2008. Building Technologies Program Planned Program Activities for 2008-2012. U.S. Department of Energy, Washington D.C.

The Energy Independence and Security Act (EISA) 2007. Pub. L. 110-14.

Energy Policy Act (EPAct) 1992. 102nd Congress H.R.776.

Federal Energy Management Program (FEMP). 2010. Federal Buildings Awarded LEED Certification. Updates available online from: http:/wwwl.eere.energy.gov/femp/program/sustainable casestudies.html

National Institute of Standards and Technology (NIST). 2010. Building \& Fire Research Laboratory: Activities, Accomplishments \& Recognitions. Gaithersburg, MD.

National Institute of Standards and Technology (NIST). 2010. Measurement Science Roadmap for NetZero Energy Buildings. Workshop summary report. Gaithersburg, MD.

National Research Council (NRC). 2001. Energy Research at DOE: Was it Worth it? National Academy Press, Washington D.C.

National Science Foundation (NSF). 2009. Building a Sustainable Energy Future: U.S. Action for an Effective Energy Economy Transformation., Arlington, VA.

National Science and Technology Council (NSTC). 2008. Federal Research and Development Agenda for Net-Zero Energy, High-Performance Green Buildings. Report of the Subcommittee on Buildings Technology Research and Development. October 2008.

Pacific Northwest National Laboratory (PNNL). 2010. Rulemaking 101: A Comprehensive Guide to the Appliances and Commercial Equipment Standards Rulemaking Process, Terminology, and Resources." DRAFT report, Richland, Washington.

U.S. Department of Energy (DOE)/U.S. Environmental Protection Agency (EPA). 2009. "Memorandum of Understanding on Improving the Energy Efficiency of Products and Buildings Between The U.S. Environmental Protection Agency and The U.S. Department of Energy.” September 30, 2009. Washington, D.C. 
U.S. Government Services Administration (GSA). 2010. Intergovernmental Solutions Newsletter: Government by Collaboration. Spring 2010. Accessed online September, 2010 at:

http://www.usaservices.gov/pdf docs/Government by Collaboration.pdf

U.S. Government Accountability Office (GAO). 2009. Federal Energy Management: Agencies Are Taking Steps to Meet High-Performance Federal Building Requirements, but Face Challenges.

Washington, D.C.

U.S. Government Accountability Office (GAO). 2008. Green Affordable Housing: HUD Has Made Progress in Promoting Green Building, but Expanding Efforts Could Help Reduce Energy Costs and Benefit Tenants. Washington, D.C.

U.S. Green Building Council (USGBC). 1996. Sustainable Building Technical Manual. Public Technology Inc., Washington D.C. 


\section{Appendix A}

\section{Summary Presentation of Study Results}





\title{
Appendix A
}

\section{Summary Presentation of Study Results}

\section{Federally Funded Programs Related to Building Energy Use: Overlaps, Challenges, and Opportunities for Collaboration}

\author{
DOE BTP Analysis and Evaluation:
}

PNNL Task 01-2010

\section{Objective}

- Conduct comprehensive inventory across all EERE and other relevant Federal agencies of potential building activities with synergistic benefits.

- Develop a taxonomy of activities with potential interdependencies.

- Solicit feedback with interviews from key parties and players to assess the potential benefits from collaboration and to determine appropriate channels that would facilitate team work and integration.

- Draft report identifying complementary or conflicting activities with recommendations for approach(es) to increase communications between the key players and organizations, thereby increasing the probabilities of success across all organizations. 


\section{SCOPE}

- DOE (EERE, OE, OS, ARPA-E)

- DOD (Facilities, DARPA)

- EPA

- GSA

- HUD

- DOC (NIST)

- NASA

- NSF

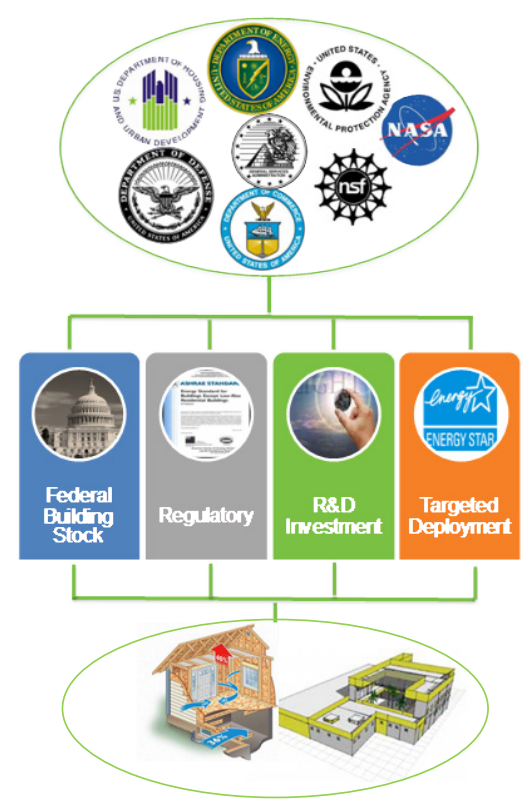

\section{Methodology}

- Database developed with information on over 100 building-related programs/projects sponsored by federal agencies

- Over 20 interviews conducted with federal agency staff and national laboratory staff supporting building-related programs

- Detailed description of findings in report form and appendices 


\section{Potential for Technical Interactions Related to Building Energy}

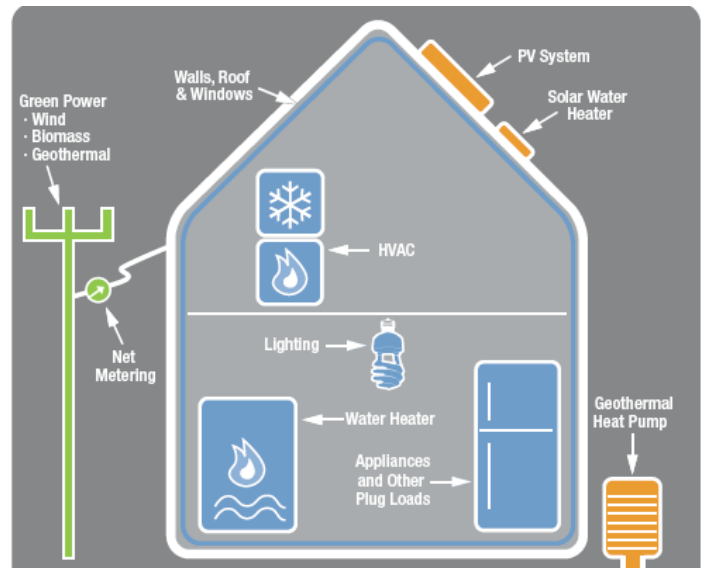

Overlap Potential Related to Federal Building Activities

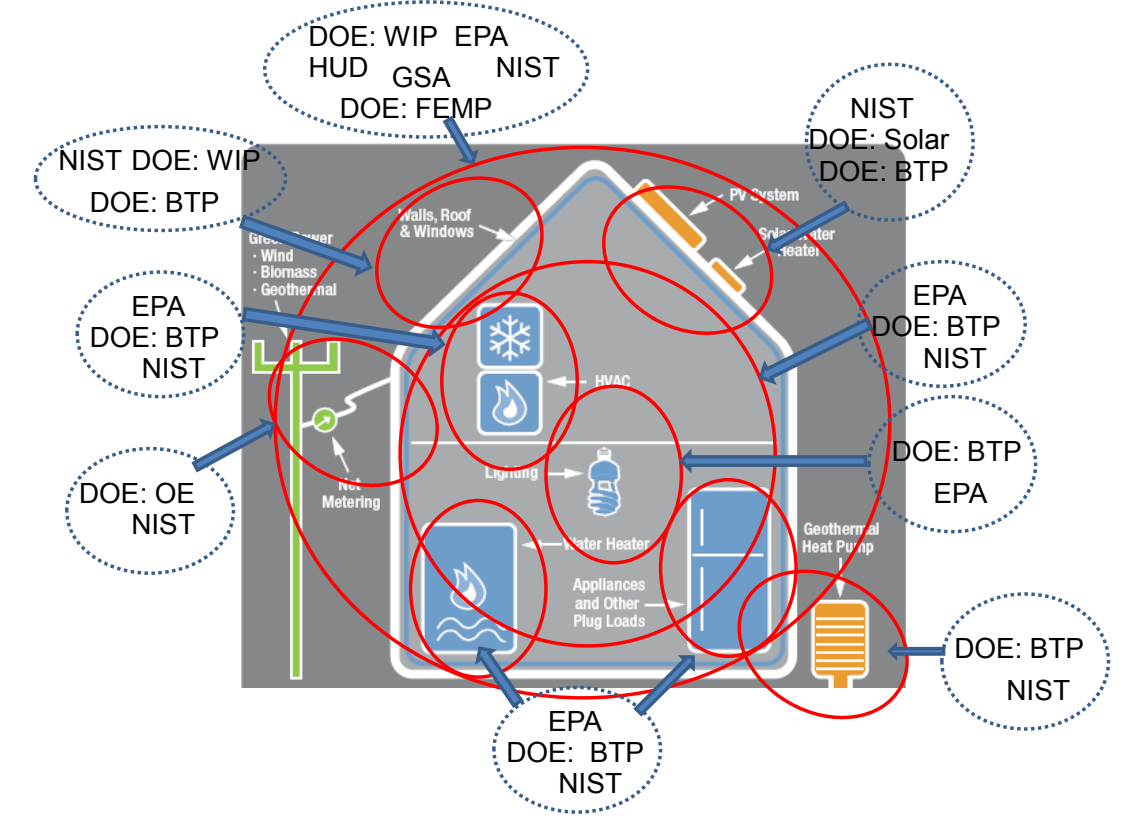




\section{Overlap "issue" exacerbated by. . .}

- Targeting a vast and diverse building stock (potential for similar and parallel efforts)

- Numerous "players" and incentives at work within building sector

- Multiple missions and goals (energy-efficiency, sustainability, affordability, grid stability)

- Targeting different phases of RD\&D for similar end-uses, technologies, designs, and systems

- Evolving renewable generation and grid capabilities

Federal Government Agencies Influence Building Energy Through Four Primary Channels

\section{Internal Federal Agency Efforts}

- Sustainability and energy-efficient initiatives, executive orders, and legislation that affect government building stock

\section{Regulatory}

- Decisions and rules written and enforced by agencies

\section{R\&D}

- Basic and applied research, development, and testing funded by federal agencies

\section{Targeted Deployment Programs}

- Voluntary partnerships

- Subsidy and targeted grant funding

- Technical assistance

- Testing and protocols

- Training and Information 


\section{Internal Government Efforts}

\section{Interactions/Collaborations that Work Well}

- Voluntary multi-agency working groups

- FEMP having dedicated role to coordinate and assist

Interactions/Collaboration Challenges

- Unfunded nature of legislation and executive orders

- Discontinuity in program implementation and shifting staff responsibilities

\section{Synergistic Opportunities}

- Identifying more areas where government building stock can be used to aid research, development, demonstration, deployment programs

- More collective feedback (e.g., lessons learned) related to deployment

Regulatory Efforts
- Interactions and collaborations are often mandated through
formal regulatory process.
Interactions/Collaboration Challenges
- Formality of interactions are driven by legal process and not
"enough" by collaborative spirit and purpose.
$\begin{aligned} & \text { Synergistic Opportunities } \\ & \text { - More formal interactions and open communication could be } \\ & \text { beneficial. }\end{aligned}$




\section{R\&D Activities}

\section{Interactions/Collaborations that Work Well}

- A number of projects have collaboration and interactions that are built into the program plan and work well.

- Formal R\&D agendas and roadmaps have helped define roles and have facilitated fruitful collaboration.

\section{Interactions/Collaboration Challenges}

- Budget and incentives often do not work in favor of collaboration.

- Mission and goals of different offices are not always well aligned and can conflict.

- Discontinuity in program implementation and shifting roles .

- Inter-agency interactions occur on ad hoc basis.

\section{Synergistic Opportunities}

- Development of revised inter-agency R\&D agenda is needed.

- Overall carbon-reduction goals could unify and potentially facilitate needed collaboration.

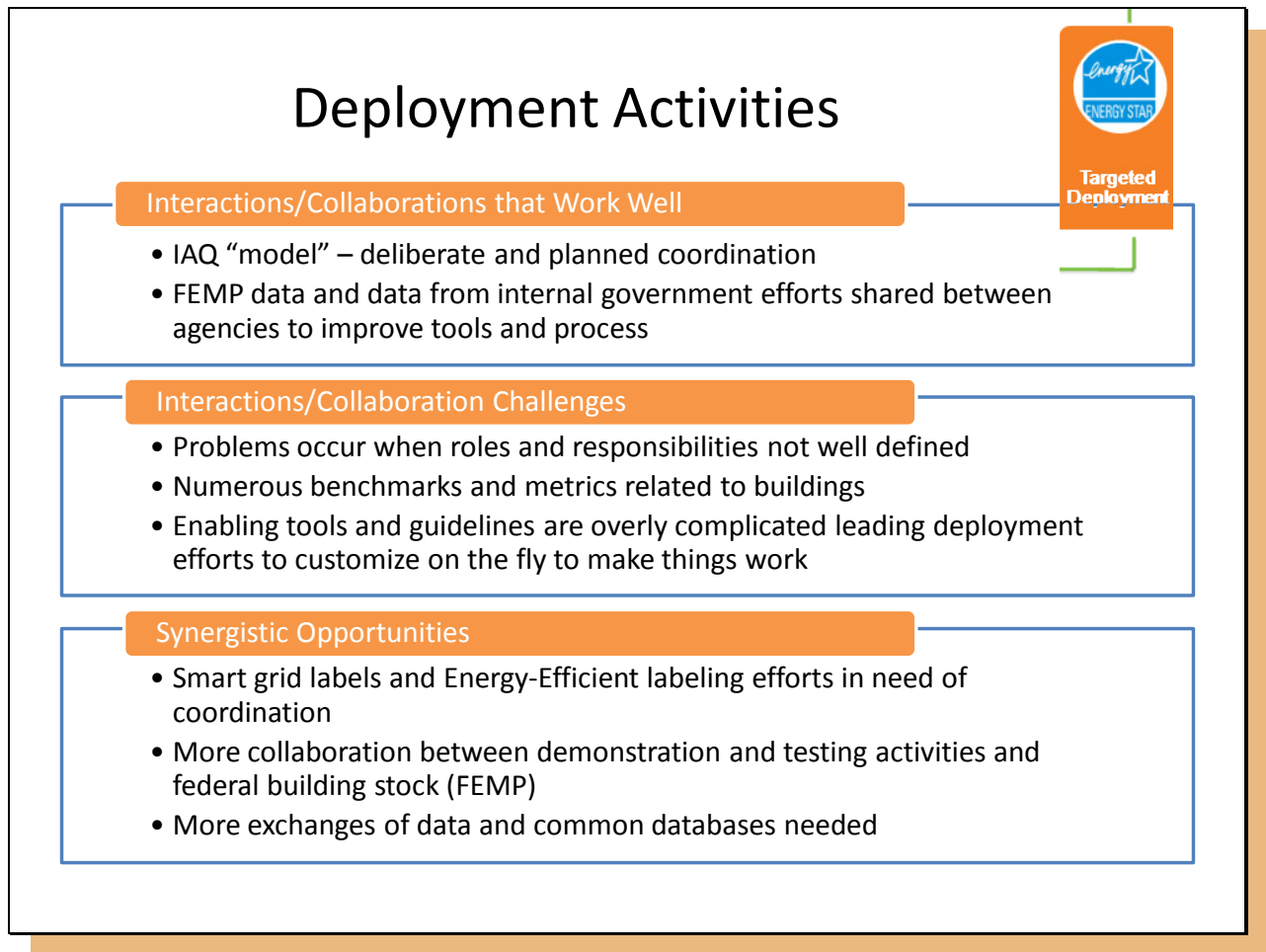




\section{Overlap $\neq$ Bad Thing}

- When overlap results in. ..

- Unnecessary duplication

- Inefficient use of resources and increasing costs without commensurate benefits

- Conflict and disorganization

$>$ Time to repair

- Overlap can also lead to synergistic opportunities benefitting multiple parties. Think "teamwork."

- More ideas and innovations

- Leverage risk

- Build momentum

- Training and mentoring opportunities

\section{Case Study of Buildings-Related Work -- Healthy Collaborations Require the Following}

1. Clear mission: The program and/or activities are guided by a clear, well-defined mission.

2. Collaboration is intentional: The collaboration and coordination amongst various players is deliberate and part of the program plan. It doesn't just happen by coincidence.

3. Transparent, documented process: The program is supported by a transparent and well-documented process accessible to a large contingency. 


\section{Synergistic Opportunities Found by Following the Links}

Linkages Found among Programs Related to Building Energy Use

- Energy Supply and Building Energy Demand: inherent technical link, but potential exists for conflicting goals

- Complementary efforts (due to multiple building system interactions)

- Shared audience linkage

- R\&D and deployment overlapping efforts and interests

- Common interest/goals link

- Similar skill sets and platforms

- Shared interest in data

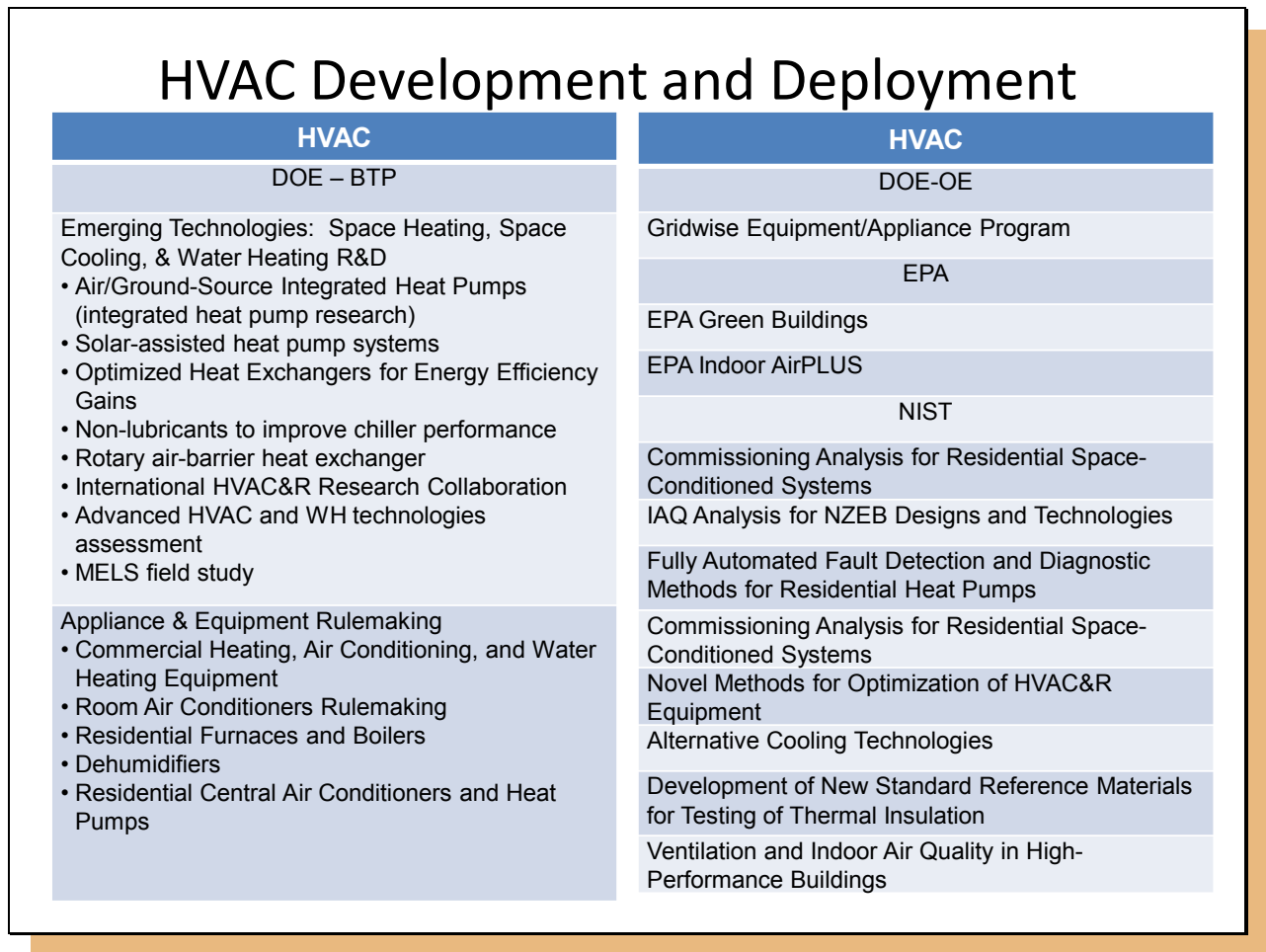




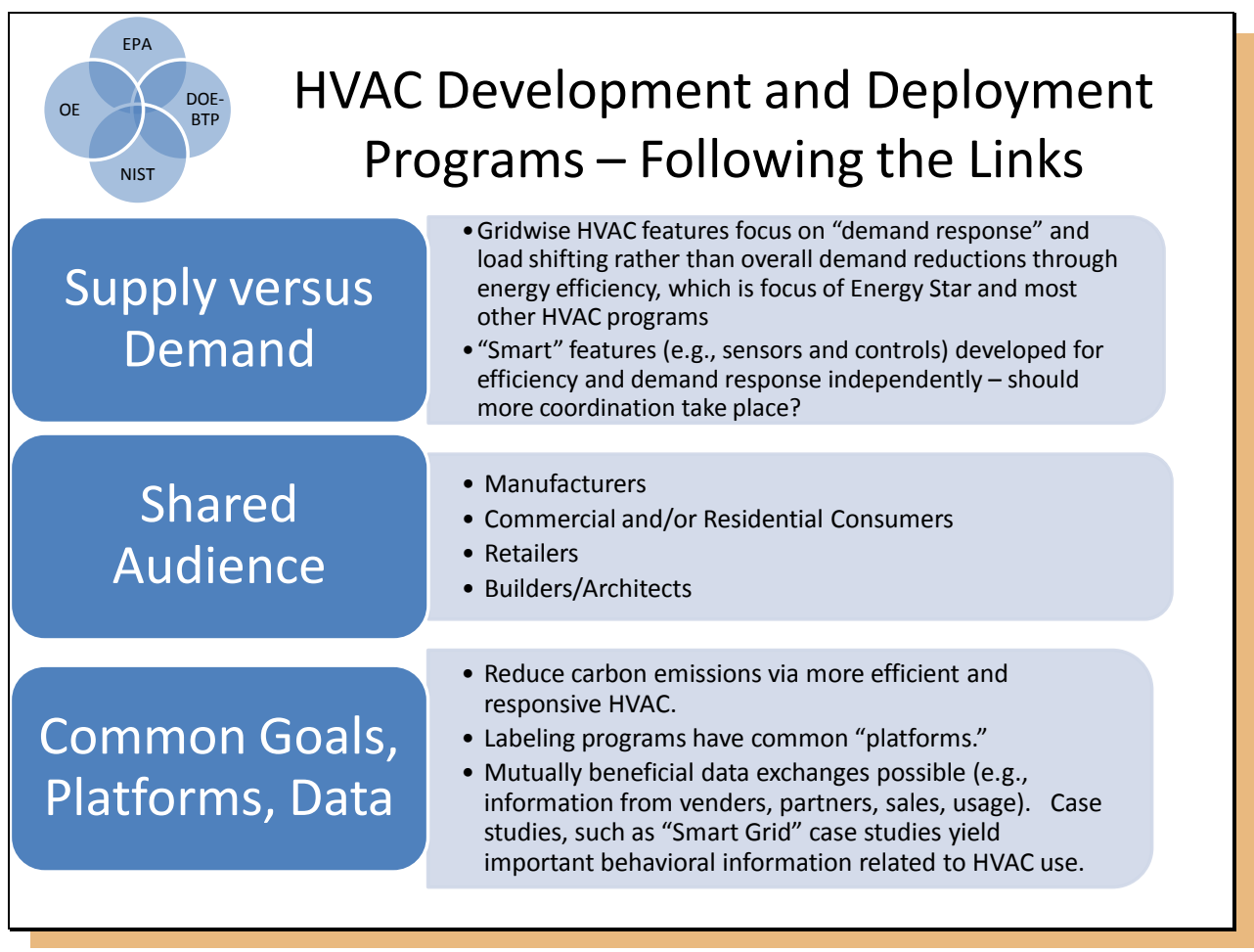

\section{Overall (High-Level) Challenges to Effective Collaborations}

- Conflicting or Vague Program Agendas

- Potential for Conflict

- Air Quality and Energy Efficiency

- Grid Stability and Distributed Generation (including onsite renewable)

- Collaboration opportunities improve as agenda becomes more well-defined

- Example: Sustainable and "Green" goals and activities

- Agency Culture and Agency Management

- Few incentives to collaborate and reach out to other offices and agencies 


\section{Overall Synergistic Needs and Opportunities Related to Building Energy Programs}

- Thinking Outside the "Channel of Influence"

- Bringing together lessons and feedback from deployment efforts to R\&D

- Making use of federal building stock for testing and development of emerging technologies

- Coming Together Under Carbon-Reduction Goals

- Uniting energy-efficiency, air-quality, and gridstability goals 


\section{Appendix B}

Contacts and Interviews 



\section{Appendix B}

\section{Contacts and Interviews}

The tables below list the primary contacts made by the Pacific Northwest National Laboratory research team to identify and characterize the current slate of federal programs and activities related to building energy. In addition to these contacts, a number of exchanges, both via phone and email, were held with various staff who support building energy programs.

Table B.1. Federal Staff Contacts

\begin{tabular}{lc}
\hline \multicolumn{1}{c}{ Agency/Program } & Date of Meeting \\
\hline DOE-BTP & $7 / 26 / 10$ meeting in DC \\
& $7 / 27 / 10$ meeting in DC \\
DOE-FEMP & $7 / 26 / 10$ meeting in DC \\
DOE-OE & $7 / 26 / 10$ meeting in DC \\
EPA & $7 / 27 / 10$ meeting in DC \\
HUD & $7 / 27 / 10$ meeting in DC \\
NIST & $7 / 28 / 10$ meeting in DC \\
\hline
\end{tabular}

Table B.2. Meetings with National Laboratory Staff Who Support Building Energy Projects

\begin{tabular}{|c|c|c|}
\hline $\begin{array}{l}\text { Sponsoring } \\
\text { Agency }\end{array}$ & $\begin{array}{c}\text { Date of } \\
\text { Meeting }\end{array}$ & Program/s \\
\hline DOE-BTP & $1 / 26 / 10$ & Appliance and Equipment Standards \\
\hline DOE-BTP & $2 / 20 / 10$ & $\begin{array}{l}\text { Commercial Buildings Integration (CBI) Commercial Building Energy Alliance; } \\
\text { Solid-State Lighting; Stage-Gate planning }\end{array}$ \\
\hline DOE-BTP & $2 / 20 / 10$ & Building Energy Codes Program \\
\hline DOE-BTP & $2 / 20 / 10$ & Building Energy Codes Program \\
\hline DOE-BTP & $2 / 3 / 10$ & $\begin{array}{l}\text { Commercial Building Partnerships; CBI training, CBI Technical Support; Building } \\
\text { America }\end{array}$ \\
\hline DOE-BTP & $2 / 16 / 10$ & CBI/Emerging Technologies Low-Lift Cooling; CBI Cross-Cutting Analysis \\
\hline DOE-BTP & $2 / 16 / 10$ & CBI/Emerging Technologies; CBI Cross-Cutting Analysis \\
\hline DOE-BTP & $2 / 4 / 10$ & Emerging Technologies: Lighting R\&D \\
\hline DOE-FEMP & $2 / 23 / 10$ & FEMP Energy O\&M effort and Water Efficiency \\
\hline DOE-FEMP & $2 / 20 / 10$ & Federal Residential and Commercial Codes \\
\hline DOE-FEMP & $1 / 25 / 10$ & Sustainable Design Program \\
\hline DOE-OE & $1 / 26 / 10$ & Grid-Friendly Appliances; Smart-Grid demonstration projects \\
\hline DOE-Wind & $9 / 14 / 10$ & Small Wind \\
\hline $\begin{array}{l}\text { DOD-Facilities- } \\
\text { Army }\end{array}$ & $1 / 25 / 10$ & $\begin{array}{l}\text { Fort Bragg Renewable; Fort Campbell Environmental Security Technology } \\
\text { Certification Program(ESTCP) }\end{array}$ \\
\hline DOD-Facilities & $2 / 8 / 10$ & $\begin{array}{l}\text { Army INCOM: Energy Management and Renewable Energy programs; } \\
\text { Sustainability Coordination; Energy Engineering Analysis Program (audits); Army } \\
\text { ACSIM }\end{array}$ \\
\hline GSA & $1 / 25 / 10$ & $\begin{array}{l}\text { Building Performance Measurements and Post-Occupancy Evaluation; Sustainable } \\
\text { Design Program; Energy and Water Conservation; Energy Awareness; Energy } \\
\text { Management Support and Services }\end{array}$ \\
\hline DOE-WIP & $9 / 15 / 10$ & E-mail correspondence related to WAP. \\
\hline DOE-FEMP & $9 / 15 / 10$ & E-mail correspondence related to sustainable design and FEMP database. \\
\hline
\end{tabular}





\section{Appendix C}

\section{List of Federal Programs and Projects Related to Buildings}





\section{Appendix C: Federal Programs/Projects Related to Buildings}

ID

Funding Source

Sponsoring Program/Office

Channel of Influence

Project Title

Brief Description

Objectives

End Use

Product Type Focus

Type of Building

Stage

Status

Primary Contact

Weblinks

ID

Funding Source

Sponsoring Program/Office

Channel of Influence

Project Title

Brief Description

Objectives

End Use

Product Type Focus

Type of Building

Stage

Status

Primary Contact

Weblinks
1

DHHS

Internal Federal Agency Efforts

Affirmative Procurement Plan

This affirmative procurement ("green purchasing") plan (APP) updates prior versions of the APP and provides guidelines for an effective green purchasing program that encompasses the purchasing and use of designated recycled content, Energy Star ${ }^{\circledR}$, EPEAT-registered, energy-efficient, biobased, and environmentally preferable products.

Reduce the adverse environmental impact of our purchasing decisions by buying goods and services from manufacturers and vendors who share our commitment to protect human health and the environment.

All

Generic Energy-Reduction Goal

Government Buildings

Market transformation \& deployment

Ongoing

http://www.hhs.gov/oamp/policies/affirmativeprocurement.pdf

2

DHS

Homeland Security Advisory Council

Internal Federal Agency Efforts

Department of Homeland Security Sustainability and Efficiency Task Force

The task force, created in June, is an experienced group of energy and environmental experts who will advise Secretary Napolitano on ways to bolster national security by maximizing resource efficiency.

Incorporate sustainable practices into DHS operations in order to enhance national security and generate cost savings.

All

Whole Building Systems

Government Buildings

Market transformation \& deployment

Ongoing

http://www.dhs.gov/ynews/releases/pr_1249064551158.shtm 
Funding Source

DOD

Sponsoring Program/Office

Washington Headquarters Services (Pentagon)

Channel of Influence Internal Federal Agency Efforts

Project Title

Brief Description

\section{SUSTAINABLE DESIGN \& CONSTRUCTABILITY}

The Integrated Sustainable Design and Constructability Team will be an ongoing source of information, guidance and direction for the reasonable integration of sustainable design and construction for all Pentagon Renovation \& Construction Program Office projects

Objectives

End Use

All

Product Type Focus

Whole Building Systems

Type of Building

Stage

Status

Government Buildings

Market transformation \& deployment

Ongoing

Primary Contact

Weblinks

http://www.whs.mil/PENREN/sustainabledesign.cfm

ID

4

Funding Source

DOD

Sponsoring Program/Office

Engineer Research And Development Center

Channel of Influence

Project Title

Internal Federal Agency Efforts

Process and Energy Optimization Assesment (PEOA)

Brief Description

A team of experts begins the PEOA by gathering data from operating personnel, energy generators and suppliers, and waste disposal operations. Advanced instrumentation monitors actual energy consumption and pollutant generation and to verify data. Experts analyze the resulting data, then recommend measures to optimize production processes, reduce energy consumption, and reduce or treat emissions, all of which can result in great cost savings.

Objectives

The PEOA incorporates a holistic view of the industrial production process from "material and energy in" to "product and waste out"; the process can accompany pollution prevention efforts to estimate energy consumption changes and new pollutant generation.

End Use

All

Product Type Focus

Type of Building

Generic Energy-Reduction Goal

Government Buildings

Stage

Analysis

Status

Ongoing

Primary Contact

Weblinks

http://www.erdc.usace.army.mil/pls/erdcpub/!www_fact_sheet.capability_page?ps_capability_nu 
Funding Source

Sponsoring Program/Office

Channel of Influence

Project Title

Brief Description

Objectives

End Use

Product Type Focus

Type of Building

Stage

Status

Primary Contact

Weblinks

ID

Funding Source

Sponsoring Program/Office

Channel of Influence

Project Title

Brief Description

Objectives

End Use

Product Type Focus

Type of Building

Stage

Status

Primary Contact

Weblinks
5

DOD

USACE

Internal Federal Agency Efforts

BUILDERTM Sustainment Management System

The BUILDERTM Sustainment Management System (SMS) is a web-based software application developed by ERDC's Construction Engineering Research Laboratory (CERL) to help civil engineers, technicians, and managers decide when, where, and how to best maintain building infrastructure.

The BUILDER decision support tool allows users to manage buildings individually or in groups, enabling effective management of historic, housing, health/environment, and safety/code issues. Projects can be BUILDER-generated or initiated externally from customer requests.

All

Whole Building Systems

Government Buildings

Market transformation \& deployment

Ongoing

http://www.erdc.usace.army.mil/pls/erdcpub/!www_fact_sheet.product_page?ps_product_numb=

6

DOD

USACE

Internal Federal Agency Efforts

CAD/BIM Technology Center for Facilities, Infrastructure, and Environment

ERDC's CAD/BIM Technology Center for Facilities, Infrastructure, and Environment coordinates the use of computer-aided design (CAD) and building information modeling (BIM) activities for facilities, infrastructure, and environment within DoD, other participating governmental agencies, and the private sector. The activities include setting standards, promoting system integration, supporting centralized acquisition, and providing assistance for the installation, training, operation, and maintenance of CAD and BIM systems. They also include directing specific applications development, promoting communications, developing and promoting standards, furnishing technical advice, interfacing with professional organizations and industry, evaluating technological developments, and recommending necessary CAD and BIM policy to ensure that maximum benefits are received from these technologies.

Heating \& Cooling, Water Heating, Lighting

Whole Building Systems

Government Buildings

Market transformation \& deployment

Ongoing

http://www.erdc.usace.army.mil/pls/erdcpub/!www_fact_sheet.capability_page?ps_capability_nu 
Funding Source

Sponsoring Program/Office

Channel of Influence

Project Title

Brief Description

Objectives

End Use

Product Type Focus

Type of Building

Stage

Status

Primary Contact

Weblinks

ID

Funding Source

Sponsoring Program/Office

Channel of Influence

Project Title

Brief Description

Objectives

End Use

Product Type Focus

Type of Building

Stage

Status

Primary Contact

Weblinks
7

DOD

USACE

Internal Federal Agency Efforts

Assistance in HVAC Commissioning of Standard Buildings on Military Installations

The Construction Engineering Research Laboratory (CERL) offers engineering services on a reimbursable basis to consult on (or to perform) commissioning, recommissioning, and retro commissioning of heating, ventilating, and air conditioning (HVAC) systems in standard buildings (or other facilities) on military installations. Such buildings would include, for example, Headquarters [HQ] office buildings, barracks, maintenance and repair shops, etc.

Heating \& Cooling

HVAC

Government Buildings

Market transformation \& deployment

Ongoing

http://www.erdc.usace.army.mil/pls/erdcpub/WWW_WELCOME.NAVIGATION_PAGE?tmp_next_pa

8

DOD

USACE

Internal Federal Agency Efforts

Sustainable Project Rating Tool (SPiRiT)

SPiRiT is a required rating tool that offers a checklist, strategies, and scores to help Army installations rate themselves on their demonstrated abilities to create and maintain sustainable facilities, and to plan improvements to the process of planning, programming, designing, building, and maintaining sustainable facilities. SPiRiT, which is based on the Green Building Council's Leadership in Energy and Environmental Design Rating System 2.0 (LEED 2.0 ${ }^{\circledR}$ ), and which is tailored to Army-specific needs, embodies accepted energy and environmental principles. SPiRiT takes a "whole building" perspective to help preserve the environment and improve facility life-cycle management, and to integrate environmentally responsible practices into the facility delivery process from its design stages.

All

Whole Building Systems

Government Buildings

Analysis

Ongoing

http://www.erdc.usace.army.mil/pls/erdcpub/WWW_WELCOME.NAVIGATION_PAGE?tmp_next_pa 
Funding Source

Sponsoring Program/Office

Channel of Influence

Project Title

Brief Description

Objectives

End Use

Product Type Focus

Type of Building

Stage

Status

Primary Contact

Weblinks

ID

Funding Source

Sponsoring Program/Office

Channel of Influence

Project Title

Brief Description

Objectives

End Use

Product Type Focus

Type of Building

Stage

Status

Primary Contact

Weblinks
DOD - Airforce

AF Center for Engineering and the Environment

Internal Federal Agency Efforts

Air Force Sustainability

This site provides information and guidance on sustainability in three areas: Sustainable Design \& Development, Sustainable Operations, and Sustainable Communities. Each page shows how sustainability can be implemented from different perspectives, namely, new construction, operations, and installation management

All

Generic Energy-Reduction Goal

Government Buildings

Analysis

Ongoing

\begin{tabular}{|r|}
\hline \\
\hline
\end{tabular}

10

DOD - Airforce

Airforce

Internal Federal Agency Efforts

TFI-F-22 Beddown Intrastructure Support

Adopting and deploying energy conservation measures to military facilities

All

Generic Energy-Reduction Goal

Government Buildings

Market transformation \& deployment

Ongoing

http://idam.ifmm.com/idambrowseservice/(S(0iat3e45nbxm2eadkp5b5045))/RetrieveAsset.aspx?id 
Funding Source

Sponsoring Program/Office

Channel of Influence

Project Title

Brief Description

Objectives

End Use

Product Type Focus

Type of Building

Stage

Status

Primary Contact

Weblinks

ID

Funding Source

Sponsoring Program/Office

Channel of Influence

Project Title

Brief Description

Objectives

End Use

Product Type Focus

Type of Building

Stage

Status

Primary Contact

Weblinks
11

DOD - Airforce

Airforce

Internal Federal Agency Efforts

Energy Conservation Investment Program

Adopting and deploying energy conservation measures to military facilities

All

Generic Energy-Reduction Goal

Government Buildings

Market transformation \& deployment

Ongoing

16

DOD - Army

Army

Basic and Applied Research and Development

Ultra Low Energy Community Systems

A firm fixed price (FFP) contract has been awarded to The Bioengineering Group, Inc. located at 18 Commercial Street, Salem MA 01970 in response to solicitation number W912HZ-09-BAA03, Topic 4-2, Ultra Low Energy Community Systems. The principal objective of this project is to test the utility of a second-law (i.e., energy quality, or exergy) approach for: 1) modeling Army communities on a systemic basis, and 2) identifying practical, economical design alternatives for achieving ultralow energy consumption levels. The period of performance will be 12 months commencing on 22 Jan 2010.

All

Whole Building Systems

Government Buildings

Applied research \& technology development

Ongoing

https://www.fbo.gov/index?s=opportunity\&mode=form\&id=58846eeb85679c3aa2ef1d7110d966e5 
Funding Source

Sponsoring Program/Office

Channel of Influence

Project Title

Brief Description

Objectives

End Use

Product Type Focus

Type of Building

Stage

Status

Primary Contact

Weblinks

ID

Funding Source

Sponsoring Program/Office

Channel of Influence

Project Title

Brief Description

Objectives

End Use

Product Type Focus

Type of Building

Stage

Status

Primary Contact

Weblinks

17

DOD - Army

Army

Basic and Applied Research and Development

Energy Security Audit \& Islanding Methodology

These funds from the American Recovery Act of 2009 are only for the funding of Army research, development, test and evaluation projects, including pilot projects, demonstrations and energy efficient manufacturing enhancements. Funds are for improvements in energy generation and efficiency, transmission, regulation, storage, and for use on military installations and within operational forces, to include research and development of energy from fuel cells, wind, solar, and other renewable energy sources to include biofuels and bioenergy. This RDT\&E appropriation is a multiple year appropriation available for obligation for two year

\section{Renewable Energy}

Distributed generation

Government Buildings

Applied research \& technology development

kevin.geiss@us.army.mil

15

DOD - Army

Army

Internal Federal Agency Efforts

Energy Conservation Investment Program (ECIP)

Energy management controls at Anniston Army Depot; ground-coupled/geothermal heat pumps at Fort Benning and Fort Gordon; efficiency improvements at Blue Grass Army Depot; a chilled water storage system at Fort Bragg; wireless digital HVAC controls at Fort Buchanan; water conservation at Fort Rucker; and UMCS at Fort Stewart. In total, 17 projects at 13 installations

Heating \& Cooling

HVAC

Government Buildings

Market transformation \& deployment

Ongoing

C-7 
Funding Source

Sponsoring Program/Office

Channel of Influence

Project Title

Brief Description

Objectives

End Use

Product Type Focus

Type of Building

Stage

Status

Primary Contact

Weblinks

ID

Funding Source

Sponsoring Program/Office

Channel of Influence

Project Title

Brief Description

Objectives

End Use

Product Type Focus

Type of Building

Stage

Status

Primary Contact

Weblinks
13

DOD - Army

Army Energy Program

Internal Federal Agency Efforts

Army's Energy Security and Implementation Strategy

Reduced energy consumption. Increased energy efficiency across platforms and facilities. Increased use of new renewable and alternative. Assured access to sufficient energy supplies. Reduced adverse impacts on the environment.

Make energy a consideration for all Army activities to reduce demand, increase efficiency, seek alternative sources, and create a culture of energy accountability while sustaining or enhancing operational capabilities.

Heating \& Cooling

Generic Energy-Reduction Goal

Government Buildings

Market transformation \& deployment

Ongoing

http://army-energy.hqda.pentagon.mil/

18

DOD - Army

Army

Internal Federal Agency Efforts

National Defense Authorization Act of 2007 (NDAA)

CONSOLIDATION AND ENHANCEMENT OF LAWS TO IMPROVE DEPARTMENT OF DEFENSE ENERGY EFFICIENCY AND CONSERVATION.

All

Generic Energy-Reduction Goal

Government Buildings

Applied research \& technology development

http://www.wifcon.com/dodauth7/dod07_2851.htm 
Funding Source

Sponsoring Program/Office

Channel of Influence

Project Title

Brief Description

Objectives

End Use

Product Type Focus

Type of Building

Stage

Status

Primary Contact

Weblinks

ID

Funding Source

Sponsoring Program/Office

Channel of Influence

Project Title

Brief Description

Objectives

End Use

Product Type Focus

Type of Building

Stage

Status

Primary Contact

Weblinks
12

DOD - Army

US Army Sustainability: Supporting, Communities and Families

Internal Federal Agency Efforts

U.S. Army Sustainability

In this section, you can learn more about how the Army is integrating sustainability concepts into general base operations support activities; development and maintenance of the facilities, roads, and other key installation support infrastructure; and the procurement, maintenance, distribution, and replacement of personnel and materiel.

Heating \& Cooling, Water Heating, Lighting

Generic Energy-Reduction Goal

Government Buildings

Market transformation \& deployment

Ongoing

http://www.afcee.af.mil/resources/sustainability/index.asp

14

DOD - Army

Army Environmental command

Internal Federal Agency Efforts

Base Realignment and Closure construction and renovation Program (BRAC)

Some of the oldest structures in the U.S. Army's inventory are gaining new life and uses under the Base Realignment and Closure (BRAC) construction and renovation program on Fort Sam Houston.

All

Generic Energy-Reduction Goal

Government Buildings

Market transformation \& deployment

Ongoing

http://aec.army.mil/usaec/newsroom/update/sum09/sum0918.html 
Funding Source

DOD - DARPA

Sponsoring Program/Office

Channel of Influence

Defense Science Office

Project Title

Brief Description

Basic and Applied Research and Development

Micro Power Sources

As the volume of a power source is reduced, the active material available is reduced, resulting in lower total energy available in the source. A proportionately larger fraction of the total volume of the energy source is consumed by inactive materials (electrolytes, salt bridges, and packaging), leading to a further lessening of energy density. To decrease these packaging penalties, the Micro Power Sources (MPS) program will develop devices to maximize the volumetric ratio of active materials available to inactive materials to sustain a high energy density.

Objectives

To accomplish this goal, researchers are exploring fabrication of power sources that are small in volume $(<1 \mathrm{~mm} 3)$ while maintaining high energy densities ( $>350 \mathrm{Wh} / \mathrm{L})$. The ability to use MPS in multiple form factors is of importance to military operations requiring small power sources. This program seeks to obtain sources with the ability to be produced in topographically different shapes, to be flexible in modular use, or to be useful for structural or other purposes. The program is incorporating innovative approaches to micro fuel cells, self-assembling battery technologies, energy scavenging micro sources, and integrally packaged 3D micro batteries.

\section{End Use}

Product Type Focus

Type of Building

Stage

Renewable Energy

Distributed generation

Non-Specific

Basic Research

Status

Primary Contact

Weblinks

Ongoing

http://www.darpa.mil/dso/thrusts/physci/power/mps/index.htm 
Funding Source

Sponsoring Program/Office

Channel of Influence

Project Title

Brief Description

Objectives

\section{End Use}

Product Type Focus

Type of Building

Stage

Status

Primary Contact

Weblinks

ID

Funding Source

Sponsoring Program/Office

Channel of Influence

Project Title

Brief Description

Objectives

End Use

Product Type Focus

Type of Building

Stage

Status

Primary Contact

Weblinks
24

DOD - DARPA

Defense Science Office

Basic and Applied Research and Development

\section{Robust Portable Power}

Today's war fighter must often carry an extremely cumbersome number of heavy primary batteries in order to provide power to various radios, laptops, laser designators, and other mission critical electronic equipment. DARPA's investments in portable power have demonstrated that fuel cell and Stirling engine generators can achieve energy densities up to seven times that of today's military logistic batteries

Building upon successes achieved in DSO's Palm Power program, the Robust Portable Power program seeks to initiate and facilitate the transition of portable fuel cell and Sterling engine technologies by pursuing collaboratively funded efforts that will further optimize and ruggedize these technologies for specific military applications in harsh environments. If deployed, these technologies could greatly reduce the weight burden associated with carrying multiple primary batteries into the field. In addition, the application of portable generators in place of battery power for small unmanned aerial vehicle (UAV) and or unmanned ground vehicle (UGV) missions would greatly increase mission duration and capability

\section{Smart Grid}

Distributed generation

Non-Specific

Basic Research

Ongoing

http://www.darpa.mil/dso/thrusts/physci/power/rpp/index.htm
22

\section{DOD - DARPA}

Defense Science Office

Basic and Applied Research and Development

Integrated High Energy Dense Capacitors

To meet the DoD requirements of more electric military platforms of the future, the Integrated High Energy Dense Capacitors (IHEDC) program will incorporate innovative approaches and improved dielectric materials to producing high energy-dense capacitors for high power systems. Currently, the passives of high power systems make up 40-50 percent of the volume and weight and are unable to match the power electronics' high temperature capabilities

Additionally, the program will integrate the capacitors with power electronics and sensors to provide smart diagnostics, and flexibility in capacitor banks of the future.

\section{Smart Grid}

Distributed generation

Non-Specific

Basic Research

Ongoing

http://www.darpa.mil/dso/thrusts/physci/power/ihedc/index.htm 
Funding Source

Sponsoring Program/Office

Channel of Influence

Project Title

Brief Description

Objectives

End Use

Product Type Focus

Type of Building

Stage

Status

Primary Contact

Weblinks

ID

Funding Source

Sponsoring Program/Office

Channel of Influence

Project Title

Brief Description

Objectives

End Use

Product Type Focus

Type of Building

Stage

Status

Primary Contact

Weblinks
21

DOD - DARPA

Microsystems Technology Office

Basic and Applied Research and Development

Personalized Assistant that Learns (PAL)

The mission of the PAL program is to radically improve the way computers support humans by enabling systems that are cognitive, i.e., computer systems that can reason, learn from experience, be told what to do, explain what they are doing, reflect on their experience, and respond robustly to surprise. More specifically, PAL will develop a series of prototype cognitive systems that can act as an assistant for commanders and staff. Successful completion of this program will usher in a new era of computational support for a broad range of human activity.

Developing cognitive systems that learn to adapt to their user could dramatically improve a wide range of military operations. The development and application of intelligent systems to support military decision-making may provide dramatic advances for traditional military roles and missions. The technologies developed under the PAL program are intended to make military decision-making more efficient and more effective at all levels.

\section{Smart Grid}

Supervisory and system integration (Sensor-Control)

Non-Specific

Basic Research

Ongoing

http://www.darpa.mil/ipto/programs/pal/pal.asp

20

DOD - DARPA

Microsystems Technology Office

Basic and Applied Research and Development

Advanced Photonic Switch (APS)

The objective of the APS program is to develop advanced, on-chip, photonic switching devices which are fabricated in a CMOS-compatible process and which maximize switching speed while simultaneously minimize device power dissipation, transmission losses, area, and sensitivity to ambient temperature variations. The photonic switches developed in this program will be spectrally broad-band, capable of simultaneously switching multiple, high bit-rate wavelength channels, temperature-insensitive and scalable to complex, MxN port switches.

\section{Smart Grid}

Distributed generation

Non-Specific

Basic Research

Ongoing

http://www.darpa.mil/mto/programs/aps/index.html 
Funding Source

DOD - DARPA

Sponsoring Program/Office

Channel of Influence

Strategic Technology Office

Project Title

Brief Description

Basic and Applied Research and Development

Very High Efficiency Solar Cell (VHESC)

The VHESC program final deliverables are to design, build and demonstrate at least $5 \mathrm{~m} 2$ of engineering prototype modules that are manufacturable and have an east-west field of view (FOV) $\geq \pm 60^{\circ}$, a north-south FOV $\geq \pm 25^{\circ}$, a system power efficiency (SPE) $\geq 40 \%$, and a module manufacturing cost per $\mathrm{m} 2 \leq \$ 1500$. The SPE includes all factors that impact the system (module) power efficiency such as the power conversion efficiency, as well as the individual efficiencies of the photovoltaic (PV) cells.

Objectives

The objective of the Very High Efficiency Solar Cell program is to design, build and demonstrate engineering prototype solar cell modules that have high efficiency and are manufacturable. To achieve this objective, the VHESC program will develop technologies to reduce the costs of the solar cells and optical components.

End Use

Smart Grid

Product Type Focus

Distributed generation

Type of Building

Non-Specific

Stage

Basic Research

Status

Ongoing

Primary Contact

Weblinks

http://www.darpa.mil/sto/programs/vhesc/index.html

ID

Funding Source

Sponsoring Program/Office

Channel of Influence

Project Title

Brief Description

Objectives

End Use

Product Type Focus

Type of Building

Stage

Status

Primary Contact

Weblinks
25

DOD - DARPA

DARPA

Basic and Applied Research and Development

Nanostructured Thin-Film Solar Cell Production

Under a DARPA funded SBIR program, Nanosolar developed improved production techniques to create high-efficiency solar cells that are lightweight, flexible, durable, cheap, and easy to produce. Nanosolar is nanotechnology to address critical power shortcomings: efficiency, durability and availability. This applying a new technique in the emerging field of technology can extend mission durations, increase the range of mission distance, and minimize supply chain logistics and the personnel risk typically associated with re-supplying power sources.

Nanosolar developed improved production techniques to create high-efficiency solar cells that are lightweight, flexible, durable, cheap, and easy to produce. Nanosolar is applying a new technique in the emerging field of nanotechnology to address critical power shortcomings: efficiency, durability and availability.

Renewable Energy

Distributed generation

Non-Specific

Applied research \& technology development

Complete

bsager@nanosolar.com

www.nanosolar.com 
Funding Source

Sponsoring Program/Office

Channel of Influence

Project Title

Brief Description

Objectives

End Use

Product Type Focus

Type of Building

Stage

Status

Primary Contact

Weblinks

ID

Funding Source

Sponsoring Program/Office

Channel of Influence

Project Title

Brief Description

Objectives

End Use

Product Type Focus

Type of Building

Stage

Status

Primary Contact

Weblinks
31

DOD - Navy

Department of Navy

Internal Federal Agency Efforts

Install Photovoltaic Systems

Install and integrate distributed photovoltaic generating technology to military facilities.

Renewable Energy

Distributed generation

Government Buildings

Market transformation \& deployment

Ongoing

http://idam.ifmm.com/idambrowseservice/(S(0iat3e45nbxm2eadkp5b5045))/RetrieveAsset.aspx?id

26

DOD - Navy

Department of Navy

Internal Federal Agency Efforts

Marine Corps Military Construction (MILCON)

Facilities modernization and sustainability upgrades program

All

Building Commissioning

Government Buildings

Applied research \& technology development

Ongoing

http://www.whitehouse.gov/omb/expectmore/detail/10003215.2006.html 
Funding Source

Sponsoring Program/Office

Channel of Influence

Project Title

Brief Description

Objectives

End Use

Product Type Focus

Type of Building

Stage

Status

Primary Contact

Weblinks

ID

Funding Source

Sponsoring Program/Office

Channel of Influence

Project Title

Brief Description

Objectives

End Use

Product Type Focus

Type of Building

Stage

Status

Primary Contact

Weblinks
27

DOD - Navy

Department of Navy

Internal Federal Agency Efforts

MARINE CORPS ENERGY INITIATIVE (Camp Pendleton, CA)

Under the DoD mandate, all villages and units will receive meters and face the same "mock" billing periods prior to live billing, housing officials said. Only electricity and natural-gas consumption will be monitored as part of Fort Benning's resident responsibility program.

Heating \& Cooling, Water Heating, Lighting

Supervisory and system integration (Sensor-Control)

Government Buildings

Market transformation \& deployment

Ongoing

http://idam.ifmm.com/idambrowseservice/(S(0iat3e45nbxm2eadkp5b5045))/RetrieveAsset.aspx?id

28

DOD - Navy

Department of Navy

Internal Federal Agency Efforts

MARINE CORPS ENERGY INITIATIVE (San Diego, CA)

Under the DoD mandate, all villages and units will receive meters and face the same "mock" billing periods prior to live billing, housing officials said. Only electricity and natural-gas consumption will be monitored as part of Fort Benning's resident responsibility program.

Heating \& Cooling, Water Heating, Lighting

Supervisory and system integration (Sensor-Control)

Government Buildings

Market transformation \& deployment

Ongoing

http://idam.ifmm.com/idambrowseservice/(S(0iat3e45nbxm2eadkp5b5045))/RetrieveAsset.aspx?id 
Funding Source

Sponsoring Program/Office

Channel of Influence

Project Title

Brief Description

Objectives

End Use

Product Type Focus

Type of Building

Stage

Status

Primary Contact

Weblinks

ID

Funding Source

Sponsoring Program/Office

Channel of Influence

Project Title

Brief Description

Objectives

End Use

Product Type Focus

Type of Building

Stage

Status

Primary Contact

Weblinks
29

DOD - Navy

Department of Navy

Internal Federal Agency Efforts

MARINE CORPS ENERGY INITIATIVE (Camp Lejune, NC)

Under the DoD mandate, all villages and units will receive meters and face the same "mock" billing periods prior to live billing, housing officials said. Only electricity and natural-gas consumption will be monitored as part of Fort Benning's resident responsibility program.

Heating \& Cooling, Water Heating, Lighting

Supervisory and system integration (Sensor-Control)

Government Buildings

Market transformation \& deployment

Ongoing

http://idam.ifmm.com/idambrowseservice/(S(0iat3e45nbxm2eadkp5b5045))/RetrieveAsset.aspx?id

30

DOD - Navy

Department of Navy

Internal Federal Agency Efforts

Facility And Photovoltaic Energy Upgrades

Install and integrate distributed photovoltaic generating technology to military facilities.

Renewable Energy

Distributed generation

Government Buildings

Market transformation \& deployment

Ongoing

http://idam.ifmm.com/idambrowseservice/(S(0iat3e45nbxm2eadkp5b5045))/RetrieveAsset.aspx?id 
Funding Source

DOE - ARPA

Sponsoring Program/Office

Channel of Influence

ARPA-E

Project Title

Brief Description

Basic and Applied Research and Development

BATTERIES FOR ELECTRICAL ENERGY STORAGE IN TRANSPORTATION (BEEST)

Batteries for Electrical Energy Storage in Transportation (BEEST) - In this topic, ARPA-E seeks to develop a new generation of ultra-high energy density, low-cost battery technologies for long electric range plug in hybrid electric vehicles and electric vehicles (EVs). The development of high energy, low cost batteries represents the critical barrier to wide-spread deployment of EVs, which if achieved would have a profound impact on U.S. oil security, greenhouse gas emissions, and economic growth. The ambitious goals for this program are largely based upon the aggressive longterm EV battery goals set forth by the United States Advanced Battery Consortium, a public-private collaboration between the U.S. Department of Energy and leading U.S. automotive companies.

Objectives

Give electrified light-duty vehicles range, performance, lifetime, and cost required to shift transportation energy from oil to the domestically powered U.S. electric grid. ARPA-E's objective is to fund high-risk, high reward research efforts that will promote leadership in this emerging EV battery market.

End Use

Smart Grid

Product Type Focus

Distributed generation

Type of Building

Residential (all)

Stage

Basic Research

Status

Ongoing

Primary Contact

Weblinks

http://arpa-e.energy.gov/ProgramsProjects/BEEST.aspx 
Funding Source

DOE - ARPA

Sponsoring Program/Office

Channel of Influence

ARPA-E

Project Title

Brief Description

Basic and Applied Research and Development

BUILDING ENERGY EFFICIENCY THROUGH INNOVATIVE THERMODEVICES (BEETIT)

ARPA-E seeks to develop energy-efficient building cooling technologies that will reduce energy consumption and GHG emissions from: (a) overall cooling and (b) refrigerants used in vapor compression systems. ARPA-E seeks innovative research and development approaches in the following areas: 1) cooling systems that use refrigerants with low global warming potential; 2) energy-efficient air conditioning (AC) systems with an increased coefficient of performance (COP) for warm and humid climates; and 3 ) vapor-compression AC systems for recirculating air loads with an increased COP in hot climates

Objectives

The U.S. market demands technologies that will retrofit into current cooling systems, while developing economies seek new cooling technologies. Developing these technologies significantly increase the U.S. technological lead in rapidly-emerging clean energy industries.

End Use

Heating \& Cooling

Product Type Focus

HVAC

Type of Building

Non-Specific

Stage

Basic Research

Status

Ongoing

Primary Contact

Weblinks

http://arpa-e.energy.gov/ProgramsProjects/BEETIT.aspx 
Funding Source

DOE - ARPA

Sponsoring Program/Office

Channel of Influence

ARPA-E

Project Title

Brief Description

Basic and Applied Research and Development

AGILE DELIVERY OF ELECTRICAL POWER TECHNOLOGY (ADEPT)

ARPA-E seeks to invest in materials for key advances in soft magnetics, high-voltage switches, and reliable, high-density charge storage. Combined with advanced circuit architectures and scalable manufacturing, these investments could potentially leapfrog existing power converter performance and reduce costs.

Objectives

Specifically, ADEPT will consider three levels of performance and integration: 1) fully-integrated, chip-scale power converters for applications, including: compact, efficient drivers for solid-state lighting, distributed micro-inverters for photovoltaics, and single-chip power supplies for computers; 2 ) kilowatt-scale package-integrated power converters by enabling applications such as low-cost, efficient inverters for grid-tied photovoltaics and variable speed motors; and 3) lightweight, solid-state, medium-voltage energy conversion for high-power applications such as solid-state electrical substations and wind turbine generators.

End Use

Smart Grid

Product Type Focus

Distributed generation

Type of Building

Non-Specific

Stage

Basic Research

Status

Ongoing

Primary Contact

Weblinks

http://arpa-e.energy.gov/ProgramsProjects/ADEPT.aspx 
Funding Source

Sponsoring Program/Office

Channel of Influence

Project Title

Brief Description

Objectives

End Use

Product Type Focus

Type of Building

Stage

Status

Primary Contact

Weblinks

ID

Funding Source

Sponsoring Program/Office

Channel of Influence

Project Title

Brief Description

Objectives

End Use

Product Type Focus

Type of Building

Stage

Status

Primary Contact

Weblinks
36

DOE - ARPA

ARPA-E

Basic and Applied Research and Development

GRID-SCALE RAMPABLE INTERMITTENT DISPATCHABLE STORAGE (GRIDS)

ARPA-E seeks to develop new technologies that enable widespread use of cost-effective grid-scale energy storage. While valuable applications for grid-scale storage exist, this program focuses on technologies that balance the short-duration variability in renewable generation. Investing in these technologies will position the U.S. as technology and manufacturing leader of the emerging, and potentially massive, global market for stationary electricity storage infrastructure.

Specifically, GRIDS considers two areas: 1) proof-of-concept storage-component projects focused on validating new, over-the-horizon, electrical energy storage concepts, and 2) advanced system prototypes that address critical shortcomings of existing grid-scale energy storage technologies. Ultimately, technologies developed through this program will be scalable to megawatt and megawatt-hour levels of power and energy capacity.

Smart Grid

Distributed generation

Non-Specific

Basic Research

Ongoing

http://arpa-e.energy.gov/ProgramsProjects/GRIDS.aspx

32

DOE - ARPA

ARPA-E

Basic and Applied Research and Development

Low-cost Electrochromic Film on Plastic for Net-Zero Energy Building

Solid-state electro chromic film on plastic substrates with roll-to-roll production process to substantially reduce the cost of electrically controlled smart windows for net-zero energy buildings.

These windows reduce heating and cooling loads and minimize overhead lighting use.

Heating \& Cooling

Windows

Commercial and Residential

Applied research \& technology development

Ongoing

http://arpa-e.energy.gov/projects/be.html\#low 
Funding Source

Sponsoring Program/Office

Channel of Influence

Project Title

Brief Description

Objectives

End Use

Product Type Focus

Type of Building

Stage

Status

Primary Contact

Weblinks

ID

Funding Source

Sponsoring Program/Office

Channel of Influence

Project Title

Brief Description

Objectives

End Use

Product Type Focus

Type of Building

Stage

Status

Primary Contact

Weblinks
34

DOE - ARPA

ARPA-E

Basic and Applied Research and Development

Large-Scale Energy Reductions through Sensors, Feedback, \& Information Technology

Sensors, software, and controls to track and improve energy use patterns. Could lead to substantial reductions in building energy use by changing human behavior through timely information and usable controls.

All

Supervisory and system integration (Sensor-Control)

Non-Specific

Applied research \& technology development

Ongoing

http://arpa-e.energy.gov/projects/be.html\#Large

33

DOE - ARPA

\section{ARPA-E}

Basic and Applied Research and Development

Momentive Performance Materials

A high-pressure ammonothermal process for the inexpensive production of high quality, single crystal GaN substrates at high crystal growth rates. Could allow production of light emitting diodes (LEDs) at costs equal to current low-cost fluorescent lighting.

Lighting

Lighting Equipment

Non-Specific

Applied research \& technology development

Ongoing

http://arpa-e.energy.gov/projects/be.html\#Ammonothermal 
Funding Source

DOE - BTP

Sponsoring Program/Office

BTP Appliance \& Equipment Standards

Channel of Influence

Regulatory

Project Title

Brief Description

Distribution Transformers

The Energy Policy and Conservation Act (EPCA) of 1975 established an energy conservation program for major household appliances. The National Energy Conservation Policy Act of 1978 amended EPCA to add Part C of Title III, which established an energy conservation program for certain industrial equipment. The Energy Policy Act of 1992 amended EPCA to add certain commercial equipment, including distribution transformers.

Objectives

End Use

Product Type Focus

\section{Plug Loads}

\section{Equipment \& Appliances}

Type of Building

Commercial (all)

Stage

Market transformation \& deployment

Status

Primary Contact

Weblinks

\section{Ongoing}

mailto:jim.raba@ee.doe.gov

http://www1.eere.energy.gov/buildings/appliance_standards/commercial/distribution_transformer

ID

Funding Source

Sponsoring Program/Office

Channel of Influence

Project Title

Brief Description

Objectives

End Use

Product Type Focus

Type of Building

Stage

Status

Primary Contact

Weblinks
76

DOE - BTP

BTP Appliance \& Equipment Standards

Regulatory

Small Electric Motors

Part A-1 of title III of the Energy Policy and Conservation Act (EPCA) provides for an energy conservation program for certain commercial and industrial equipment (42 U.S.C. 6311-6317). In particular, section 346(b)(1) of EPCA directs the Secretary of Energy to prescribe testing requirements and energy conservation standards for those small electric motors for which the Secretary determines that standards would be technologically feasible and economically justified, and would result in significant energy savings. (42 U.S.C. 6317(b)(1))

Plug Loads

Equipment \& Appliances

Commercial (all)

Market transformation \& deployment

Ongoing

mailto:jim.raba@ee.doe.gov

http://www1.eere.energy.gov/buildings/appliance_standards/commercial/small_electric_motors.ht 
Funding Source

DOE - BTP

Sponsoring Program/Office

Channel of Influence

BTP Appliance \& Equipment Standards

Project Title

Brief Description

Objectives

End Use

Product Type Focus

Regulatory

Commercial Refrigeration Equipment

The U.S. Department of Energy (DOE) is required by the Energy Policy and Conservation Act, as amended by section 136(c)(1) of the Energy Policy Act of 2005, to establish energy conservation standards for the following commercial refrigeration equipment manufactured on or after January 1, 2012: commercial ice-cream freezers; self-contained commercial refrigerators, commercial freezers, and commercial refrigerator-freezers without doors; and remote condensing commercial refrigerators, commercial freezers, and commercial refrigerator-freezers. (42 U.S.C. 6313(c)(4)(A))

Type of Building

Stage

Status

Primary Contact

\section{Plug Loads}

Refrigeration

Commercial (all)

Market transformation \& deployment

Ongoing

mailto:charles.llenza@ee.doe.gov

Weblinks

http://www1.eere.energy.gov/buildings/appliance_standards/commercial/refrigeration_equipment

ID

Funding Source

Sponsoring Program/Office

Channel of Influence

Project Title

Brief Description

Objectives

End Use

Product Type Focus

Type of Building

Stage

Status

Primary Contact

Weblinks

\section{4}

DOE - BTP

BTP Appliance \& Equipment Standards

Regulatory

Refrigerated Beverage Vending Machines

The U.S. Department of Energy (DOE) is required to establish energy conservation standards for refrigerated bottled or canned beverage vending machines by the Energy Policy and Conservation Act, as amended in section 135(c)(4) of the Energy Policy Act of 2005. (42 U.S.C. 6295 (v)(1)-(3)).

\section{Plug Loads}

Refrigeration

Commercial (all)

Market transformation \& deployment

Ongoing

mailto:charles.llenza@ee.doe.gov

http://www1.eere.energy.gov/buildings/appliance_standards/commercial/beverage_machines.htm 
Funding Source

DOE - BTP

Sponsoring Program/Office

BTP Appliance \& Equipment Standards

Channel of Influence Regulatory

Project Title

Brief Description

Objectives

End Use

Product Type Focus

Type of Building

Stage

Status

Primary Contact

Weblinks

Packaged Terminal Air Conditioners and Heat Pumps

The Energy Policy and Conservation Act (EPCA) of 1975 prescribes energy conservation standards for various consumer products and commercial and industrial equipment, and requires the Department of Energy (DOE) to administer an energy conservation program for these products. EPCA, as amended, provides DOE the authority to establish energy conservation standard for certain commercial equipment covered by the American Society of Heating, Refrigerating, and AirConditioning Engineers (ASHRAE) and the Illuminating Engineerings Society of North America (IESNA) Standard 90.1, including packaged terminal air conditioners (PTACS) and packaged terminal heat pumps (PTHPs). (42 U.S.C. 6113(a)(6)9A)) Section 342(a)(6)(A) provides that the DOE may prescribe a standard more stringent than the level in ASHRAE/IESNA Standard 90.1, after ASHRAE amends the energy conservation standards found in ASHRAE/IESNA Standard 90.1, if DOE can demonstrate "by clear and convincing evidence" that such a more stringent standard "would result in significant additional conservation of energy and is technologically feasible and economically justified."

Heating \& Cooling

HVAC

Commercial (all)

Market transformation \& deployment

Ongoing

mailto:wes.anderson@ee.doe.gov

http://www1.eere.energy.gov/buildings/appliance_standards/commercial/packaged_ac_hp.html 
Funding Source

Sponsoring Program/Office

Channel of Influence

Project Title

Brief Description

Objectives

End Use

Product Type Focus

Type of Building

Stage

Status

Primary Contact

Weblinks

ID

Funding Source

Sponsoring Program/Office

Channel of Influence

Project Title

Brief Description

Objectives

End Use

Product Type Focus

Type of Building

Stage

Status

Primary Contact

Weblinks
71

DOE - BTP

BTP Appliance \& Equipment Standards

Regulatory

High Intensity Discharge Lamps

High Intensity Discharge (HID) Lamps are electric lamps that produce light in a small arc tube under high internal pressure. Typical applications for these lamps are street and roadway lighting, area lighting such as parking lots and stadiums, industrial and commercial building interior lighting, commercial, industrial and residential security lighting, and landscape lighting. There are three HID lamp types: mercury vapor, metal halide, and high pressure sodium. The Energy Policy and Conservation Act (EPCA, 42 U.S.C.6317(a)(1)) requires the Department of Energy (the Department) to undertake a determination to see if energy conservation standards for HID lamps would be technologically feasible and economically justified, and would result in significant energy savings.

Lighting

Lighting Equipment

Commercial (all)

Market transformation \& deployment

Ongoing

mailto:linda.graves@ee.doe.gov

http://www1.eere.energy.gov/buildings/appliance_standards/commercial/high_intensity_lamps.ht

79

DOE - BTP

BTP Appliance \& Equipment Standards

Regulatory

Water Heaters

Pursuant to Part C of Title III of the Energy Policy and Conservation Act (EPCA), the Department of Energy (DOE) promulgates a rule prescribing test procedures to rate the energy efficiency of warm air furnaces. For commercial heating, air conditioning and water heating products generally, the rule prescribes definitions and procedural provisions, and incorporates from EPCA general enforcement and administrative provisions.

\section{Water Heating}

Water Heat

Commercial (all)

Market transformation \& deployment

Ongoing

http://www1.eere.energy.gov/buildings/appliance_standards/commercial/waterheaters.html 
Funding Source

DOE - BTP

Sponsoring Program/Office

BTP Appliance \& Equipment Standards

Channel of Influence

Regulatory

Project Title

Brief Description

Commercial Clothes Washers

The Energy Policy and Conservation Act (EPCA) (42 USC 6295 (e)), as amended, requires the U.S. Department of Energy (DOE) to determine whether amended, more stringent standards would be technologically feasible and economically justified. Commercial clothes washers were originally included in the final rule for residential dishwashers, dehumidifiers, and cooking products, and commercial clothes washers. However, DOE needed to conduct supplemental rulemaking analyses to complete the rulemaking. As a result, the standards for commercial clothes washers are under development in a separate rulemaking through a supplemental notice of proposed rulemaking (SNOPR) and final rule.

Objectives

End Use

Product Type Focus

Plug Loads

Equipment \& Appliances

Type of Building

Stage

Status

Primary Contact

Weblinks

Commercial (all)

Market transformation \& deployment

Ongoing

mailto:stephen.witkowski@ee.doe.gov

http://www1.eere.energy.gov/buildings/appliance_standards/commercial/clothes_washers.html

ID

Funding Source

Sponsoring Program/Office

Channel of Influence

Project Title

Brief Description

Objectives

End Use

Product Type Focus

Type of Building

Stage

Status

Primary Contact

Weblinks

248

DOE - BTP

BTP

Targeted Deployment Programs

\section{Energy Star}

Energy Star is a joint program of the U.S. Environmental Protection Agency and the U.S.

Department of Energy : DOE performs testing for Energy Star and measures performance as part of rating for Energy Star appliances, lighting and equipment

All

HVAC; Lighting; Equipment \& Appliances

Non-specific

Market transformation \& deployment

Ongoing 
Funding Source

DOE - BTP

Sponsoring Program/Office

BTP Appliance \& Equipment Standards

Channel of Influence

Project Title

Brief Description

Objectives

End Use

Product Type Focus

Type of Building

Stage

Status

Primary Contact

Weblinks

ID

Funding Source

Sponsoring Program/Office

Channel of Influence

Project Title

Brief Description

Objectives

End Use

Product Type Focus

Type of Building

Stage

Status

Primary Contact

Weblinks

Regulatory

Residential Clothes Washers

The Energy Policy and Conservation Act (42 U.S.C. 6291, et seq.) established the Energy Conservation Program for Consumer Products Other than Automobiles, covering major household appliances including residential clothes washers. Later, the National Appliance Energy Conservation Act of 1987 amended EPCA by establishing energy conservation standards for residential clothes washers and requiring the U.S. Department of Energy (DOE) to consider amending standards in two subsequent rulemakings. In 2007, the Energy Independence and Security Act of 2007 (EISA 2007) prescribed new standards for residential clothes washers and required that DOE consider amending these standards. DOE is currently developing a rulemaking to review and amend energy conservation standards for residential clothes washers pursuant to 42 U.S.C. 6295(g)(9)(B)(i).

\section{Plug Loads}

Equipment \& Appliances

Residential (all)

Market transformation \& deployment

Ongoing

54

DOE - BTP

BTP Appliance \& Equipment Standards

Regulatory

Residential Central Air Conditioners and Heat Pumps Rulemaking

The U.S. Department of Energy (DOE or The Department) published a Notice of Availability of the Frame Document (PDF 82 KB) in the Federal Register on June 6th, 2008 to begin the new rulemaking process for a Final Rule to be published in 2011. For more information on the documents for the new rulemaking see the Standards and Rulemaking Webpage. The Department will hold a Framework public meeting on June 12, 2008, to discuss issues and procedures involved in energy conservation standards rulemaking for residential central air conditioners and heat pumps.

Heating \& Cooling

HVAC

Residential (all)

Market transformation \& deployment

Ongoing 
Funding Source

Sponsoring Program/Office

Channel of Influence

Project Title

Brief Description

Objectives

End Use

Product Type Focus

Type of Building

Stage

Status

Primary Contact

Weblinks

ID

Funding Source

Sponsoring Program/Office

Channel of Influence

Project Title

Brief Description

Objectives

End Use

Product Type Focus

Type of Building

Stage

Status

Primary Contact

Weblinks
53

DOE - BTP

BTP Appliance \& Equipment Standards

Regulatory

Appliances and Comercial Equip Standards: Ceiling Fans and Ceiling Fan Light Kits

The standards for ceiling fan light kits apply to certain socket types as of January 1, 2007, and other socket types on January 1, 2009. Links below provide further information for manufacturers and consumers.

Plug Loads, Heating, Cooling

MELS; HVAC

Commercial and Residential

Market transformation \& deployment

Ongoing

mailto:linda.graves@ee.doe.gov

http://www1.eere.energy.gov/buildings/appliance_standards/residential/ceiling_fans.html

72

DOE - BTP

BTP Appliance \& Equipment Standards

Regulatory

Metal Halide Lamp Fixtures

Energy conservation standards cover metal halide lamp fixtures, however, the ballast is the energyusing device regulated in the fixture. The fixture manufacturers must comply with energy conservation standards when shipping fixtures or separately shipping ballast enclosures containing ballasts. Therefore, the information here focuses on metal halide lamp fixtures and the metal halide ballasts used within those fixtures.

Lighting

Lighting Equipment

Commercial (all)

Market transformation \& deployment

Ongoing

mailto:linda.graves@ee.doe.gov

http://www1.eere.energy.gov/buildings/appliance_standards/commercial/metal_halide_lamp_ball 
Funding Source

Sponsoring Program/Office

Channel of Influence

Project Title

Brief Description

Objectives

End Use

Product Type Focus

Type of Building

Stage

Status

Primary Contact

Weblinks

ID

Funding Source

Sponsoring Program/Office

Channel of Influence

Project Title

Brief Description

Objectives

End Use

Product Type Focus

Type of Building

Stage

Status

Primary Contact

Weblinks
78

DOE - BTP

BTP Appliance \& Equipment Standards

Regulatory

Walk-In Coolers and Walk-In Freezers

The National Energy Conservation Policy Act (NECPA), Pub. L. 95-619, amended the Energy Policy and Conservation Act of 1975 (EPCA) to add part C of title III (42 U.S.C. 6311-6317), which established an energy conservation program for certain industrial equipment including WICF. In addition, section 312 of the Energy Independence and Security Act of 2007 (EISA 2007) (PDF 1.0 MB) amended section 342 of EPCA by adding subsection 342(f)(3) (42 U.S.C. 6313(f)(3)), to establish prescriptive requirements, mandated by Congress, for walk-in coolers and walk-in freezers with transparent reach-in doors manufactured on or after January 1, 2009, as set forth in EISA.

\section{Cooling}

Refrigeration

Commercial (all)

Market transformation \& deployment

Ongoing

mailto:charles.llenza@ee.doe.gov

http://www1.eere.energy.gov/buildings/appliance_standards/commercial/wicf.html

80

DOE - BTP

BTP Commercial Buildings

Basic and Applied Research and Development

Rebuild America

The Rebuild America Program element is aligned with the Building Technology Program's research and development activities to accelerate the adoption of advances in building integrated design, software tools, practices and advanced controls, equipment and lighting. The program will expand and update its technical assistance and delivery mechanisms and partners to effectively transfer the technological advances in R\&D.

BT will continue implementation of the Commercial Lighting initiative, EnergySmart Hospitals, EnergySmart Schools, the National Builder's Challenge, and the Building Efficiency Application Centers. The National Builder's Challenge is a program designed to support America's homebuilding industry in its efforts to design, build, and sell 100,000 high performance homes by 2009 . The Commercial Lighting Initiative is a high-profile campaign challenging commercial building owners to improve their building lighting efficiency by 30 percent or more

All

\section{Generic Energy-Reduction Goal}

Non-Specific

Applied research \& technology development

Ongoing

http://apps1.eere.energy.gov/state_energy_program/topic_definition_detail.cfm/topic=112 
Funding Source

Sponsoring Program/Office

Channel of Influence

Project Title

Brief Description

Objectives

End Use

Product Type Focus

Type of Building

Stage

Status

Primary Contact

Weblinks

ID

Funding Source

Sponsoring Program/Office

Channel of Influence

Project Title

Brief Description

Objectives

End Use

Product Type Focus

Type of Building

Stage

Status

Primary Contact

Weblinks

81

DOE - BTP

EERE

Targeted Deployment Programs

Better Buildings (Retrofit Ramp Up)

U.S. Secretary of Energy Steven Chu today announced a new $\$ 450$ million program designed to catalyze a nationwide energy upgrade that experts estimate could save $\$ 100$ million annually in utility bills for households and businesses. The Recovery Act's "Retrofit Ramp-Up" program will pioneer innovative models for rolling out energy efficiency to hundreds of thousands of homes and businesses in a variety of communities. Much like past roll-outs for cable TV or the Internet, DOE intends to create models that, when undertaken nationally, will save consumers billions of dollars on their utility bills and make the huge savings of energy efficiency available to everyone.

All

Generic Energy-Reduction Goal

Residential (all)

Market transformation \& deployment

Ongoing

http://www.energy.gov/news/8005.htm

82

DOE - BTP

BTP Emerging Technologies

Basic and Applied Research and Development

Air ---Source and Ground---Source Integrated Heat Pumps

Applied R\&D and assessment of challenges/barriers in retrofit market

Development of centrally ducted integrated heat pump (IHP) technology for zero energy home (ZEH) application - a concept centered around a small capacity variable-speed electric heat pump and designed to address all the energy service needs of a ZEH (space heating and cooling, water heating, ventilation, and humidity control).

Heating \& Cooling

HVAC

Non-Specific

Analysis

Ongoing 
Funding Source

Sponsoring Program/Office

Channel of Influence

Project Title

Brief Description

Objectives

End Use

Product Type Focus

Type of Building

Stage

Status

Primary Contact

Weblinks

ID

Funding Source

Sponsoring Program/Office

Channel of Influence

Project Title

Brief Description

Objectives

End Use

Product Type Focus

Type of Building

Stage

Status

Primary Contact

Weblinks

83

DOE - BTP

BTP Emerging Technologies

Basic and Applied Research and Development

Solar-assisted heat pump systems

Applied HVAC R\&D

Technical evaluation of energy savings of Solar-Assisted Heat Pump Systems

Heating \& Cooling

HVAC

Non-Specific

Applied research \& technology development

Ongoing

(2)

84

DOE - BTP

BTP Emerging Technologies

Basic and Applied Research and Development

Optimized Heat Exchangers for Energy Efficiency Gains

Applied HVAC R\&D

Demonstration of the system efficiency gains resulting from genetic algorithm-based optimization of the evaporator in a 7.5 ton roof-top air-conditioning unit

Heating \& Cooling

HVAC

Non-Specific

Applied research \& technology development

Ongoing

C-31 
Funding Source

DOE - BTP

Sponsoring Program/Office

Channel of Influence

BTP Emerging Technologies

Project Title

Basic and Applied Research and Development

Brief Description

MELS field study

Objectives

End Use

Product Type Focus

Type of Building

Comprehensive data collection and analysis of MELS

Stage

Plug Loads

Plug Loads

MELS

Non-Specific

Analysis

Status

Ongoing

Primary Contact

Weblinks

ID

86

Funding Source

DOE - BTP

Sponsoring Program/Office

BTP Emerging Technologies

Channel of Influence

Basic and Applied Research and Development

Project Title

Absorption Water Heaters

Brief Description

Objectives

Assess challenges/barriers in retrofit market

End Use

Product Type Focus

Draft report documenting the fluids/cycle scoping study of the absorption water heater

Type of Building

Heating \& Cooling, Water Heating

HVAC

Stage

Non-Specific

Analysis

Status

Ongoing

Primary Contact

Weblinks 
Funding Source

Sponsoring Program/Office

Channel of Influence

Project Title

Brief Description

Objectives

End Use

Product Type Focus

Type of Building

Stage

Status

Primary Contact

Weblinks

ID

Funding Source

Sponsoring Program/Office

Channel of Influence

Project Title

Brief Description

Objectives

End Use

Product Type Focus

Type of Building

Stage

Status

Primary Contact

Weblinks
87

DOE - BTP

BTP Emerging Technologies

Basic and Applied Research and Development

Heat pump Water Heaters

Complete 2,500 cycle durability test program on final production design of HPWH product

- [ Complete design and fabrication of bench scale $\mathrm{CO} 2 \mathrm{HPWH}$

-[? Development of efficient electric HPWH for cold climates

\begin{tabular}{|l|}
\hline Water Heating \\
\hline Water Heat \\
\hline Non-Specific \\
\hline Applied research \& technology development \\
\hline Ongoing \\
\hline
\end{tabular}

249

DOE - BTP

BTP Emerging Technologies

Applied Research and Development

Building Envelope R\&D: Roofs, Walls, Floors

Research and development on the building envelope in the areas of walls, roofs, and foundations and windows and doors.

Opaque envelope objectives/priorities include: Next Generation of Attic/Roof Systems: New Material Development

Dynamic and Advanced Insulation, Dynamic membranes, Dynamic roof surfaces; Advanced Walls; Initiate Foundation Systems, Enabling Research: Cool Roofs, Moisture design, analysis and modeling; Air barrier, Standards development

Heating \& Cooling

Envelope

Non-specific

Field testing \& demonstration

Ongoing 
Funding Source

DOE - BTP

Sponsoring Program/Office

BTP Appliance \& Equipment Standards

Channel of Influence

Regulatory

Project Title

Brief Description

Objectives

End Use

Product Type Focus

Residential Pool Heaters

Title III of the Energy Policy and Conservation Act (EPCA) (42 U.S.C. 6291, et seq.) established the Energy Conservation Program for Consumer Products Other than Automobiles, covering major household appliances including water heaters and home heating equipment. Subsequent amendments expanded title III of EPCA to include additional consumer products and certain commercial and industrial equipment, including residential pool heaters. (42 U.S.C. 6291, et seq.) Furthermore, the National Appliance Energy Conservation Act of 1987 (NAECA) amended EPCA by establishing energy conservation standards for residential water heaters, "direct heating equipment" (replacing the term "home heating equipment" previously used in EPCA), and pool heaters (collectively referred to as the residential heating products), as well as requirements for determining whether these standards should be amended. (42 U.S.C. 6295(e)(1) through (4))

Type of Building

Stage

Status

Primary Contact

\section{Plug Loads}

Equipment \& Appliances

Residential (all)

Market transformation \& deployment

Ongoing

mailto:Mohammed.Khan@hq.doe.gov

Weblinks

http://www1.eere.energy.gov/buildings/appliance_standards/residential/pool_heaters.html

ID

Funding Source

Sponsoring Program/Office

Channel of Influence

Project Title

Brief Description

Objectives

End Use

Product Type Focus

Type of Building

Stage

Status

Primary Contact

Weblinks
52

DOE - BTP

\section{BTP Appliance \& Equipment Standards}

Regulatory

Appliances and Comercial Equip Standards: Battery Chargers and External Power Supplies

Rulemaking activities and regulations regarding energy efficiency for battery chargers and external power supplies.

\section{Plug Loads}

MELS

Commercial and Residential

Market transformation \& deployment

Ongoing

mailto:victor.petrolati@ee.doe.gov

http://www1.eere.energy.gov/buildings/appliance_standards/residential/battery_external.html 
Funding Source

Sponsoring Program/Office

Channel of Influence

Project Title

Brief Description

Objectives

End Use

Product Type Focus

Type of Building

Stage

Status

Primary Contact

Weblinks

ID

Funding Source

Sponsoring Program/Office

Channel of Influence

Project Title

Brief Description

Objectives

End Use

Product Type Focus

Type of Building

Stage

Status

Primary Contact

Weblinks
77

DOE - BTP

BTP Appliance \& Equipment Standards

Regulatory

Commercial Unitary Air Conditioners and Heat Pumps

The Department has gathered and analyzed data and information for the Advance Notice of Proposed Rulemaking (ANOPR) and its Technical Support Document (TSD), as part of the standards rulemaking process. To fulfill DOE's commitment to the July 1996 Process Rule (61 FR 36974) - to make information available to the public as soon as possible - the ANOPR document, the TSD, and the analysis tools for the ANOPR analysis are available below.

Heating \& Cooling

HVAC

Commercial (all)

Market transformation \& deployment

Ongoing

mailto:jim.raba@ee.doe.gov

http://www1.eere.energy.gov/buildings/appliance_standards/commercial/ac_hp.html

58

DOE - BTP

BTP Appliance \& Equipment Standards

Regulatory

Residential Direct Heating Equipment

Title III of the Energy Policy and Conservation Act (EPCA) (42 U.S.C. 6291, et seq.) established the Energy Conservation Program for Consumer Products Other than Automobiles, covering major household appliances including water heaters and home heating equipment. Subsequent amendments expanded title III of EPCA to include additional consumer products and certain commercial and industrial equipment, including residential pool heaters. (42 U.S.C. 6291, et seq.) Furthermore, the National Appliance Energy Conservation Act of 1987 (NAECA) amended EPCA by establishing energy conservation standards for residential water heaters, "direct heating equipment" (replacing the term "home heating equipment" previously used in EPCA), and pool heaters (collectively referred to as the residential heating products), as well as requirements for determining whether these standards should be amended. (42 U.S.C. 6295(e)(1) through (4))

Heating

HVAC

Residential (all)

Market transformation \& deployment

Ongoing

mailto:Mohammed.Khan@hq.doe.gov 
Funding Source

DOE - BTP

Sponsoring Program/Office

Channel of Influence

BTP Appliance \& Equipment Standards

Project Title

Brief Description

Regulatory

Room Air Conditioners Rulemaking

The Energy Policy and Conservation Act (EPCA) (42 U.S.C. 6291, et seq.) established the Energy Conservation Program for Consumer Products Other than Automobiles, covering major household appliances including room air conditioners. The National Appliance Energy Conservation Act of 1987 subsequently amended EPCA by establishing energy conservation standards for room air conditioners. The U.S. Department of Energy is currently developing the second rulemaking to review and amend energy conservation standards pursuant to 42 U.S.C. 6295(c)(2).

\section{Objectives}

End Use

Product Type Focus

\section{Cooling}

HVAC

Type of Building

Residential (all)

Stage

Status

Market transformation \& deployment

Ongoing

Primary Contact

mailto:stephen.witkowski@ee.doe.gov

Weblinks

http://www1.eere.energy.gov/buildings/appliance_standards/residential/room_ac.html

ID

Funding Source

Sponsoring Program/Office

Channel of Influence

Project Title

Brief Description

Objectives

End Use

Product Type Focus

Type of Building

Stage

Status

Primary Contact

Weblinks
51

DOE - BTP

BTP

Targeted Deployment Programs

EnergySmart Schools

EnergySmart Schools mean healthier children and teachers - and a healthy planet. They also save money for America's school districts.

All

Building Commissioning

School

Market transformation \& deployment

Ongoing

http://www1.eere.energy.gov/buildings/energysmartschools/ 
Funding Source

Sponsoring Program/Office

Channel of Influence

Project Title

Brief Description

Objectives

End Use

Product Type Focus

Type of Building

Stage

Status

Primary Contact

Weblinks

ID

Funding Source

Sponsoring Program/Office

Channel of Influence

Project Title

Brief Description

Objectives

End Use

Product Type Focus

Type of Building

Stage

Status

Primary Contact

Weblinks
41

DOE - BTP

BTP

Basic and Applied Research and Development

Net-Zero Energy Commercial Building Initiative

The Net-Zero Energy Commercial Building Initiative aims to achieve marketable net-zero energy commercial buildings by 2025 . Net-zero energy buildings generate as much energy as they consume through efficiency technologies and on-site power generation.

Achieve marketable net-zero energy commercial buildings by 2025 .

All

Whole Building Systems

Commercial (all)

Field testing \& demonstration

Ongoing

http://www1.eere.energy.gov/buildings/commercial_initiative/

42

DOE - BTP

BTP Commercial Buildings

Targeted Deployment Programs

Commercial Building Energy Alliances

The U.S. Department of Energy's Commercial Building Energy Alliances are driven and managed by key industry partners. Their goal is to transform the energy efficiency of commercial buildings. These alliances play a critical role in achieving the goals of the Commercial Building Initiative. Here you will find an overview of the alliances and how they operate.

Transform the energy efficiency of commercial buildings.

All

Whole Building Systems

Commercial (all)

Market transformation \& deployment

Ongoing

http://www1.eere.energy.gov/buildings/commercial_initiative/alliances.html 
Funding Source

Sponsoring Program/Office

Channel of Influence

Project Title

Brief Description

Objectives

End Use

Product Type Focus

Type of Building

Stage

Status

Primary Contact

Weblinks

ID

Funding Source

Sponsoring Program/Office

Channel of Influence

Project Title

Brief Description

Objectives

End Use

Product Type Focus

Type of Building

Stage

Status

Primary Contact

Weblinks
43

DOE - BTP

BTP Commercial Buildings

Basic and Applied Research and Development

Whole Building Design R\&D

A key strategy in meeting the program's zero energy goals is using a whole buildings approach to energy efficiency for commercial and residential buildings. R\&D emphasis is on whole building, systems engineering approaches that optimize efficiency for specific climate zones and applications, while integrating efficiency with renewable energy technologies.

A whole building approach takes into account the complex and dynamic interactions between a building and its environment, among a building's energy systems, and between a building and its occupants. This approach has achieved energy savings of $30 \%$ beyond those obtainable by focusing solely on individual building components.

All

Whole Building Systems

Commercial and Residential

Applied research \& technology development

Ongoing

http://www1.eere.energy.gov/buildings/whole_building.html

44

DOE - BTP

BTP

Basic and Applied Research and Development

Water Heating R\&D

Heat pump water heaters (HPWH) can attain much higher efficiencies than conventional electric water heaters. Yet the residential market for HPWHs has remained small because of long payback times, low perceived reliability, and the need for specialized installation and service. DOE, in a cooperative effort with private industry and the Oak Ridge National Laboratory, developed and tested a HPWH that overcomes these drawbacks, opening the way to greater market acceptance.

DOE's goal is to reduce the first cost of an advanced HPWH by $65 \%$, compared to today's HPWH costs

Water Heating

Water Heat

Residential Single Family

Applied research \& technology development

Ongoing

http://www1.eere.energy.gov/buildings/water_heating.html 
Funding Source

Sponsoring Program/Office

Channel of Influence

Project Title

Brief Description

Objectives

End Use

Product Type Focus

Type of Building

Stage

Status

Primary Contact

Weblinks

ID

Funding Source

Sponsoring Program/Office

Channel of Influence

Project Title

Brief Description

Objectives

End Use

Product Type Focus

Type of Building

Stage

Status

Primary Contact

Weblinks
45

DOE - BTP

BTP

Basic and Applied Research and Development

Lighting R\&D

DOE's solid-state lighting portfolio activities target improvements in the efficiency, performance, lifetime, and quality of light from both organic and inorganic light emitting diodes. Solid-state lighting systems have the potential to more than double the efficiency of today's lighting systems, and these research and development efforts represent an essential component of meeting the Building Technologies Program's zero energy goals.

Increase energy efficiency in buildings by pursuing new and evolving lighting technologies and practices.

Lighting

Lighting Equipment

Non-Specific

Applied research \& technology development

Ongoing

http://www1.eere.energy.gov/buildings/lighting.html

46

DOE - BTP

BTP Emerging Technologies

Basic and Applied Research and Development

Building Envelope R\&D: Windows

Research and development on the building envelope in the areas of walls, roofs, and foundations and windows and doors.

Window R\&D objectives/priorities include: Commercialize Cost Effective R5 Windows, Develop Market for Low E Storms, Develop Affordable Dynamic Windows, Develop Next Generation of R10, Windows

Promote Efficient Products with Enabling Research

Develop Integrated Daylighting Strategies

Develop Fenestration Test, Ratings, and Infrastructure Internationally

Heating \& Cooling

Envelope

Non-Specific

Applied research \& technology development

Ongoing

http://www1.eere.energy.gov/buildings/envelope_rd.html 
Funding Source

Sponsoring Program/Office

Channel of Influence

Project Title

Brief Description

Objectives

End Use

Product Type Focus

Type of Building

Stage

Status

Primary Contact

Weblinks

ID

Funding Source

Sponsoring Program/Office

Channel of Influence

Project Title

Brief Description

Objectives

End Use

Product Type Focus

Type of Building

Stage

Status

Primary Contact

Weblinks
47

DOE - BTP

BTP

Basic and Applied Research and Development

\section{Appliances R\&D}

With continued R\&D into appliance technologies, DOE seeks to build on this record of success; developing and demonstrating technologies that will enable manufacturers to further improve the energy efficiency of appliances, while maintaining or enhancing their performance and value.

Improved User Interface of Residential Thermostats

Improvement of the user interface of residential thermostats to improve usability and help consumers operate their heating and cooling systems more efficiently

Advanced Appliances Pathway Assessment

Evaluation and prioritization of the leading appliance technologies and recommendations on future development

Plug Loads

MELS

Commercial and Residential

Applied research \& technology development

Ongoing

http://www1.eere.energy.gov/buildings/appliances_rd.html

48

DOE - BTP

BTP

Basic and Applied Research and Development

Utility Solar Water Heating Initiative

USH2O advocates the application of solar water heating for renewable portfolio standards (requiring that a percentage of utility electric sales are produced or offset by the use of renewable energy sources) and green pricing programs (providing customers with the option to purchase and support renewables).

Water Heating

Water Heat

Non-Specific

Applied research \& technology development

Ongoing

http://www1.eere.energy.gov/buildings/ush2o/ 
Funding Source

DOE - BTP

Sponsoring Program/Office

BTP Appliance \& Equipment Standards

Channel of Influence

Regulatory

Project Title

Brief Description

Objectives

End Use

Product Type Focus

Type of Building

Stage

Status

Primary Contact

Weblinks

Dehumidifiers

The Energy Policy and Conservation Act (EPCA), as amended by the Energy Policy Act of 2005 (EPACT 2005), prescribes energy conservation standards for various consumer products and commercial and industrial equipment. EPCA also requires the U.S. Department of Energy (DOE) to determine whether amended, more stringent, standards would be technologically feasible and economically justified, and would save a significant amount of energy. The Energy Independence and Security Act of 2007 (EISA 2007) subsequently prescribed standards for dehumidifiers, fulfilling DOE's obligation. Therefore, DOE did not propose standards for dehumidifiers in the final rule for residential dishwashers, dehumidifiers, and cooking products, and commercial clothes washers, but instead codified the statutory standards in the EISA En Masse Technical Amendment.

Plug Loads

HVAC; Thermal Distribution; Appliances

Residential (all)

Market transformation \& deployment

Ongoing

mailto:stephen.witkowskir@ee.doe.gov

ID

Funding Source

Sponsoring Program/Office

Channel of Influence

Project Title

Brief Description

Objectives

End Use

Product Type Focus

Type of Building

Stage

Status

Primary Contact

Weblinks
40

DOE - BTP

\section{BTP}

Regulatory

Building Energy Codes

The Building Technologies Program's Building Energy Codes initiative works with other government agencies, state and local jurisdictions, national code organizations, and industry to help develop improved national model energy codes. To improve appliances and equipment standards, the Building Technologies Program participates in rulemaking and product test procedures through a public process.

Heating \& Cooling, Water Heating, Lighting

Envelope; HVAC; Lighting

Commercial and Residential

Analysis

Ongoing

http://www.energycodes.gov/ 
Funding Source

DOE - BTP

Sponsoring Program/Office

BTP Appliance \& Equipment Standards

Channel of Influence

Regulatory

Project Title

Brief Description

Objectives

End Use

Product Type Focus

Type of Building

Stage

Status

Primary Contact

Weblinks

\section{Dishwashers}

The Energy Policy and Conservation Act (EPCA), as amended, prescribes energy conservation standards for various consumer products and commercial and industrial equipment. EPCA also requires the U.S. Department of Energy (DOE) to determine whether amended, more stringent standards would be technologically feasible and economically justified, and would save a significant amount of energy. The Energy Independence and Security Act of 2007 (EISA 2007) subsequently prescribed standards for dishwashers, fulfilling DOE's obligation. Therefore, DOE is not proposing standards for dishwashers in the final rule for residential dishwashers, dehumidifiers, and cooking products, and commercial clothes washers, but will instead codify the statutory standards in the EISA En Masse.

Plug Loads

Equipment \& Appliances

Residential (all)

Market transformation \& deployment

Ongoing

mailto:stephen.witkowski@ee.doe.gov

http://www1.eere.energy.gov/buildings/appliance_standards/residential/dishwashers.html

ID

Funding Source

Sponsoring Program/Office

Channel of Influence

Project Title

Brief Description

Objectives

End Use

Product Type Focus

Type of Building

Stage

Status

Primary Contact

Weblinks
60

DOE - BTP

BTP Appliance \& Equipment Standards

Regulatory

Residential Furnaces and Boilers

The U.S. Department of Energy (DOE) is required by the Energy Policy and Conservation Act (EPCA) and its amendments to consider national energy conservation standards for residential furnaces and boilers. The Energy Independence and Security Act of 2007 (EISA 2007), Pub. L. 110-140, was enacted on December 19, 2007. The EISA 2007 amendments to EPCA, in relevant part, require DOE to amend the test procedures for all covered products to include measures of standby mode and off mode energy consumption

\section{Heating}

HVAC

Residential (all)

Market transformation \& deployment

Ongoing

mailto:mohammed.khan@hq.doe.gov

http://www1.eere.energy.gov/buildings/appliance_standards/residential/furnaces_boilers.html 
Funding Source

DOE - BTP

Sponsoring Program/Office

Channel of Influence

BTP Appliance \& Equipment Standards

Project Title

Brief Description

Objectives

End Use

Product Type Focus

Regulatory

Fluorescent Lamp Ballasts

The Energy Policy and Conservation Act (EPCA) of 1975, Pub. L. 94-163, (42 U.S.C. 6291-6309)

established an energy conservation program for major household appliances. Additional amendments to EPCA have given DOE the authority to regulate the energy efficiency of many products, including certain fluorescent lamp ballasts. Amendments to EPCA in the National Appliance Energy Conservation Amendments of 1988, P.L. 100-357, established energy conservation standards for certain fluorescent lamp ballasts. (42 U.S.C. 6295(g)(5)) These same amendments also directed DOE to 1) conduct two rulemaking cycles to determine whether to amend these standards and 2) for each rulemaking cycle, determine whether the standards in effect for fluorescent lamp ballasts should be amended so that they would be applicable to additional fluorescent lamp ballasts. (42 U.S.C. 6295(g)(7)(A)-(B))

Type of Building

Stage

Status

Primary Contact

Lighting

Lighting Equipment

Residential (all)

Market transformation \& deployment

Ongoing

mailto:linda.graves@ee.doe.gov

Weblinks

http://www1.eere.energy.gov/buildings/appliance_standards/residential/fluorescent_lamp_ballast 
Funding Source

DOE - BTP

Sponsoring Program/Office

BTP Appliance \& Equipment Standards

Channel of Influence

Regulatory

Project Title

Brief Description

Fluorescent and Incandescent Lamps

The Energy Policy and Conservation Act (EPCA) of 1975 established an energy conservation program for major household appliances. Title III of EPCA (42 U.S.C. 6291 et seq.) set forth provisions designed to improve energy efficiency. Amendments to title III of EPCA in the Energy Policy Act of 1992, P.L. 102-486, established energy conservation standards for certain types of fluorescent lamps and incandescent reflector lamps, and authorized the U.S. Department of Energy (DOE) to amend these standards if such amendments were warranted. (42 U.S.C. 6291(1), 6295(i)(1) and (3)-(4)) The same amendments authorized DOE to adopt standards for additional types of general service fluorescent lamps if such additional standards were warranted. (42 U.S.C. $6295(i)(5))$

Objectives

End Use

Lighting

Product Type Focus

Lighting Equipment

Type of Building

Residential (all)

Stage

Market transformation \& deployment

Status

Ongoing

Primary Contact

mailto:linda.graves@ee.doe.gov

Weblinks

http://www1.eere.energy.gov/buildings/appliance_standards/residential/incandescent_lamps.html 
Funding Source

DOE - BTP

Sponsoring Program/Office

BTP Appliance \& Equipment Standards

Channel of Influence

Regulatory

Project Title

Brief Description

Objectives

End Use

Product Type Focus

Type of Building

Stage

Status

Primary Contact

Weblinks

Refrigerator, Refrigerator-Freezer and Freezers Rulemaking

The Energy Policy and Conservation Act (EPCA) (42 U.S.C. 6291, et seq.) established the Energy Conservation Program for Consumer Products Other than Automobiles, covering major household appliances including residential refrigerators, refrigerator-freezers, and freezers. The National Appliance Energy Conservation Act of 1987 subsequently amended EPCA by establishing energy conservation standards for residential refrigerators, refrigerator-freezers, and freezers. The Energy Independence and Security Act of 2007 (EISA) then required the U.S. Department of Energy (DOE) to review and amend energy conservation standards for residential refrigerators, refrigeratorfreezers, and freezers. DOE is currently developing amended standards pursuant to 42 U.S.C. $6295(b)(4)$.

\begin{tabular}{|l|}
\hline \\
\hline Plug Loads \\
\hline Refrigeration \\
\hline Residential (all) \\
\hline Market transformation \& deployment \\
\hline Ongoing \\
\hline mailto:lucas.adin@ee.doe.gov \\
\hline http://www1.eere.energy.gov/buildings/appliance_standards/residential/refrigerators_freezers.ht \\
\hline
\end{tabular}

ID

Funding Source

Sponsoring Program/Office

Channel of Influence

Project Title

Brief Description

Objectives

End Use

Product Type Focus

Type of Building

Stage

Status

Primary Contact

Weblinks
39

DOE - BTP

BTP Residential Buildings

Basic and Applied Research and Development

Building America

Building America forms research partnerships with all facets of the residential building industry to improve the quality and energy efficiency of homes. The goal is to develop cost effective solutions that reduce the average energy use of housing by $40 \%$ to $100 \%$. Ultimately, Building America research will lead to net zero energy homes, which produce as much energy as they use

All

Whole Building Systems

Residential (all)

Applied research \& technology development

Ongoing

mailto:George.James@ee.doe.gov

http://www1.eere.energy.gov/buildings/building_america/ 
Funding Source

DOE - BTP

Sponsoring Program/Office

BTP Appliance \& Equipment Standards

Channel of Influence

Regulatory

Project Title

Brief Description

Torchieres

The Energy Policy and Conservation Act (EPCA), as amended by the Energy Policy Act of 2005 (EPACT 2005), defines a torchiere as a "portable electric lamp with a reflector bowl that directs light upward to give indirect illumination." (42 U.S.C. 6291(42)) Section 325(x)of EPCA requires that torchieres manufactured on or after January 1, 2006, must not consume more than 190 watts. (42 U.S.C. $6295(x)$ ).

Objectives

End Use

Product Type Focus

Lighting

Lighting Equipment

Type of Building

Residential (all)

Stage

Market transformation \& deployment

Status

Primary Contact

Weblinks

Ongoing

mailto:linda.graves@ee.doe.gov

http://www1.eere.energy.gov/buildings/appliance_standards/residential/torchieres.html

ID

Funding Source

Sponsoring Program/Office

Channel of Influence

Project Title

Brief Description

Objectives

End Use

Product Type Focus

Type of Building

Stage

Status

Primary Contact

Weblinks
67

DOE - BTP

BTP Appliance \& Equipment Standards

Regulatory

Residential Water Heaters

Title III of the Energy Policy and Conservation Act (EPCA) (42 U.S.C. 6291, et seq.) established the Energy Conservation Program for Consumer Products Other than Automobiles, covering major household appliances including water heaters and home heating equipment. Subsequent amendments expanded title III of EPCA to include additional consumer products and certain commercial and industrial equipment, including residential pool heaters. (42 U.S.C. 6291, et seq.) Furthermore, the National Appliance Energy Conservation Act of 1987 (NAECA) amended EPCA by establishing energy conservation standards for residential water heaters, "direct heating equipment" (replacing the term "home heating equipment" previously used in EPCA), and pool heaters (collectively referred to as residential heating products), as well as requirements for determining whether these standards should be amended. (42 U.S.C. 6295(e)(1) through (4))

Water Heating

Water Heat

Residential (all)

Market transformation \& deployment

Ongoing

mailto:Mohammed.Khan@hq.doe.gov

http://www1.eere.energy.gov/buildings/appliance_standards/residential/waterheaters.html 
Funding Source

DOE - BTP

Sponsoring Program/Office

BTP Appliance \& Equipment Standards

Channel of Influence

Regulatory

Project Title

Brief Description

Commercial Heating, Air Conditioning, and Water Heating Equipment

The Energy Policy and Conservation Act (EPCA) sets energy conservation standards for commercial heating, air conditioning, and water heater equipment. (42 U.S.C. 6313(a)) Specifically, the statute sets standards for small, large, and very large commercial package air conditioning and heating equipment, packaged terminal air conditioners (PTACs), packaged terminal heat pumps (PTHPs), warm-air furnaces, packaged boilers, storage water heaters, and unfired hot water storage tanks. For these types of equipment, EPCA established Federal energy conservation standards that generally correspond to the levels set in the American Society of Heating, Refrigeration, and AirConditioning Engineers (ASHRAE) Standard 90.1.

Objectives

End Use

Product Type Focus

Type of Building

Stage

Status

Primary Contact

Weblinks

Heating \& Cooling

HVAC; Water Heat

Commercial (all)

Market transformation \& deployment

Ongoing

mailto:Mohammed.Khan@hq.doe.gov

http://www1.eere.energy.gov/buildings/appliance_standards/commercial/ashrae_products_docs_

ID

Funding Source

Sponsoring Program/Office

Channel of Influence

Project Title

Brief Description

Objectives

End Use

Product Type Focus

Type of Building

Stage

Status

Primary Contact

Weblinks
49

DOE - BTP

BTP

Basic and Applied Research and Development

Indoor Air Quality

As tighter building envelopes and high-efficiency windows make buildings more energy efficient, they also increase the need for adequate ventilation to compensate for the air that gets into buildings through cracks and small holes. Increased ventilation generally translates into improved indoor air quality, but there is often a related energy penalty-for example, hot air pulled in from the outside for ventilation must be cooled and dehumidified.

DOE's Indoor Air Quality (IAQ) R\&D activities focus on developing new ventilation strategies that simultaneously improve indoor air quality and reduce the energy impact of increased ventilation.

\section{Heating \& Cooling}

HVAC

Non-Specific

Applied research \& technology development

Ongoing

http://www1.eere.energy.gov/buildings/indoor_air.html 
Funding Source

DOE - BTP

Sponsoring Program/Office

Channel of Influence BTP

Project Title

Brief Description

Targeted Deployment Programs

EnergySmart Hospitals

EnergySmart Hospitals is supporting our nation's hospitals with the tools and resources needed to integrate energy-efficiency and renewable energy technologies into design, construction, retrofit, and operations and maintenance. Through partnerships, design support, training, and outreach, EnergySmart Hospitals is validating the benefits of energy efficiency and renewable energy as highly effective strategies that are impacting bottom lines and helping hospitals meet mission-critical goals.

Objectives

End Use

Product Type Focus

Type of Building

Stage

Status

Primary Contact

Weblinks

ID

Funding Source

Sponsoring Program/Office

Channel of Influence

Project Title

Brief Description

Objectives

End Use

Product Type Focus

Type of Building

Stage

Status

Primary Contact

Weblinks
All

Building Commissioning

Hospital

Market transformation \& deployment

Ongoing

http://www1.eere.energy.gov/buildings/energysmarthospitals/

56

DOE - BTP

BTP Appliance \& Equipment Standards

Regulatory

Cooking Products

The Energy Policy and Conservation Act (EPCA) (42 USC 6295 (h)), as amended, requires the U.S. Department of Energy (DOE) to determine whether amended, more stringent standards would be technologically feasible and economically justified. On April 8, 2009, DOE published a final rule amending the energy conservation standards for gas and electric kitchen ranges and ovens. DOE raised the standards for gas kitchen ranges and ovens and determined that standards for electric kitchen ranges and ovens did not warrant revision-a "no-standard" standard. Dehumidifiers and dishwashers were originally included in this rulemaking, but have been excluded because the Energy Independence and Security Act of 2007 (EISA 2007) prescribed standards for both of these products.

Plug Loads

Equipment \& Appliances

Residential (all)

Market transformation \& deployment

Ongoing

mailto:stephen.witkowskir@ee.doe.gov 
Funding Source

Sponsoring Program/Office

Channel of Influence

Project Title

Brief Description

Objectives

End Use

Product Type Focus

Type of Building

Stage

Status

Primary Contact

Weblinks

ID

Funding Source

Sponsoring Program/Office

Channel of Influence

Project Title

Brief Description

Objectives

End Use

Product Type Focus

Type of Building

Stage

Status

Primary Contact

Weblinks
91

DOE - FEMP

\section{FEMP}

Internal Federal Agency Efforts

Federal Interagency Energy Management Task Force (IATF)

Composed of Federal energy managers, the IATF provides analysis and recommendations surrounding legislation, technical issues, and the implementation of Federal energy management activities. The IATF establishes working groups to resolve specific technical or programmatic issues and to develop new initiatives. It also serves as a forum for sharing lessons learned across Federal agencies.

All

Generic Energy-Reduction Goal

Government Buildings

Market transformation \& deployment

Ongoing

http://www1.eere.energy.gov/femp/about/iatf.html

93

DOE - FEMP

\section{FEMP}

Internal Federal Agency Efforts

Technical Guidance and Assistance

Technical Guidance and Assistance helps Federal agencies take advantage of innovative technologies, tools, and best practices in the areas of energy efficiency, renewable energy and water conservation. These activities support agency development of new and existing high performance buildings that are moving toward the

All

Generic Energy-Reduction Goal

Government Buildings

Market transformation \& deployment

Ongoing 
Funding Source

Sponsoring Program/Office

Channel of Influence

Project Title

Brief Description

Objectives

End Use

Product Type Focus

Type of Building

Stage

Status

Primary Contact

Weblinks

ID

Funding Source

Sponsoring Program/Office

Channel of Influence

Project Title

Brief Description

Objectives

End Use

Product Type Focus

Type of Building

Stage

Status

Primary Contact

Weblinks

\section{2}

DOE - FEMP

\section{FEMP}

Internal Federal Agency Efforts

Utility energy Service Contracts

FEMP facilitates Federal agencies access to private sector financing to fund energy efficiency improvements through its Energy Savings Performance Contracts (ESPCs), public benefit funds, and Utility Energy Service Contracts (UESCs) program support. It provides guidance, documentation and individual project assistance to Federal agencies that utilize these programs which help develop and finance energy improvements at Federal facilities that are in need of significant energy system retrofits

All

Generic Energy-Reduction Goal

Government Buildings

Market transformation \& deployment

Ongoing

88

DOE - FEMP

\section{FEMP}

Targeted Deployment Programs

Laboratories for the 21st Century

Laboratories for the 21st Century (Labs21) is a voluntary partnership program dedicated to improving the environmental performance of U.S. laboratories. The program is a joint initiative between the Department of Energy (DOE) and Environmental Protection Agency (EPA).

All

Generic Energy-Reduction Goal

Government Buildings

Analysis

Ongoing

http://www1.eere.energy.gov/femp/program/labs21.html 
Funding Source

Sponsoring Program/Office

Channel of Influence

Project Title

Brief Description

Objectives

End Use

Product Type Focus

Type of Building

Stage

Status

Primary Contact

Weblinks

ID

Funding Source

Sponsoring Program/Office

Channel of Influence

Project Title

Brief Description

Objectives

\section{End Use}

Product Type Focus

Type of Building

Stage

Status

Primary Contact

Weblinks
90

DOE - FEMP

\section{FEMP}

Internal Federal Agency Efforts

Data Center Energy Efficiency

The Federal Government is leading by example to alleviate the burden of growing data center energy consumption. FEMP plays a critical role in the execution of that leadership.

This group develops tools and resources to make data centers more efficient throughout the United States.

\section{Cooling}

Whole Building Systems

Government Buildings

Market transformation \& deployment

Ongoing

http://www1.eere.energy.gov/femp/program/data_center.html

89

DOE - FEMP

\section{FEMP}

Internal Federal Agency Efforts

Transformational Energy Action Management

The Transformational Energy Action Management (TEAM) Initiative is a plan put forth by the Department of Energy (DOE) to transform the Department's energy, environmental and transportation management in compliance with the National Energy Conservation Policy Act and the Energy Conservation Policy Act of 2005.

Reduce energy consumption by $30 \%$ and water consumption by $16 \%$ in all DOE facilities. Attain a LEED Gold standard on all new buildings with a value greater than $\$ 5 \mathrm{M}$ and on all buildings that undergo major renovations of greater than $\$ 5 \mathrm{M}$. Improve the energy efficiency of all data centers by $10 \%$ by 2011 .

All

Generic Energy-Reduction Goal

Government Buildings

Market transformation \& deployment

Ongoing

http://www.sc.doe.gov/sc-31/infrastructure/TEAM.html 
Funding Source

Sponsoring Program/Office

Channel of Influence

Project Title

Brief Description

Objectives

End Use

Product Type Focus

Type of Building

Stage

Status

Primary Contact

Weblinks

ID

Funding Source

Sponsoring Program/Office

Channel of Influence

Project Title

Brief Description

Objectives

End Use

Product Type Focus

Type of Building

Stage

Status

Primary Contact

Weblinks
94

DOE - NETL

NETL

Basic and Applied Research and Development

Modern Grid Strategy

As the authors of these seven Principal Characteristics of a Smart Grid, the MGS team is uniquely qualified to provide vision and depth for key stakeholders seeking a richer understanding of key technologies and the characteristics of a smart grid. The MGS team is broadly recognized as having a deep understanding of the key technologies, implementation and fundamental vision of tomorrow's electric grid. The MGS team has provided educational presentations and seminars regarding modernizing the grid to numerous key stakeholder groups both domestic and foreign. The MGS team continues to reach out to key stakeholders and new entrants in the smart grid field.

\section{Smart Grid}

Generic Energy-Reduction Goal

Non-Specific

Market transformation \& deployment

Ongoing

http://www.netl.doe.gov/moderngrid/

101

DOE - OS

OS

Basic and Applied Research and Development

Physical Biosciences

The research provides basic structure-function information necessary to accomplish solid-phase nanoscale synthesis in a targeted manner, i.e., controlling the basic architecture of energy transduction and storage systems. This impacts numerous DOE interests, including improved biochemical pathways for biofuel production, next generation energy conversion/storage devices, and efficient, environmentally benign, sustainable catalysts.

In FY 2010, continued emphasis will be placed on probing the organizational principles of biological energy transduction and chemical storage systems using advanced molecular imaging and x-ray or neutron methods for structural determination. Of particular interest is the molecular scale characterization of the structure and chemistry of the biopolymers of the plant cell wall, knowledge that is required for the direct catalytic conversion of biomass into chemical fuels

\section{Smart Grid}

Distributed generation

Non-Specific

Basic Research

Ongoing

http://www.science.doe.gov/bes/archives/budget.html (Page 78 of 2010 Request) 
Funding Source

Sponsoring Program/Office

Channel of Influence

Project Title

Brief Description

Objectives

End Use

Product Type Focus

Type of Building

Stage

Status

Primary Contact

Weblinks
95

DOE - OS

OS

Basic and Applied Research and Development

Physical Behavior of Materials

The research supported by this activity is necessary for improving materials reliability in chemical, electrical, and electrochemical applications and for improving the ability to generate and store energy in materials. Materials in energy-relevant environments are increasingly being exposed to extreme temperatures, strong magnetic fields, and hostile chemical conditions. A detailed understanding of how materials behavior is linked to the surroundings and treatment history is critical to our understanding of corrosion, photovoltaics, fast-ion conducting electrolytes for batteries and fuel cells, novel magnetic materials for low magnetic loss power generation, magneto caloric materials for high-efficiency refrigeration, and new materials for high-temperature gasification

In FY 2010, this activity will support research on energy conversion designed to achieve low cost power conversion.

All

Distributed generation

Non-Specific

Basic Research

Ongoing

http://www.science.doe.gov/bes/archives/budget.html (Page 75 of 2010 Request) 
Funding Source

Sponsoring Program/Office

Channel of Influence

Project Title

Brief Description

Objectives

End Use

Product Type Focus

Type of Building

Stage

Status

Primary Contact

Weblinks
96

DOE - OS

OS

Basic and Applied Research and Development

Synthesis and Processing Science

Synthesis and processing science is a key component in the discovery and design of a wide variety of energy relevant materials. In this regard, the activity supports the DOE's mission in the synthesis of wide bandgap semiconductors for solid state lighting; light-weight metallic alloys for efficient transportation; novel materials such as metal organic frameworks for hydrogen storage; and structural ceramics and the processing of high temperature superconductors for near zero-loss electricity transmission. The research activity aims at providing synthesis and processing capabilities to enable the manipulation of individual spin, charge, and atomic configurations in ways to probe the atomistic basis for materials properties

In FY 2010, research will seek to develop novel design rules for synthesizing nanostructured materials and assemblies for energy relevant systems. Research on advanced materials for electrical energy storage will include studies on the fundamental electrochemical characteristics of the nanoscale building blocks with varying size and shape and in confined geometry.

Lighting

Lighting Equipment

Non-Specific

Basic Research

Ongoing

http://www.science.doe.gov/bes/archives/budget.html (Page 78 of 2010 Request) 
Funding Source

DOE - OS

Sponsoring Program/Office

Channel of Influence OS

Project Title

Brief Description

Objectives

Basic and Applied Research and Development

Materials Chemistry and Biomolecular Materials

This activity supports basic research in chemical and bio-inspired synthesis and discovery of new materials. In the materials chemistry area, discovery, design, and synthesis of novel materials with an emphasis on the chemistry and chemical control of structure and collective properties are supported. Major thrust areas include nanoscale chemical synthesis and assembly; solid state chemistry for controlled synthesis and tailored reactivities; novel polymeric materials; surface and interfacial chemistry including electrochemistry; and the development of new, science-driven, laboratory-based analytical tools and techniques. In the biomolecular materials area, research supported includes biomimetic and bioinspired functional materials and complex structures, and materials aspects of energy conversion processes based on principles and concepts of biology.

Research supported in this activity underpins many energy-related technological areas such as batteries and fuel cells, catalysis, energy conversion and storage, friction and lubrication, high efficiency electronic devices, hydrogen generation and storage, light-emitting materials, lightweight high-strength materials, and membranes for advanced separations.

\section{End Use}

Product Type Focus

Type of Building

Stage

Status

Primary Contact

Weblinks
Lighting

Lighting Equipment

Non-Specific

Basic Research

Ongoing

http://www.science.doe.gov/bes/archives/budget.html (Page 78 of 2010 Request) 
Funding Source

DOE - OS

Sponsoring Program/Office

Channel of Influence

Basic and Applied Research and Development

Project Title

Brief Description

Objectives

Energy Frontier Research Centers

While EFRCs are inherently multi-disciplinary in nature, this activity includes EFRCs that are focused on the design, discovery, synthesis, and characterization of new materials for improved conversion of solar energy into electricity; that store electrical energy in innovative new ways with greatly increased capacity; that are resistant to corrosion, decay, or failure in extreme conditions of temperature, pressure, radiation, or chemical exposures; that take advantage of emergent phenomena, such as superconductivity, to improve energy transmission; and that optimize and control photon management in solid state materials to improve energy efficiency. The Centers will enhance our fundamental understanding of complex materials by combining experimental research with theory, computation and advanced simulations.

Unifying themes in the research include the synthesis and characterization of materials and phenomena on the nanometer length scale and ultrafast (femtoseconds to attoseconds) timescales. Observing the dynamics of energy flow in theses systems is necessary if we are to learn to control their behavior

End Use

All

Product Type Focus

Distributed generation

Type of Building

Non-Specific

Stage

Basic Research

Status

Ongoing

Primary Contact

Weblinks

http://www.science.doe.gov/bes/archives/budget.html (Page 78 of 2010 Request) 
Funding Source

DOE - OS

Sponsoring Program/Office

Channel of Influence OS

Project Title

Brief Description

Objectives

Basic and Applied Research and Development

Energy Innovation Hub - Batteries and Energy Storage

Improved energy storage is critical for load-leveling and peak-shaving for more efficient and reliable smart electric grid technologies; plug-in hybrid or all-electric vehicles in the transportation sector vehicles; and the deployment of intermittent renewable energy power sources such as solar, wind, and wave energy into the utility sector. Today's electrical energy storage approaches, such as batteries and electrochemical devices, suffer from limited energy and power capacities, lower-thandesired rates of charge and discharge, calendar and cycle life limitations, low abuse tolerance, high cost, and poor performance at high or low temperatures. These performance deficiencies adversely affected the successful use and integration of renewable, intermittent power sources such as solar, wind, and wave energy into the utility sector.

Radically new concepts in materials design can be developed for producing storage devices with materials that are abundant and low in manufacturing cost, are capable of storing higher energy densities, have long cycle lifetimes, and have high safety and abuse tolerance. Together, these new capabilities provide the potential for addressing the gaps in cost and performance separating the current electrical energy storage technologies and those required for sustainable utility and transportation needs.

End Use

Smart Grid

Product Type Focus

Distributed generation

Type of Building

Stage

Non-Specific

Basic Research

Status

Ongoing

Primary Contact

Weblinks

http://www.science.doe.gov/bes/archives/budget.html (Page 78 of 2010 Request) 
Funding Source

Sponsoring Program/Office

Channel of Influence

Project Title

Brief Description

Objectives

End Use

Product Type Focus

Type of Building

Stage

Status

Primary Contact

Weblinks

ID

Funding Source

Sponsoring Program/Office

Channel of Influence

Project Title

Brief Description

Objectives

End Use

Product Type Focus

Type of Building

Stage

Status

Primary Contact

Weblinks
100

DOE - OS

OS

Basic and Applied Research and Development

Solar Photochemistry

Solar photochemical energy conversion is an important option for generating electricity and chemical fuels and therefore plays a vital role in the DOE's development of solar energy as a viable component of the nation's energy supply. Photoelectrochemistry provides an alternative to semiconductor photovoltaic cells for electricity generation from sunlight using closed, renewable energy cycles. Solar photo catalysis, achieved by coupling artificial photosynthetic systems for light harvesting and charge transport with the appropriate electrochemistry, provides a direct route to the generation of fuels such as hydrogen, methane, and complex hydrocarbons.

In FY 2010, continued emphasis will be placed on studies of semiconductor/polymer interfaces, multiple charge generation within semiconductor nanoparticles, and dye-sensitized solar cells. In FY 2010, there is an increase for research on inorganic/organic donor-acceptor molecular assemblies and the use of nanoscale materials in solar photo catalytic generation of chemical fuels.

Renewable Energy

Distributed generation

Non-Specific

Basic Research

Ongoing

http://www.science.doe.gov/bes/archives/budget.html (Page 78 of 2010 Request)

108

DOE - SOLAR

EERE

Targeted Deployment Programs

Builder Technical Outreach

The Solar Energy Technologies Program's effort to provide information to builders is a work in progress. Builders who are interested in incorporating solar into their building plans can consult "A Homebuilder's Guide to Going Solar" to begin learning about the technology and the steps to consider when working with solar.

Renewable Energy

Distributed generation

Residential (all)

Market transformation \& deployment

Ongoing

http://www1.eere.energy.gov/solar/pv_builders.html 
Funding Source

Sponsoring Program/Office

Channel of Influence

Project Title

Brief Description

Objectives

End Use

Product Type Focus

Type of Building

Stage

Status

Primary Contact

Weblinks

ID

Funding Source

Sponsoring Program/Office

Channel of Influence

Project Title

Brief Description

Objectives

End Use

Product Type Focus

Type of Building

Stage

Status

Primary Contact

Weblinks
107

DOE - SOLAR

EERE

Targeted Deployment Programs

Education, Training, and Workforce Development

The U.S. Department of Energy Solar Energy Technologies Program (SETP or Solar Program) supports efforts to increase the number of qualified workers for a growing solar industry. A welltrained workforce is necessary to ensure quality installations, cost reductions, and consumer confidence in the reliability of solar installations. Education, Training, and Workforce Development activities are funded through the Solar Program's Market Transformation efforts. These activities currently focus on building the capacity of U.S. educational institutions to respond to the increased demand for high-quality training for solar installers and code officials.

\section{Renewable Energy}

Distributed generation

\section{Non-Specific}

Market transformation \& deployment

Ongoing

http://www1.eere.energy.gov/solar/education_training.html

106

\section{DOE - SOLAR}

\section{EERE}

Targeted Deployment Programs

State Technical Outreach

Through its State Technical Outreach activity, the U.S. Department of Energy (DOE) Solar Energy Technologies Program provides state policymakers and energy agencies with information and tools to improve state energy programs. The goal of the State Technical Outreach effort is to create more robust solar markets at the state level by removing market barriers that hinder the further development of these programs.

DOE partners with these organizations to support the unique strengths of each organization in providing state lawmakers and regulatory utility commissioners with accurate information about solar energy. DOE also supports these organizations' collaborations on issues that affect both state lawmaker and utility commissioner stakeholder groups.

Renewable Energy

Distributed generation

Non-Specific

Market transformation \& deployment

Ongoing

http://www1.eere.energy.gov/solar/state_technical_outreach.html 
Funding Source

Sponsoring Program/Office

Channel of Influence

Project Title

Brief Description

Objectives

End Use

Product Type Focus

Type of Building

Stage

Status

Primary Contact

Weblinks

ID

Funding Source

Sponsoring Program/Office

Channel of Influence

Project Title

Brief Description

Objectives

End Use

Product Type Focus

Type of Building

Stage

Status

Primary Contact

Weblinks
Regulatory

Solar Codes and Standards

The Solar America Board for Codes and Standards is a collaborative effort of photovoltaic (PV) codes and standards experts who gather and prioritize input from the broad spectrum of PV stakeholders, including policymakers, manufacturers, installers, and consumers. The group administers coordinated recommendations to organizations that establish codes and standards for existing and new solar technologies. The Solar America Board for Codes and Standards (Solar ABCs) generates and distributes consensus 'best practice' materials, answers code-related questions, and provides feedback to the U.S. Department of Energy (DOE) and other government agencies on issues relating to codes and standards. DOE's Solar Energy Technologies Program funds Solar ABCs as part of its commitment to facilitate the widespread adoption of safe, reliable, and cost-effective solar technologies.

Renewable Energy

Distributed generation

Non-Specific

Market transformation \& deployment

Ongoing

http://www1.eere.energy.gov/solar/solar_america_board_codes_standards.html

104

DOE - SOLAR

\section{EERE}

Basic and Applied Research and Development

Solar America Showcases

The U.S. Department of Energy Solar Energy Technologies Program provides free technical assistance to projects that feature large-scale installations of commercially available solar technologies through its Solar America Showcases activity. The goal of the Solar America Showcases project is to accelerate the demand for solar technologies by supporting projects that inspire local governments, citizens, and organizations to use solar energy technologies. The Solar Program is seeking proposals for 2009 Solar America Showcases.

Solar America Showcases awarded until April of 2009 also were required to include projects with solar systems greater than 100 kilowatts. This requirement was increased to a minimum of 250 kilowatts for the most recent winners.

Renewable Energy

Distributed generation

Non-Specific

Market transformation \& deployment

Ongoing

http://www1.eere.energy.gov/solar/solar_america_showcases.html 
Funding Source

Sponsoring Program/Office

Channel of Influence

Project Title

Brief Description

Objectives

End Use

Product Type Focus

Type of Building

Stage

Status

Primary Contact

Weblinks

ID

Funding Source

Sponsoring Program/Office

Channel of Influence

Project Title

Brief Description

Objectives

End Use

Product Type Focus

Type of Building

Stage

Status

Primary Contact

Weblinks
102

DOE - SOLAR

EERE

Basic and Applied Research and Development

Solar Decathalon

The Solar Decathlon joins 20 college and university teams in a competition to design, build, and operate the most attractive and energy-efficient solar-powered house. While the home needs to be efficient, students are also charged with the responsibility of making their homes as attractive and livable as possible. The student teams proved successful in showcasing and demonstrating one of the Decathlon's prime objectives: to demonstrate that market-ready technologies exist that can meet the energy requirements of our daily activities by tapping into the sun's power.

Renewable Energy

Whole Building Systems

Residential detached single family-manufactured

Field testing \& demonstration

Ongoing

http://www1.eere.energy.gov/solar/initiatives.html

103

DOE - SOLAR

EERE

Basic and Applied Research and Development

Solar America Cities

Through the Solar America Cities effort, the U.S. Department of Energy (DOE) is working to rapidly increase the use and integration of solar energy in communities across the country

DOE recognizes the important role of local governments in accelerating widespread solar energy adoption. As the nation's centers of electricity consumption, cities are uniquely positioned to reduce global climate change, strengthen America's energy independence, and support the transition to a clean energy economy by converting to solar energy sources.

Renewable Energy

Distributed generation

Non-Specific

Market transformation \& deployment

Ongoing

http://www1.eere.energy.gov/solar/solar_america_cities.html 
Funding Source

Sponsoring Program/Office

Channel of Influence

Project Title

Brief Description

Objectives

End Use

Product Type Focus

Type of Building

Stage

Status

Primary Contact

Weblinks

ID

Funding Source

Sponsoring Program/Office

Channel of Influence

Project Title

Brief Description

Objectives

End Use

Product Type Focus

Type of Building

Stage

Status

Primary Contact

Weblinks
111

DOE - WIP

WIP

Internal Federal Agency Efforts

State Energy Program

The Weatherization and Intergovernmental Program staffs manage the U.S. Department of Energy (DOE) State Energy Program (SEP). SEP provides grants to the states for them to design and carry out their renewable energy and energy efficiency programs in a way that makes the most sense for their resources and economies. For more information

Weatherize and reduce energy consumption of buildings through efficiency upgrades

Heating \& Cooling

Generic Energy-Reduction Goal

Residential (all)

Market transformation \& deployment

Ongoing

http://apps1.eere.energy.gov/state_energy_program/

114

DOE - WIP

WIP

Internal Federal Agency Efforts

Tribal Energy Activities

Tribal Energy Activities build partnerships with tribal governments to address Native American energy needs for residential, commercial and industrial uses. The program provides financial and technical assistance to tribes for the evaluation and development of clean energy resources. Financial grants support the most promising tribal proposals. Technical assistance objectives include the development of model financial solutions and legal frameworks to spur broader project development and expanded outreach to Native Americans.

Heating \& Cooling

Generic Energy-Reduction Goal

Residential (all)

Market transformation \& deployment

Ongoing

\begin{tabular}{|r|}
\hline \\
\hline
\end{tabular}


Funding Source

Sponsoring Program/Office

Channel of Influence

Project Title

Brief Description

Objectives

End Use

Product Type Focus

Type of Building

Stage

Status

Primary Contact

Weblinks

ID

Funding Source

Sponsoring Program/Office

Channel of Influence

Project Title

Brief Description

Objectives

End Use

Product Type Focus

Type of Building

Stage

Status

Primary Contact

Weblinks
WIP

Internal Federal Agency Efforts

Technical Assistance Project for State and Local Officials (TAP)

The Technical Assistance Project (TAP) is designed to provide state and local officials with quick, short-term access to experts at U.S. Department of Energy (DOE) national laboratories for assistance with their renewable energy and energy efficiency policies and programs.

Weatherize and reduce energy consumption of buildings through efficiency upgrades

Heating \& Cooling

Generic Energy-Reduction Goal

Residential (Low Income)

Market transformation \& deployment

Ongoing

http://apps1.eere.energy.gov/wip/tap.cfm

112

DOE - WIP

WIP

Targeted Deployment Programs

Clean Energy and Air Quality

The U.S. Department of Energy (DOE) Clean Energy and Air Quality Integration Initiative works with state and local governments to include renewable energy and energy efficiency projects in their airquality programs.

Weatherize and reduce energy consumption of buildings through efficiency upgrades

Heating \& Cooling

Generic Energy-Reduction Goal

Residential (all)

Market transformation \& deployment

Ongoing

http://apps1.eere.energy.gov/wip/air_quality.cfm 
Funding Source

Sponsoring Program/Office

Channel of Influence

Project Title

Brief Description

Objectives

End Use

Product Type Focus

Type of Building

Stage

Status

Primary Contact

Weblinks

ID

Funding Source

Sponsoring Program/Office

Channel of Influence

Project Title

Brief Description

Objectives

End Use

Product Type Focus

Type of Building

Stage

Status

Primary Contact

Weblinks

\section{3}

DOE - WIP

WIP

Targeted Deployment Programs

Weatherization Assistance

Weatherization Assistance Program reduces energy costs for low-income households by increasing the energy efficiency of their homes while ensuring their health and safety. DOE provides funding to states, which manage the day-to-day details of the program. Low-income families receive services from a network of more than 900 local weatherization service providers.

Weatherize and reduce energy consumption of buildings through efficiency upgrades

Heating \& Cooling

Generic Energy-Reduction Goal

Residential (Low Income)

Market transformation \& deployment

Ongoing

http://apps1.eere.energy.gov/wip/weatherization.cfm

109

DOE - WIP

WIP

Targeted Deployment Programs

Energy Efficiency and Conservation Block Grant (EECBG) Program

Provides funds to units of local and state government, Indian tribes, and territories to develop and implement projects to improve energy efficiency and reduce energy use and fossil fuel emissions in their communities.

Weatherize and reduce energy consumption of buildings through efficiency upgrades

Heating \& Cooling

Insulating Materials

Residential (Low Income)

Market transformation \& deployment

Ongoing

http://www.eecbg.energy.gov/ 
Funding Source

Sponsoring Program/Office

Channel of Influence

Project Title

Brief Description

Objectives

End Use

Product Type Focus

Type of Building

Stage

Status

Primary Contact

Weblinks

ID

Funding Source

Sponsoring Program/Office

Channel of Influence

Project Title

Brief Description

Objectives

End Use

Product Type Focus

Type of Building

Stage

Status

Primary Contact

Weblinks

Basic and Applied Research and Development

Building Sensors and Controls: Building optimization controller

Supervisory controller integrating metering feedback into building systems.

Detect spikes in electricity and provides this information to controller in order to optimize energy usage.

All

Supervisory and system integration (Sensor-Control)

Commercial and Residential

Applied research \& technology development

Ongoing

Conrad Flemming

http://EERE. . .

116

DOE-FEMP

\section{FEMP}

Internal Federal Agency Efforts

Interagency Sustainability Working Group (ISWG)

As the largest single "landlord" in the United States, the Federal Government oversees approximately 500,000 buildings. Historically, approximately $\$ 20$ billion is spent annually on acquiring or substantially renovating Federal facilities. More than $\$ 3.5$ billion is spent on energy for these facilities with almost $\$ 200$ billion for personnel compensation and benefits for civilian employees. This represents an enormous opportunity to transfer sustainable technologies and practices on a large scale and help transform the marketplace

The Interagency Sustainability Working Group (ISWG) publishes numerous resources to assist Federal sustainability efforts.

All

Whole Building Systems

Government Buildings

Analysis

Ongoing

http://www1.eere.energy.gov/femp/program/sustainable_iswgresources.html 
Funding Source

DOI

Sponsoring Program/Office

Channel of Influence

Internal Federal Agency Efforts

Project Title

Brief Description

Objectives

End Use

Product Type Focus

Type of Building

Department of the Interior's Federal Leadership in High Performance and Sustainable Buildings Impl

Stage

Dill

All

Generic Energy-Reduction Goal

Government Buildings

Analysis

Status

Ongoing

Primary Contact

Weblinks

http://www.doi.gov/greening/buildings/

ID

Funding Source

Sponsoring Program/Office

Channel of Influence

Project Title

Brief Description

Objectives

End Use

Product Type Focus

Type of Building

Stage

Status

Primary Contact

Weblinks
118

DOJ

DOJ: Environmental Programs

Internal Federal Agency Efforts

DOJ Environmental Working Group (EWG)

DOJ's Environmental Stewardship Council was established in 2007 to set forth DOJ's policies and procedures for effectively managing environmental programs while complementing the efforts and systems that support the agency's mission. The primary functional areas of responsibility that encompass environmental aspects include budget, facilities, purchasing, information technology, environmental management, security, and overall administration.

All

Generic Energy-Reduction Goal

Government Buildings

Analysis

Ongoing

http://www.justice.gov/jmd/ep/index.html 
Funding Source

DOT

Sponsoring Program/Office

Federal Transit Administration

Channel of Influence

Internal Federal Agency Efforts

Project Title

Brief Description

Transit Green Building Action Plan

Reduced energy consumption and increased energy efficiency in transportation facilities. Build new facilities to meet LEED requirements

Objectives

The primary green building rating system used in design of new and renovated buildings is Leadership in Energy and Environmental Design or LEED ${ }^{\circledR}$.

End Use

All

Product Type Focus

Generic Energy-Reduction Goal

Type of Building

Stage

Government Buildings

Market transformation \& deployment

Status

Ongoing

Primary Contact

Weblinks

http://www.fta.dot.gov/publications/publications_10318.html

ID

Funding Source

Sponsoring Program/Office

Channel of Influence

Project Title

Brief Description

Objectives

End Use

Product Type Focus

Type of Building

Stage

Status

Primary Contact

Weblinks
123

EPA

Urban Sustainability \& the Built Environment

Basic and Applied Research and Development

Environmentally Responsible Redevelopment and Reuse (ER3)

By promoting and facilitating environmentally responsible redevelopment at formerly contaminated sites, the goal of ER3 is to establish the next generation of environmental protection - one that proactively prevents and/or reduces contamination in the developed environment.

To achieve this goal, EPA, through ER3, will collaborate with federal, state, public, and private partners to identify, develop, and deliver incentives to encourage developers and property owners to implement sustainable practices during the redevelopment of contaminated sites.

All

Generic Energy-Reduction Goal

Non-Specific

Market transformation \& deployment

Ongoing

http://epa.gov/oecaerth/cleanup/revitalization/er3/index.html 
Funding Source

Sponsoring Program/Office

Channel of Influence

Project Title

Brief Description

Objectives

End Use

Product Type Focus

Type of Building

Stage

Status

Primary Contact

Weblinks

ID

Funding Source

Sponsoring Program/Office

Channel of Influence

Project Title

Brief Description

Objectives

End Use

Product Type Focus

Type of Building

Stage

Status

Primary Contact

Weblinks
131

EPA

Energy Star

Targeted Deployment Programs

Utility and Regional Energy Efficiency Program Sponsors (EEPS) Resources

ENERGY STAR provides a powerful platform for utilities, state agencies, and other organizations implementing energy efficiency programs to make a bigger difference in their communities. Using ENERGY STAR tools and strategies, organizations can reduce program costs and implementation timelines while increasing the efficacy of their programs.

Promote improved energy performance in existing homes, Work with retailers to promote ENERGY STAR products, Promote energy performance in new homes, and Promote improvements in wholebuilding energy performance.

All

Generic Energy-Reduction Goal

Residential (all)

Market transformation \& deployment

Ongoing

http://www.energystar.gov/index.cfm?c=reps.pt_reps

130

EPA

Urban Sustainability \& the Built Environment

Internal Federal Agency Efforts

Greening EPA

EPA's Energy and Water Efficiency Program ensures that the Agency uses natural resources efficiently when designing, constructing, and maintaining its facilities. Originally established to meet the requirements of the Energy Policy Act of 1992 (EPAct 1992) and Executive Order (E.O.) 13123 , this program reduces energy consumption by upgrading existing heating, ventilation, and air conditioning (HVAC) systems; incorporating energy-efficient and renewable technologies; and relying on aggressive energy-efficiency projects financed through energy savings performance contracts. With more rigorous energy reduction requirements included in the Energy Independence and Security Act of 2007 (EISA), E.O. 13423 (which strengthened the requirements included in E.O. 13123), and the Energy Policy Act of 2005 (EPAct 2005),

All

Generic Energy-Reduction Goal

Government Buildings

Market transformation \& deployment

Ongoing

http://www.epa.gov/oaintrnt/energy/index.htm 
Funding Source

EPA

Sponsoring Program/Office

Urban Sustainability \& the Built Environment

Channel of Influence

Targeted Deployment Programs

Project Title

Brief Description

\section{Sustainable Skylines}

Under the SSI, an area can choose to perform projects from seven categories: renewing community livability, climate change and energy efficiency, land use and transportation strategies, fossil-fueled engine and motor sources, green buildings development, facilities and businesses and innovative and sustainable practices. While the primary focus of SSI is air, communities are encouraged to select activities which will result in synergistic reductions from all medias such as water, hazardous/solid waste, and energy. It should be stressed that the SSI is not a regulatory program nor is it an in-lieu of regulatory program. A strong performance accountability mechanism is incorporated into the framework for both the community and all participating partners. This framework can help communities achieve measurable emissions reductions within 3 years

Objectives

End Use

All

Product Type Focus

Generic Energy-Reduction Goal

Type of Building

Stage

Status

Primary Contact

Weblinks

\section{Non-Specific}

Market transformation \& deployment

Ongoing

\section{http://www.epa.gov/sustainableskylines/overview.html\#howitworks}

128

EPA

Funding Source

Sponsoring Program/Office

Channel of Influence

rban Sustainability \& the Built Environment

Project Title

Brief Description

Targeted Deployment Programs

Smart Growth and Schools

While a first-rate education in a safe facility must always be the primary consideration when making school spending decisions, a growing number of communities are using these investments to meet multiple goals -- educational, health, environmental, economic, social, and fiscal.

Objectives

End Use

Conserves resources and land;

All

Product Type Focus

Whole Building Systems

Type of Building

School

Stage

Market transformation \& deployment

Status

Ongoing

Primary Contact

Weblinks

http://www.epa.gov/smartgrowth/schools.htm 
Funding Source

EPA

Sponsoring Program/Office

Urban Sustainability \& the Built Environment

Channel of Influence

Internal Federal Agency Efforts

Project Title

HUD-DOT-EPA Interagency Partnership for Sustainable Communities

Brief Description

Through a set of guiding livability principles and a partnership agreement that will guide the agencies' efforts, this partnership will coordinate federal housing, transportation, and other infrastructure investments to protect the environment, promote equitable development, and help to address the challenges of climate change.

Objectives

End Use

All

Product Type Focus

Whole Building Systems

Type of Building

Stage

Non-Specific

Market transformation \& deployment

Status

Ongoing

Primary Contact

Weblinks

http://www.epa.gov/livability/2009-0616-epahuddot.htm

ID

Funding Source

Sponsoring Program/Office

Channel of Influence

Project Title

Brief Description

Objectives

End Use

Product Type Focus

Type of Building

Stage

Status

Primary Contact

Weblinks
126

EPA

Urban Sustainability \& the Built Environment

Targeted Deployment Programs

Green Communities

The Green Communities website is your portal to tools and information on the best strategies, programs and policies to reduce your environmental footprint. A 5-step environmental planning framework leads you to a greener, sustainable future.

All

Whole Building Systems

New Buildings

Market transformation \& deployment

Ongoing

http://www.epa.gov/greenkit/index.htm 
Funding Source

EPA

Sponsoring Program/Office

Channel of Influence

Urban Sustainability \& the Built Environment

Project Title

Targeted Deployment Programs

Brief Description

Green Building

EPA and U.S. Department of Energy's ENERGY STAR ${ }^{\circledR}$ program promotes partnerships with homebuilders, office building managers, product manufacturers, and many other organizations to improve the energy efficiency of homes, buildings, and various building components and appliances.

Objectives

End Use

All

Product Type Focus

Generic Energy-Reduction Goal

Type of Building

Stage

Non-Specific

Market transformation \& deployment

Status

Ongoing

Primary Contact

Weblinks

http://www.epa.gov/opptintr/greenbuilding/

ID

Funding Source

Sponsoring Program/Office

Channel of Influence

Project Title

Brief Description

Objectives

End Use

Product Type Focus

Type of Building

Stage

Status

Primary Contact

Weblinks
122

EPA

Urban Sustainability \& the Built Environment

Targeted Deployment Programs

Energy Star

ENERGY STAR is a joint program of the U.S. Environmental Protection Agency and the U.S. Department of Energy : EPA's ENERGY STAR partnership offers a proven energy management strategy that helps in measuring current energy performance, setting goals, tracking savings, and rewarding improvements. For Energy Star also rates appliances on their energy consumption

All

Generic Energy-Reduction Goal

Non-Specific

Market transformation \& deployment

Ongoing

http://www.energystar.gov/ 
Funding Source

EPA

Sponsoring Program/Office

Urban Sustainability \& the Built Environment

Channel of Influence

Internal Federal Agency Efforts

Project Title

Environmentally Preferable Purchasing (EPP)

Brief Description

Environmentally Preferable Purchasing (EPP) helps the federal government "buy green," and in doing so, uses the federal government's enormous buying power to stimulate market demand for green products and services. Geared first to help federal purchasers, this site can help green vendors, businesses large and small -- and consumers

Objectives

Manage green purchasing processes.

End Use

All

Product Type Focus

Generic Energy-Reduction Goal

Type of Building

Stage

Government Buildings

Market transformation \& deployment

Status

Ongoing

Primary Contact

Weblinks

http://www.epa.gov/opptintr/epp/

ID

Funding Source

Sponsoring Program/Office

Channel of Influence

Project Title

Brief Description

Objectives

End Use

Product Type Focus

Type of Building

Stage

Status

Primary Contact

Weblinks
120

EPA

Greening EPA

Internal Federal Agency Efforts

EPA Green Buildings

EPA addresses these challenges by promoting energy and resource efficiency, waste reduction and pollution prevention practices, indoor air quality standards, and other environmental initiatives for both new construction and existing buildings.

All

Generic Energy-Reduction Goal

Government Buildings

Analysis

Ongoing

http://www.epa.gov/greeningepa/projects/index.htm 
Funding Source

EPA

Sponsoring Program/Office

Urban Sustainability \& the Built Environment

Channel of Influence

Targeted Deployment Programs

Project Title

Brief Description

\section{Green Construction}

Pollution prevention initiatives are required to be considered in all plans, drawings, work statements, specifications, or other product descriptions.

Objectives

For each CPG item there is a Recovered Materials Advisory Notice (RMAN), which establishes the recommended recycle content level for a given product.

End Use

All

Product Type Focus

Generic Energy-Reduction Goal

Type of Building

Stage

Non-Specific

Market transformation \& deployment

Status

Ongoing

Primary Contact

Weblinks

http://www.fedcenter.gov/resources/facilitytour/construction/green/

ID

Funding Source

Sponsoring Program/Office

Channel of Influence

Project Title

Brief Description

Objectives

End Use

Product Type Focus

Type of Building

Stage

Status

Primary Contact

Weblinks
136

GSA

Sustainable Design Program

Internal Federal Agency Efforts

Sustainable Design Program

Sustainable design seeks to reduce negative impacts on the environment, and the health and comfort of building occupants, thereby improving building performance. The basic objectives of sustainability are to reduce consumption of non-renewable resources, minimize waste, and create healthy, productive environments.

As a means of evaluating and measuring our green building achievements, all GSA new construction projects and substantial renovations must achieve Silver certification through the Leadership in Energy and Environmental Design (LEED ${ }^{\circledR}$ ) Green Building Rating System of the U.S. Green Building Council. Projects are encouraged to exceed LEED ${ }^{\circledR}$ Silver and achieve LEED ${ }^{\circledR}$ Gold. LEED ${ }^{\circledR}$ consists of a set of prerequisites and credits with specific requirements for obtaining points in order to become a certified green building.

All

Building Commissioning

Government Buildings

Market transformation \& deployment

Ongoing

donald.horn@gsa.gov

http://www.gsa.gov/Portal/gsa/ep/channelView.do?pageTypeld=17109\&channelPage=\%2Fep\%2Fc 
Funding Source

GSA

Sponsoring Program/Office

Channel of Influence

Sustainable Design Program

Project Title

Internal Federal Agency Efforts

Brief Description

\section{Energy Management Support and Services}

The Energy Management Solutions on Schedule 03FAC provide highly qualified energy contractors that offer a full suite of services such as: comprehensive energy management, energy audits and baseline assessments, metering and advanced metering services, building commissioning, energy management training, water conservation, turn-key renewable energy solutions, resource efficiency management, bill auditing and consolidation, LEED consulting, sustainability and carbon management, and assistance with developing energy project statements of work.

Objectives

End Use

All

Product Type Focus

Generic Energy-Reduction Goal

Type of Building

Government Buildings

Stage

Status

Primary Contact

Market transformation \& deployment

Ongoing

mailto:HSSMarketing@gsa.gov

Weblinks

http://www.gsa.gov/Portal/gsa/ep/channelView.do?pageTypeld=17110\&channelPage=\%2Fep\%2Fc

ID

Funding Source

Sponsoring Program/Office

Channel of Influence

Project Title

Brief Description

Objectives

End Use

Product Type Focus

Type of Building

Stage

Status

Primary Contact

Weblinks
133

GSA

Sustainable Design Program

Internal Federal Agency Efforts

Energy and Water Conservation

GSA through the Energy Center of Expertise reduces federal utility costs by promoting optimal energy use. Resources are offered to all federal agencies and non-profit organizations.

GSA brings value to organizations by offering strategic energy management programs that result in increased net operating income and enhanced asset value of real properties.

All

Generic Energy-Reduction Goal

Government Buildings

Market transformation \& deployment

\section{Ongoing}

mark.ewing@gsa.gov

http://www.gsa.gov/Portal/gsa/ep/channelView.do?pageTypeld=17109\&channelPage=\%2Fep\%2Fc 
Funding Source

Sponsoring Program/Office

Channel of Influence

Project Title

Brief Description

Objectives

End Use

Product Type Focus

Type of Building

Stage

Status

Primary Contact

Weblinks

ID

Funding Source

Sponsoring Program/Office

Channel of Influence

Project Title

Brief Description

Objectives

End Use

Product Type Focus

Type of Building

Stage

Status

Primary Contact

Weblinks
134

GSA

Sustainable Design Program

Internal Federal Agency Efforts

Energy Awareness

GSA has made great strides over the years reducing energy consumption in buildings and complying with related executive orders and mandates. Attainment of these goals coincides with GSA's efforts to perform in the most businesslike manner possible.

The current energy reduction target in GSA buildings is 30 percent by 2005 and 35 percent by 2010 against the 1985 baseline.

All

Generic Energy-Reduction Goal

Government Buildings

Market transformation \& deployment

Ongoing

mark.ewing@gsa.gov

http://www.gsa.gov/Portal/gsa/ep/contentView.do?programld=14659\&channelld=-24344\&ooid=8

132

GSA

Sustainable Design Program

Internal Federal Agency Efforts

Sustainable Design Program

Sustainable design seeks to reduce negative impacts on the environment, and the health and comfort of building occupants, thereby improving building performance. The basic objectives of sustainability are to reduce consumption of non-renewable resources, minimize waste, and create healthy, productive environments.

All

Generic Energy-Reduction Goal

Government Buildings

Analysis

Ongoing

mailto:donald.horn@gsa.gov

http://www.gsa.gov/Portal/gsa/ep/contentView.do?contentld=8154\&contentType=GSA_OVERVIE 
Funding Source

Sponsoring Program/Office

Channel of Influence

Project Title

Brief Description

Objectives

End Use

Product Type Focus

Type of Building

Stage

Status

Primary Contact

Weblinks

ID

Funding Source

Sponsoring Program/Office

Channel of Influence

Project Title

Brief Description

Objectives

End Use

Product Type Focus

Type of Building

Stage

Status

Primary Contact

Weblinks
137

HUD

HUD

Basic and Applied Research and Development

Costs and Benefits of Building Green Affordable Housing

This project has examined the incremental costs and measureable financial savings of the "greening" of affordable housing construction projects. The contractor estimated, using the ANSI green building standard, the green rating of a number of HUD-assisted affordable housing developments and then modeled the changes - cost and construction changes-necessary to achieve ratings across a range of incremental ratings. The study also modeled long-term cost savings resulting from the changes. The project will help inform decisions regarding the value of green ratings in the design and construction of affordable housing.

All

Generic Energy-Reduction Goal

Residential (all)

Analysis

Ongoing

http://www.huduser.org/portal/research/strat_goal4.html

138

HUD

HUD

Basic and Applied Research and Development

Improved Energy Efficiency in 202/811 Housing

The objective of these tasks is to develop a roadmap for Section 202 and Section 811 housing to improve the energy efficiency of existing units as well as to construct energy efficient units through energy efficient technologies and practices promoted by DOE and EPA.

All

Generic Energy-Reduction Goal

Residential (all)

Analysis

Ongoing

http://www.huduser.org/portal/research/strat_goal4.html 
Funding Source

Sponsoring Program/Office

Channel of Influence

Project Title

Brief Description

Objectives

End Use

Product Type Focus

Type of Building

Stage

Status

Primary Contact

Weblinks

ID

Funding Source

Sponsoring Program/Office

Channel of Influence

Project Title

Brief Description

Objectives

End Use

Product Type Focus

Type of Building

Stage

Status

Primary Contact

Weblinks
141

NASA

SBIR

Basic and Applied Research and Development

Advanced Flexible Thin Film PV (FTFPV) Ultra Flex Solar Array System

Advanced solar panels

Develop the next generation of solar panels that are smaller and lighter than present technology and opening up a wider range of military and civil applications

Renewable Energy

Distributed generation

Non-Specific

Applied research \& technology development

Complete

atk.corporate@atk.com

142

NASA

SBIR

Basic and Applied Research and Development

Tandem amorphous silicon modules on a polyimide substrate

Optical modeling to calculate thicknesses of device layers for maximum AMO solar spectrum absorption

Renewable Energy

Distributed generation

Non-Specific

Applied research \& technology development

Complete

\begin{tabular}{|l|}
\hline \\
\hline
\end{tabular}


Funding Source

Sponsoring Program/Office

Channel of Influence

Project Title

Brief Description

Objectives

End Use

Product Type Focus

Type of Building

Stage

Status

Primary Contact

Weblinks

ID

Funding Source

Sponsoring Program/Office

Channel of Influence

Project Title

Brief Description

Objectives

End Use

Product Type Focus

Type of Building

Stage

Status

Primary Contact

Weblinks

140

NASA

SBIR

Basic and Applied Research and Development

Advanced Aerogel Insulation Products

Aspen Systems, Inc., developed an improved aero gel-based flexible thermal insulation system. This system provides cost effective and easier-to-handle alternatives to various types of multilayer and evacuated powder insulations now used on cryogenic equipment as well as many other applications.

High-resistance insulation

Heating \& Cooling

Insulating Materials

Non-Specific

Field testing \& demonstration

Complete

klee@aspensystems.com

139

\section{NASA}

Basic and Applied Research and Development

LED Photodynamic Therapy Research

PDT uses high-intensity, monochromatic light to turn on the cancer-killing properties of a drug, allowing physicians to activate a drug in the tumor only. This keeps the healthy areas around the tumor from being negatively impacted.

Lighting

Lighting Equipment

Applied research \& technology development

Ongoing 
Funding Source

Sponsoring Program/Office

Channel of Influence

Project Title

Brief Description

Objectives

End Use

Product Type Focus

Type of Building

Stage

Status

Primary Contact

Weblinks

ID

Funding Source

Sponsoring Program/Office

Channel of Influence

Project Title

Brief Description

Objectives

End Use

Product Type Focus

Type of Building

Stage

Status

Primary Contact

Weblinks
143

NASA

SBIR

Basic and Applied Research and Development

Light-Weight Flexible Thin Film Solar Cells for Space Applications

Light-weight, high power density thin film solar cells on flexible substrates

Produced polycrystalline copper-indium- diselenide (CIS) solar cells on flexible metal foils, demonstration for the first time of CIS solar cells with over $1 \mathrm{~kW} / \mathrm{kg}$ power density on polymeric substrates

Renewable Energy

Distributed generation

Non-Specific

Applied research \& technology development

Complete

info@isetinc.com

148

NIST

BRFL: Cybernetic Building Systems

Basic and Applied Research and Development

Commissioning Analysis for Residential Space-Conditioned Systems

While these actions are a good start for energy conservation (ENERYG STAR requirements), they are not based on a complete understanding of the different inefficiencies related to the commissioning process: it is unclear whether these inefficiencies are additive, whether small variances within a given attribute are significant, or which attributes - in various applications and geographical locations - have a larger impact than others. If this information is known, resources and efforts can be focused on the most important parameters

An increasing emphasis on energy efficiency and the environment requires that space-conditioning equipment be highly efficient. To assure that this equipment operates in the field at its designed efficiency, good installation practices must parallel the efforts of equipment manufacturers to improve rated efficiency. To this end, the project seeks to develop an understanding of the impact of different commissioning parameters on system performance in order to optimize the commissioning process. The study will cover two residential building design types located in four climates

Heating \& Cooling

HVAC

Residential detached single family-stick built

Applications Guidance

Ongoing

mailto:vance.payne@nist.gov

http://www.bfrl.nist.gov/goals_programs/prgmCBS.htm 
Funding Source

Sponsoring Program/Office

Channel of Influence

Project Title

Brief Description

Objectives

End Use

Product Type Focus

Type of Building

Stage

Status

Primary Contact

Weblinks

ID

Funding Source

Sponsoring Program/Office

Channel of Influence

Project Title

Brief Description

Objectives

End Use

Product Type Focus

Type of Building

Stage

Status

Primary Contact

Weblinks
167

NIST

Basic and Applied Research and Development

Smart Grid Interoperability Standards Project

Under the Energy Independence and Security Act (EISA) of 2007, the National Institute of Standards and Technology (NIST) has "primary responsibility to coordinate development of a framework that includes protocols and model standards for information management to achieve interoperability of smart grid devices and systems..."

Interoperability - the ability of diverse systems and their components to work together-is vitally important to the performance of the Smart Grid at every level. It enables integration, effective cooperation, and two-way communication among the many interconnected elements of the electric power grid.

\section{Smart Grid}

Supervisory and system integration (Sensor-Control)

Non-Specific

Field testing \& demonstration

Ongoing

mailto:smartgrid@nist.gov

http://www.nist.gov/bfrl/highperformance_buildings/ibep_program.cfm

166

NIST

BFRL

Basic and Applied Research and Development

Integration of Building Project-Data and Geospatial-Data Systems

The technology developments aimed at bridging between the two standards communities are proceeding in a piecemeal fashion, so that is difficult to determine what has been done, what needs to be done, and how the work from the two communities can be put into use in real-world projects. Further, there are no established measurement technologies and metrics by which the technology developments can be assessed for their capability, compatibility, and completeness and by which software implementations of the technology can be assessed for their ability to interoperate.

Develop an integration $R \& D$ roadmap with industry and deliver integration measurement technologies needed to assure the interoperability of building information systems and geospatial information systems.

All

Whole Building Systems

Non-Specific

Applied research \& technology development

Ongoing

http://www2.bfrl.nist.gov/profiles/profiles.asp?firstname=Kent\&lastname=Reed

http://www.nist.gov/public_affairs/factsheet/green_buildings_2010.html 
Funding Source

NIST

Sponsoring Program/Office

Channel of Influence

Basic and Applied Research and Development

Project Title

Brief Description

Powering Up America: Accelerating an Interoperable Smart Grid

A smart electric power grid is a transformative networking technology, vital to achieving energy independence and a sustainable energy future. It will use digital technology to improve reliability, security and efficiency of the electric system: from large generation, through the delivery systems to electricity consumers and a growing number of distributed-generation and storage resources. Under the Energy Independence and Security Act (EISA) of 2007, NIST has "primary responsibility to coordinate development of a framework that includes protocols and model standards for information management to achieve interoperability of smart grid devices and systems ..."

Objectives

End Use

Product Type Focus

\section{Smart Grid}

Distributed generation

Type of Building

Stage

Non-Specific

Applied research \& technology development

Status

Ongoing

Primary Contact

Weblinks

http://www.nist.gov/bfrl/highperformance_buildings/eib_program.cfm 
Funding Source

NIST

Sponsoring Program/Office

Channel of Influence

Project Title

Brief Description

Objectives

End Use

Product Type Focus

Type of Building

Stage

Status

Primary Contact

Weblinks
BFRL

Basic and Applied Research and Development

CONSIAT: Construction Integration and Automation Technologies

The construction industry has repeatedly identified the importance of advancements in information, communication and automation technologies to achieve fully-integrated and automated project delivery. Unfortunately, research in these areas has focused on isolated problems, independent of how integration within and across enterprises and combinations of these new technologies can enable major productivity improvements. The FIATECH Capital Projects Technology Roadmap, a cooperative effort of associations, consortia, government agencies, and industry, recognizes that the construction industry greatly lags other sectors, such as manufacturing, in exploiting these technological advances. The Construction Industry Institute's Strategic Plan emphasizes the evaluation of these new technologies that may have application to the industry and the development of methods to use these technologies to overcome challenges associated with the globalization of the construction industry.

To develop enabling measurement science, methods, protocols, and knowledge to improve construction productivity with the integration of information, communication, sensing and automation technologies.

All

Whole Building Systems

New Buildings

Applied research \& technology development

Ongoing

http://www2.bfrl.nist.gov/profiles/profiles.asp?lastname=Palmer

http://www.nist.gov/public_affairs/factsheet/smartgrid_2010.html 
Funding Source

NIST

Sponsoring Program/Office

Channel of Influence

Basic and Applied Research and Development

Project Title

Brief Description

Measurement Science for Net-Zero Energy, High-Performance Green Buildings

New or updated standards, codes, and monitoring and control practices that increase the energy efficiency and sustainability of buildings and improve construction practices; Measurement and evaluation tools to help guide buying and investment decisions on the basis of the projected longterm performance and environmental impact (over the life cycle) of a building material, product, or system; and Significantly more energy-efficient federal buildings.

Objectives

Enable energy-use reductions through in-situ performance monitoring over a building's life, facilitate intelligence in building control systems to enable building energy-use reductions in real time, reliably asses the energy performance of emerging building technologies, enable development and usage of sustainable materials, components, and systems, and provide new metrics and tools enabling accurate assessments of the carbon footprint and sustainability of buildings in order to evaluate the environmental and economic benefits of green building techs

End Use

All

Product Type Focus

Supervisory and system integration (Sensor-Control)

Type of Building

Stage

Non-Specific

Applied research \& technology development

Status

Ongoing

Primary Contact

Weblinks

http://www.nist.gov/bfrl/highperformance_buildings/abet_program.cfm 
Funding Source

NIST

Sponsoring Program/Office

Channel of Influence

Basic and Applied Research and Development

Project Title

Brief Description

Improved Building Energy Performance Program

Numerous technologies are emerging to reduce energy consumption in buildings, but it is often difficult to determine the performance of buildings as they are constructed. This performance not only relates to energy consumption, but it also applies to the level of indoor environmental quality and economics of the energy measures.

Objectives

This program will transform U.S. innovation and competitiveness in the building sector by developing the means to assess next-generation building technologies needed to achieve net-zero energy buildings. Additional impacts of this program include significant reduction in the nation's $\mathrm{CO} 2$ emissions and reduced stress on the electrical power grid. Previous impacts of this program have included methods of testing and rating procedures that are used exclusively throughout the appliance and solar thermal industries, leadership in the formation of the U.S. Green Building Council, and providing the technical foundation for energy and indoor air quality standards adopted by the American Society of Heating, Refrigerating, and Air-Conditioning Engineers (ASHRAE.)

End Use

All

Product Type Focus

HVAC

Type of Building

Stage

Commercial (all)

Applied research \& technology development

Status

Ongoing

Primary Contact

Weblinks

mailto:william.healy@nist.gov

http://www.bfrl.nist.gov/863/HVAC/HVACIndex.htm 
Funding Source

NIST

Sponsoring Program/Office

BRFL: Cybernetic Building Systems

Channel of Influence

Project Title

Brief Description

Objectives

End Use

Product Type Focus

Type of Building

Stage

Status

Primary Contact

Weblinks
Basic and Applied Research and Development

Fully Automated Fault Detection and Diagnostic Methods for Residential Heat Pumps

Faulty heat pumps waste energy, and the occurrence of faults is common. Proctor performed a field survey of 55,000 air conditioning units and found that $95 \%$ failed a diagnostic test due to improper refrigerant charge, duct leakage, improper airflow, non-condensable gas contamination, or oversizing4. Another independent survey of 1500 rooftop units showed that the average efficiency was only $80 \%$ of the expected value, primarily due to improper refrigerant charge 5 . Heating efficiency degradation will waste even more electrical energy because any shortfall in heating capacity must be met by using lower efficiency electrical resistance heaters.

An increasing emphasis on energy efficiency and the environment requires that heat pumps be highly efficient and free of refrigerant leaks. To assure that HVAC equipment operates in the field at its designed efficiency, good installation practices and performance monitoring must parallel the efforts of equipment manufacturers to improve their equipment rated efficiency. To this end, the project seeks to develop and implement fault detection and diagnostics (FDD) that can assist in equipment commissioning, promote system operational efficiency, and ensure a homeowner's comfort.

Heating \& Cooling

HVAC

Residential (all)

Applications Guidance

Ongoing

mailto:vance.payne@nist.gov

http://www.nist.gov/bfrl/highperformance_buildings/performance/fully_auto_faultdetec_heatpum 
Funding Source

NIST

Sponsoring Program/Office

BRFL: Cybernetic Building Systems

Channel of Influence

Basic and Applied Research and Development

Project Title

Brief Description

IAQ Analysis for NZEB Designs and Technologies

As energy efficient building designs and technologies are pursued, current analysis methods are not able to assess the IAQ impacts of key design decisions, nor are they able to analyze the energy and IAQ impacts of technologies that can contribute to both goals. Furthermore, the metrics to assess IAQ impacts are not well established, limiting the ability to compare different NZEB designs and technical solutions.

Objectives

BFRL is developing tools and metrics to evaluate the indoor air quality (IAQ) impacts of designs and technologies used to achieve netzero energy buildings (NZEB). This work has two primary motivations: to reduce the likelihood that efforts to achieve NZEB will negatively impact IAQ, and to support the application of approaches that can simultaneously reduce energy use and improve IAQ. Simulation capabilities and analysis tools are being developed to enable airflow and IAQ analysis in conjunction with energy analysis and design tools. In addition, reference cases and data are being developed to support ventilation and IAQ analyses of NZEB designs.

End Use

Heating \& Cooling

Product Type Focus

HVAC

Type of Building

Stage

Residential (all)

Applications Guidance

Status

Ongoing

Primary Contact

Weblinks

apersily@nist.gov

http://www.nist.gov/bfrl/highperformance_buildings/performance/iaq_analysis.cfm 
Funding Source

NIST

Sponsoring Program/Office

BRFL: Cybernetic Building Systems

Channel of Influence

Basic and Applied Research and Development

Project Title

Brief Description

Commissioning Analysis for Residential Space-Conditioned Systems

While these actions are a good start for energy conservation (ENERYG STAR requirements), they are not based on a complete understanding of the different inefficiencies related to the commissioning process: it is unclear whether these inefficiencies are additive, whether small variances within a given attribute are significant, or which attributes - in various applications and geographical locations - have a larger impact than others. If this information is known, resources and efforts can be focused on the most important parameters

Objectives

An increasing emphasis on energy efficiency and the environment requires that space-conditioning equipment be highly efficient. To assure that this equipment operates in the field at its designed efficiency, good installation practices must parallel the efforts of equipment manufacturers to improve rated efficiency. To this end, the project seeks to develop an understanding of the impact of different commissioning parameters on system performance in order to optimize the commissioning process. The study will cover two residential building design types located in four climates

End Use

Heating \& Cooling

Product Type Focus

HVAC

Type of Building

Residential detached single family-stick built

Stage

Applications Guidance

Status

Primary Contact

Ongoing

mailto:vance.payne@nist.gov

Weblinks

http://www.nist.gov/bfrl/highperformance_buildings/performance/space_conditioning.cfm 
Funding Source

Sponsoring Program/Office

Channel of Influence

Project Title

Brief Description

Objectives

End Use

Product Type Focus

Type of Building

Stage

Status

Primary Contact

Weblinks

ID

Funding Source

Sponsoring Program/Office

Channel of Influence

Project Title

Brief Description

Objectives

End Use

Product Type Focus

Type of Building

Stage

Status

Primary Contact

Weblinks
171

NIST

BFRL

Basic and Applied Research and Development

Embedded Intelligence in Buildings

The research plan consists of eight key interrelated areas of measurement science needed to achieve successful development and implementation of cybernetic building systems with embedded intelligence. Collectively they provide a comprehensive approach that will result in a radical market transformation in building design and operation.

A cybernetic building system integrates intelligent building automation and control systems for energy management, fire detection, security, and vertical transport. It also integrates the building systems with outside service providers and utilities. This research program aims to address building systems measurement needs in a holistic, integrated manner that considers complex system interactions and their impact on energy consumption, comfort, safety, and maintenance.

All

Supervisory and system integration (Sensor-Control)

Large commercial

Applied research \& technology development

Ongoing

mailto:steven.bushby@nist.gov

http://www.nsf.gov/funding/pgm_summ.jsp?pims_id=13380

173

NIST

BFRL

Basic and Applied Research and Development

HVAC\&R Equipment Performance Group

The Group's research focuses on ways and means that improve the energy efficiency of HVAC\&R equipment, which is the predominant end-user of energy in buildings.

System studies through laboratory measurements and computer simulations, Development of Computational Intelligence-based tools for optimization of component and system designs, Development of fully automated fault detection and diagnostic methods, Fundamental two-phase heat transfer measurements for single-component refrigerants, refrigerant mixtures, and refrigerant/nanolubricant mixtures, Development of testing and rating procedures for refrigerators, air conditioners, and heat pumps for the U.S. Department of Energy Appliance Program

Heating \& Cooling

HVAC

Residential (all)

Market transformation \& deployment

Ongoing

mailto:piotr.domanski@nist.gov

http://www.nsf.gov/funding/pgm_summ.jsp?pims_id=503307\&org=NSF 
Funding Source

NIST

Sponsoring Program/Office

Manufacturing Engineering Laboratory

Channel of Influence

Project Title

Brief Description

Objectives

End Use

Product Type Focus

Type of Building

Stage

Status

Primary Contact

Weblinks
Basic and Applied Research and Development

Sustainable and Lifecycle Information-based Manufacturing

In software models, precise information exchange between design, engineering, manufacturing and disposal steps is key for the adjustments that can make huge differences in profits or environmental impact. For green manufacturing systems to achieve their goals, rigorous, clearlydefined measurements are essential.

NIST's project in Sustainable and Lifecycle Information-based Manufacturing has three primary objectives. First is providing the standards requirements for sustainable manufacturing. Second, the project is providing the framework for environmental manufacturing models by determining the key attributes necessary for sustainable manufacturing. Third, project researchers are developing protocols for testing and simulating green standards.

All

Generic Energy-Reduction Goal

Non-Specific

Applied research \& technology development

Ongoing

Ram D. Sriram

http://www.nist.gov/smartgrid/ 
Funding Source

NIST

Sponsoring Program/Office

Channel of Influence

Project Title

Brief Description

Objectives

\section{End Use}

Product Type Focus

Type of Building

Stage

Status

Primary Contact

Weblinks
BFRL

Basic and Applied Research and Development

Advanced Building Energy Technologies

The program's topical focus is on three technology thrusts: Space Conditioning, Renewable and Distributed Energy Technologies, and Cleaning and Control Technologies for Indoor Air Quality. This last focus area is important and so included because the impact of net-zero energy technologies on the indoor environment must be assessed to ensure that indoor air quality is not compromised but preferably enhanced.

The path to achieving net-zero energy residential and commercial buildings is projected to be realized from a combination of resources. Full utilization of technologies that are available today provides the means to reduce the building energy consumption on the order of 40 to 50 percent at no or minimum life cycle cost. Consequently, the remaining 50 to 60 percent of energy savings must be realized through on-site deployment of renewable energy generation and by novel energy efficient solutions. The goal of this program is to develop the measurement science needed to deploy renewable and new, energy efficient technologies that will help bridge the 50 to 60 percent energy savings gap that remains after employing current energy conserving technologies.

All

Generic Energy-Reduction Goal

Non-Specific

Applied research \& technology development

Ongoing

mailto:piotr.domanski@nist.gov

http://www.nsf.gov/funding/pgm_summ.jsp?pims_id=13575 
Funding Source

Sponsoring Program/Office

Channel of Influence

Project Title

Brief Description

Objectives

End Use

Product Type Focus

Type of Building

Stage

Status

Primary Contact

Weblinks

ID

Funding Source

Sponsoring Program/Office

Channel of Influence

Project Title

Brief Description

Objectives

End Use

Product Type Focus

Type of Building

Stage

Status

Primary Contact

Weblinks
144

NIST

BRFL: Cybernetic Building Systems

Basic and Applied Research and Development

Automated and Integrated Infrastructure Construction Processes

This program was initiated with the investigation of the challenges and evolving technologies applicable to construction integration and automation.

The program strategy is to develop, in parallel, metrics for multifactor construction productivity, real-time sensing and control, data model characterization and validation, and interoperability testing. These new metrics are being applied to priority work processes and technologies identified in collaboration with industry. Those processes and technologies serve as test cases for evaluating the application of the measurement science in the Intelligent and Automated Construction Research Test bed (described later) and in collaborative projects with industry partners.

All

Supervisory and system integration (Sensor-Control)

Non-Specific

Applied research \& technology development

Ongoing

mark.palmer@nist.gov

http://www.nist.gov/bfrl/construction_productivity/cp_program.cfm

149

NIST

BRFL: Cybernetic Building Systems

Basic and Applied Research and Development

Integrating Building Automation Systems with a Smart Utility Grid

This project will address data representation and application protocols for RTP and DG, working with industry stakeholders to analyze use cases and develop approaches that can be adopted through consensus standards. In addition, this project will look more broadly at potential interactions between buildings and the electrical grid by supporting an industry road mapping exercise called for in the EISA legislation to identify other needs and to identify gaps in standards and technology that must be addressed.

To develop a technical basis for industry standards that will enable interconnection of building automation and control systems with a future "smart" utility grid and support industry efforts to develop the needed standards.

Smart Grid

Supervisory and system integration (Sensor-Control)

Non-Specific

Applied research \& technology development

Ongoing

David Holmberg

http://www.bfrl.nist.gov/goals_programs/prgmCBS.htm 
Funding Source

Sponsoring Program/Office

Channel of Influence

Project Title

Brief Description

Objectives

End Use

Product Type Focus

Type of Building

Stage

Status

Primary Contact

Weblinks

ID

Funding Source

Sponsoring Program/Office

Channel of Influence

Project Title

Brief Description

Objectives

End Use

Product Type Focus

Type of Building

Stage

Status

Primary Contact

Weblinks
156

NIST

BRFL: Healthy and Sustainable Buildings

Basic and Applied Research and Development

Novel Methods for Optimization of HVAC\&R Equipment

To provide the measurement science needed to reduce the energy consumption associated with HVAC\&R equipment through the development of computational intelligence based design tools for heat exchangers.

To provide the measurement science needed to reduce the energy consumption associated with HVAC\&R equipment through the development of computational intelligence based design tools for heat exchangers.

Heating \& Cooling

HVAC

Non-Specific

Applied research \& technology development

Ongoing

Piotr Domanski

http://www.bfrl.nist.gov/goals_programs/prgmHSB.htm

154

NIST

BRFL: Healthy and Sustainable Buildings

Basic and Applied Research and Development

Energy Monitoring System for Net Zero-Energy Buildings

A monitoring system is needed that can provide the energy consumption of various devices/systems in a building in both real time and for user selected time intervals without undue complexity, cost, and installation issues

To develop the measurement science to provide real time energy data for various end uses within buildings and develop methods of test to evaluate energy monitoring technologies.

All

Supervisory and system integration (Sensor-Control)

Residential (all)

applied research \& technology development

Ongoing

William Healy

http://www.bfrl.nist.gov/goals_programs/prgmHSB.htm 
Funding Source

NIST

Sponsoring Program/Office

BRFL: Cybernetic Building Systems

Channel of Influence

Basic and Applied Research and Development

Project Title

Brief Description

Economic Support for BFRL

The problem is that essential methods, metrics, and tools needed for measuring economic performance are unavailable (1) for industry to choose the most cost-effective building technologies, designs, and practices, and (2) for the energy, fire, and homeland security agencies to choose the most cost-effective technologies, policies, and equipment for energy conservation, for protecting first responders and potential victims from injury and death, and for reducing disasterrelated losses to constructed facilities.

Objectives

To provide delivery through the ASTM Building Economics Subcommittee, the measurement science to help the building community evaluate new technologies, choose economic material/design combinations, and choose cost-effective, life-cycle management practices, while constructing affordable buildings that optimize building life-cycle performance.

End Use

All

Product Type Focus

Whole Building Systems

Type of Building

Non-Specific

Stage

Status

Primary Contact

Applied research \& technology development

Ongoing

Robert E. Chapman,

Weblinks

http://www.bfrl.nist.gov/goals_programs/prgmHSB.htm

ID

Funding Source

Sponsoring Program/Office

Channel of Influence

Project Title

Brief Description

Objectives

End Use

Product Type Focus

Type of Building

Stage

Status

Primary Contact

Weblinks
152

NIST

BRFL: Cybernetic Building Systems

Basic and Applied Research and Development

Commissioning, Fault Detection, and Diagnostics of Commercial Heating, Ventilating, and Air-Condit

The measurement science needed to enable new technologies and practices to achieve these significant efficiency improvements is lacking and the Department of Energy (DOE) has cited it as a critical component to achieving efficiency improvements through new technologies and practices.

To improve the operating efficiency of commercial heating, ventilating, and air-conditioning (HVAC) systems by $10 \%$ to $30 \%$ through development and demonstration of measurement science that enables more complete and effective system commissioning practices, and automated fault detection and diagnostics (FDD), transferring the proven technologies to the private sector.

Heating \& Cooling

Building Commissioning

Non-Specific

Applied research \& technology development

Ongoing

Natascha S. Castro

http://www.bfrl.nist.gov/goals_programs/prgmHSB.htm 
Funding Source

Sponsoring Program/Office

Channel of Influence

Project Title

Brief Description

Objectives

End Use

Product Type Focus

Type of Building

Stage

Status

Primary Contact

Weblinks

ID

Funding Source

Sponsoring Program/Office

Channel of Influence

Project Title

Brief Description

Objectives

End Use

Product Type Focus

Type of Building

Stage

Status

Primary Contact

Weblinks
151

NIST

BRFL: Cybernetic Building Systems

Basic and Applied Research and Development

Intelligent Building Agents

In order to achieve these energy reduction goals, new control approaches are needed to optimize the energy efficiency of integrated building systems.

To substantially reduce energy consumption in commercial building systems by developing and demonstrating the feasibility of distributed artificial intelligence techniques for optimizing the control and performance of interacting building systems.

All

Supervisory and system integration (Sensor-Control)

Non-Specific

Applied research \& technology development

Ongoing

Steven T. Bushby

http://www.bfrl.nist.gov/goals_programs/prgmHSB.htm

155

NIST

BRFL: Healthy and Sustainable Buildings

Basic and Applied Research and Development

Nanofluids Heat Transfer Measurements

Recent BFRL work has demonstrated that nanoparticles can significantly improve refrigerant/lubricant-boiling performance. The potential for improving the boiling heat transfer is unknown because a fundamental understanding of how the size, shape, and material of a nanoparticle can be chosen to optimize refrigerant boiling does not exist. For this reason, the measurement science developed in this project will form the basis of a nanolubricant evaluation for use by manufacturers of new chillers and operators of existing chillers.

To support the goal of Net Zero energy buildings1 by developing a fundamental understanding of the mechanisms associated with heat transfer enhancement of nanolubricants for improving the energy efficiency of chillers by 2013. Nanoparticles of various size, shape, and material will be investigated.

Heating \& Cooling

HVAC

Non-Specific

Applied research \& technology development

Ongoing

Mark Kedzierski

http://www.bfrl.nist.gov/goals programs/prgmHSB.htm 
Funding Source

Sponsoring Program/Office

Channel of Influence

Project Title

Brief Description

Objectives

End Use

Product Type Focus

Type of Building

Stage

Status

Primary Contact

Weblinks

ID

Funding Source

Sponsoring Program/Office

Channel of Influence

Project Title

Brief Description

Objectives

End Use

Product Type Focus

Type of Building

Stage

Status

Primary Contact

Weblinks
163

NIST

BRFL: Service Life Prediction (SLP) of Nanostructured Polymeric Materials

Basic and Applied Research and Development

Economic Impacts of Improved Service Life Prediction

Improved methods for measuring economic impacts are essential to BFRL to help select the "best" among competing research programs, to evaluate the cost-effectiveness of existing research programs, and to justify programs on the basis of their economic impact. This need for measurement methods exists across programs in both BFRL and NIST. Another objective of NIST and BFRL is to promote innovation by U.S. industries.

Identify industries affected by BFRL's Measurement Science for Sustainable Infrastructure Materials research, estimate economic impacts resulting from BFRL's SLP-related research, and estimate the return on BFRL's SLP-related research investment dollars.

All

Generic Energy-Reduction Goal

Non-Specific

Applied research \& technology development

Ongoing

Robert E. Chapman

http://www2.bfrl.nist.gov/projects/projcontain.asp?cc $=8635015000$

157

NIST

BRFL: Healthy and Sustainable Buildings

Basic and Applied Research and Development

Fault Detection and Diagnosis (FDD)

Heating efficiency degradation will waste even more electrical energy because any shortfall in heating capacity must be met by using lower efficiency electrical resistance heaters

BFRL will develop and validate Fault Detection and Diagnosis (FDD) methods for residential heat pump systems and system components and validate these methods, as installed, to ensure these heat pumps perform as designed throughout their lifetime, thus saving energy, reducing refrigerant emissions, and providing reliable comfort for home owners.

Heating \& Cooling

HVAC

Non-Specific

Applied research \& technology development

Ongoing

Vance Payne

http://www.bfrl.nist.gov/goals_programs/prgmHSB.htm 
Funding Source

Sponsoring Program/Office

Channel of Influence

Project Title

Brief Description

Objectives

End Use

Product Type Focus

Type of Building

Stage

Status

Primary Contact

Weblinks

ID

Funding Source

Sponsoring Program/Office

Channel of Influence

Project Title

Brief Description

Objectives

End Use

Product Type Focus

Type of Building

Stage

Status

Primary Contact

Weblinks
158

NIST

BRFL: Healthy and Sustainable Buildings

Basic and Applied Research and Development

Alternative Cooling Technologies

Vapor compression-based cooling and heating equipment is a technology which matured over a century of research and development. Considering the increasing environmental pressure to limit refrigerant options for vapor compression and the need to assess all technologies that move the Nation towards zero energy buildings, it is necessary to assess emerging cooling technologies

To evaluate the measurement science needs for alternative cooling and heating technologies that could supplant vapor compression-based cooling and heating systems and offer significant energy savings.

Heating \& Cooling

HVAC

Non-Specific

Applied research \& technology development

Ongoing

Piotr A. Domanski

http://www.bfrl.nist.gov/goals_programs/prgmHSB.htm

159

NIST

BRFL: Healthy and Sustainable Buildings

Basic and Applied Research and Development

Development of a Rating Methodology for Micro-Cogeneration Technologies

A Measurement Need has been submitted to the US Measurement System program office that addresses this particular issue. Unfortunately, the measurement science to translate simple system efficiency into consumer energy savings (or payback) is lacking.

Develop the enabling measurement science needed to capture the performance of microcogeneration systems.

All

Distributed generation

Non-Specific

Applied research \& technology development

Ongoing

Mark Davis

http://www.bfrl.nist.gov/goals_programs/prgmHSB.htm 
Funding Source

Sponsoring Program/Office

Channel of Influence

Project Title

Brief Description

Objectives

End Use

Product Type Focus

Type of Building

Stage

Status

Primary Contact

Weblinks

ID

Funding Source

Sponsoring Program/Office

Channel of Influence

Project Title

Brief Description

Objectives

End Use

Product Type Focus

Type of Building

Stage

Status

Primary Contact

Weblinks
160

NIST

BRFL: Healthy and Sustainable Buildings

Basic and Applied Research and Development

Development of New Standard Reference Materials for Testing of Thermal Insulation

The introduction of new/replacement reference materials requires measurements of thermo physical properties on candidate materials and development of the science to minimize measurement uncertainty, especially at high temperatures.

To reduce uncertainties in measurements of the thermal resistance of insulating materials by developing high temperature measurement capabilities, a high-temperature reference material (i.e., $\mathrm{SRM}^{\circledR}$ and/or Calibration), and a replacement for SRM 1450c, Fibrous-Glass Board, using BFRL guarded-hot-plate facilities.

Heating \& Cooling

Insulating Materials

Non-Specific

Applied research \& technology development

Ongoing

Robert Zarr

http://www.bfrl.nist.gov/goals_programs/prgmSLP.htm

161

NIST

BRFL: Healthy and Sustainable Buildings

Basic and Applied Research and Development

Ventilation and Indoor Air Quality in High-Performance Buildings

One of the key functions of buildings is to provide a place for people to live, work and learn, and it is critical that high-performance buildings continue to serve these functions and actually improve the health, comfort and productivity of the occupants relative to current practice. The connection of indoor air quality and ventilation to occupant health and performance has been noted in a number of key studies and research plans, including the report of a 2005 Surgeon Generals workshop on healthy indoor environments1, key EPA planning documents 23 . and an ASHRAE roadmap to net zero energy buildings 4

To improve ventilation and IAQ in high performance buildings through the development and application of building airflow measurement science and technical recommendations.

Heating \& Cooling

HVAC

Non-Specific

applied research \& technology development

Ongoing

Steven J. Emmerich

http://www.mel.nist.gov/programs/slim.htm 
Funding Source

Sponsoring Program/Office

Channel of Influence

Project Title

Brief Description

Objectives

End Use

Product Type Focus

Type of Building

Stage

Status

Primary Contact

Weblinks

ID

Funding Source

Sponsoring Program/Office

Channel of Influence

Project Title

Brief Description

Objectives

End Use

Product Type Focus

Type of Building

Stage

Status

Primary Contact

Weblinks
162

NIST

BRFL: Healthy and Sustainable Buildings

Basic and Applied Research and Development

Metrics and Tools for Sustainable Building

The OSTP/NSTC buildings technology R\&D subcommittee has concluded that, to enable a transformation to performance-based design and operation of the Nation's buildings, nextgeneration metrics, methods, and tools must be developed that permit a building's sustainability to be measured across the dimensions of performance, scale, and time

To develop, integrate, and apply measurement science assessing the sustainability performance of energy technologies and systems in an integrated building design and operation context.

All

Whole Building Systems

Non-Specific

Applied research \& technology development

Ongoing

Barbara C. Lippiatt

http://www2.bfrl.nist.gov/projects/2008ProgramContainer.asp?BFRLProgram=CIA

NIST

BRFL: Cybernetic Building Systems

Basic and Applied Research and Development

Virtual Cybernetic Building Testbed

Building owners need standards, performance metrics, and best practice guidelines to achieve their goals. Ideas are emerging about new ways to make use of the information rich environment that cybernetic building systems can offer and conservative economic estimates indicate the potential for $\$ 1.1$ billion per year savings in office buildings alone. Research to advance these ideas to the stage of commercialization depends upon tools that can reliably and reproducibly test and evaluate alternatives. Building automation system manufacturers and service providers need assistance in developing, testing, and certifying new products.

To create and maintain a whole building emulator capable of reproducibly simulating normal operation and a variety of faulty and hazardous conditions in order to serve as a test bed for investigating a wide range of issues important to the development of cybernetic building technology including commissioning, fault detection and diagnostics, optimization strategies for interacting building systems, aiding emergency responders, and extending communication protocols.

Smart Grid

Supervisory and system integration (Sensor-Control)

Non-Specific

Applied research \& technology development

Ongoing

http://www.bfrl.nist.gov/goals_programs/prgmCBS.htm 
Funding Source

NSF

Sponsoring Program/Office

Channel of Influence

Basic and Applied Research and Development

Project Title

Brief Description

Networking Technology and Systems

The Networking Technology and Systems (NeTS) program supports the exploration of innovative and possibly radical network architectures, algorithms, protocols, and technologies that are responsive to the evolving requirements of current and yet to be discovered network services and applications operating in various environments.

Objectives

Research in innovative paradigms, architectures, algorithms and protocols to address various challenges, in wired, wireless and sensor networks. Examples include the interconnection of heterogeneous networks, topology management, resource and service discovery, naming and addressing, routing and congestion control, mobility management at different levels and granularities, virtualization at scale and programmability of heterogeneous physical substrates, strategies for the location of intelligence within the network and at endpoints, and the impact of widely distributed, data intensive computing resources as in cloud computing.

End Use

\section{Smart Grid}

Product Type Focus

Supervisory and system integration (Sensor-Control)

Type of Building

Stage

Non-Specific

Applied research \& technology development

Status

Primary Contact

Ongoing

http://www.nsf.gov/staff/sub_div.jsp?org=CNS\&orgld=207\&from_org=CNS

Weblinks

http://www.nsf.gov/funding/pgm_summ.jsp?pims_id=503298 
Funding Source

NSF

Sponsoring Program/Office

Channel of Influence

Basic and Applied Research and Development

Project Title

Brief Description

Energy, Power, and Adaptive Systems (EPAS)

The Energy, Power, and Adaptive Systems (EPAS) program invests in the design and analysis of intelligent and adaptive engineering networks, including sensing, imaging, controls, and computational technologies for a variety of application domains. EPAS places emphasis on electric power networks and grids, including generation, transmission and integration of renewable, sustainable and distributed energy systems; high power electronics and drives; and understanding of associated regulatory and economic structures.

Objectives

The program supports distributed control of multi-agent systems with embedded computation for sensor and adaptive networks. EPAS invests in adaptive dynamic programming, brain-like networked architectures performing real-time learning, neuromorphic engineering, telerobotics, and systems theory. The program supports distributed control of multi-agent systems with embedded computation for sensor and adaptive networks.

End Use

Smart Grid

Product Type Focus

Distributed generation

Type of Building

Stage

Non-Specific

Basic Research

Status

Ongoing

Primary Contact

mailto:rbaheti@nsf.gov

Weblinks

http://www.nsf.gov/funding/pgm_summ.jsp?pims_id=13380 
Funding Source

NSF

Sponsoring Program/Office

Channel of Influence

NSF

Project Title

Brief Description

Objectives

End Use

Product Type Focus

Type of Building

Stage

Status

Primary Contact

Weblinks

Basic and Applied Research and Development

Building Engineered Complex Systems (BECS)

The Directorate for Engineering (ENG) and the Division of Mathematical Sciences (DMS) in the Directorate for Mathematical and Physical Sciences (MPS) at the National Science Foundation (NSF) are collaborating in this solicitation to provide "seed funding" for small teams of innovative engineers and mathematical scientists (mathematicians or statisticians) to seek and develop a theoretical basis of complex systems, with the aim of developing formal methods for the design of engineered complex systems. A complex system is characterized by its display of patterns of structure or behavior at one level of organization of the system that are diagnostic of interactions among parts of the system at other levels; the emergent behaviors or structures are not evident from considering only the system's separate components.

Many engineered systems fall into this category and unexpected failures and other consequences have been experienced as these systems function near the edge of their expected performance capacity, for example in power grids, traffic systems, critical civil infrastructures, materials, chemical industrial systems, manufacturing and service enterprises, and environmental systems. Although these unexpected behaviors can be undesirable, it has also been recognized that complex systems with their ability to display emergent behaviors can be designed to be resilient and robust, features that are desirable in engineered systems.

\section{Smart Grid}

\section{Generic Energy-Reduction Goal}

Non-Specific

Basic Research

Ongoing

emisawa@nsf.gov

http://www.nsf.gov/funding/pgm_summ.jsp?pims_id=503431

179

NSF

Funding Source

NSF

Sponsoring Program/Office

Channel of Influence

Basic and Applied Research and Development

Project Title

Brief Description

Energy Technology Assessment

Interdisciplinary approaches for sustainable energy technology assessment which include a fundamental engineering analysis component will be considered by this program.

Objectives

End Use

All

Product Type Focus

Generic Energy-Reduction Goal

Type of Building

Stage

Status

Non-Specific

Analysis

Ongoing

Primary Contact

Weblinks

gprentic@nsf.gov

http://www.nsf.gov/funding/pgm_summ.jsp?pims_id=501026\&org=CBET\&from=home 
Funding Source

Sponsoring Program/Office

Channel of Influence

Project Title

Brief Description

Objectives

End Use

Product Type Focus

Type of Building

Stage

Status

Primary Contact

Weblinks

ID

Funding Source

Sponsoring Program/Office

Channel of Influence

Project Title

Brief Description

Objectives

End Use

Product Type Focus

Type of Building

Stage

Status

Primary Contact

Weblinks
181

NSF

NSF

Basic and Applied Research and Development

Communications and Information Foundations

The Communications and Information Foundations (CIF) program supports transformative research that addresses the theoretical underpinnings and current and future enabling technologies for information acquisition, transmission, and processing in communication and information networks.

Research issues that lie at the intersections of communications and information theory, signal processing, and networking. Examples include the impact of physical-layer performance on the higher network layers; sensor networks including applications to environmental monitoring, civil infrastructure monitoring, data communications system monitoring, and power grid monitoring; and network tomography, which involves detecting and classifying spatially distributed anomalies within complex large-scale systems from multiple monitoring (sensor) sites.

\section{Smart Grid}

Supervisory and system integration (Sensor-Control)

Non-Specific

Applied research \& technology development

Ongoing

http://www.nsf.gov/staff/sub_div.jsp?org=CCF\&orgld=906\&from_org=CCF

182

NSF

NSF

Basic and Applied Research and Development

Civil Infrastructure Systems

The CIS program supports research leading to the intelligent engineering of distributed infrastructure systems.

Areas of interest include intra- and inter-dependencies in infrastructure design and operation for resilience and sustainability, infrastructure protection, and advanced information technologies for health monitoring, condition assessment, deterioration and asset management. Special emphasis is on risk analysis, life-cycle frameworks, cyber-enabled simulation, and technologies for design, construction and operation of resilient and sustainable infrastructure networks.

All

Supervisory and system integration (Sensor-Control)

Non-Specific

Applied research \& technology development

Ongoing

dwenger@nsf.gov 
Funding Source

Sponsoring Program/Office

Channel of Influence

Project Title

Brief Description

Objectives

End Use

Product Type Focus

Type of Building

Stage

Status

Primary Contact

Weblinks

ID

Funding Source

Sponsoring Program/Office

Channel of Influence

Project Title

Brief Description

Objectives

End Use

Product Type Focus

Type of Building

Stage

Status

Primary Contact

Weblinks
174

NSF

NSF

Basic and Applied Research and Development

Power, Controls and Adaptive Networks (PCAN)

The Power, Controls and Adaptive Networks (PCAN) program invests in the design and analysis of intelligent and adaptive engineering networks, including sensing, imaging, controls, and computational technologies for a variety of application domains.

All

Supervisory and system integration (Sensor-Control)

Non-Specific

Applied research \& technology development

Ongoing

rbaheti@nsf.gov

http://www.nsf.gov/funding/pgm_summ.jsp?pims_id=503300\&org=NSF

178

NSF

NSF

Basic and Applied Research and Development

Photovoltaic Solar Energy.

Solar photovoltaic (PV) devices harvest and convert sunlight directly to electricity. Future PV materials, such as nanostructured semiconductors, plasmonic or photonic materials, and photoconducting polymers, when integrated into a solar PV device stack, have considerable promise for enhancing solar energy conversion efficiency and reducing unit cost. Many photovoltaic devices are fabricated from toxic and non-recyclable materials. Fundamental research on environmentally- benign materials and processes for photovoltaic devices is a strong interest area of this program.

The generation of thermal energy by solar radiation is not an area supported by this program, but is an area supported by the Thermal Transport Processes program within CBET

Renewable Energy

Distributed generation

Non-Specific

Basic Research

Ongoing

grorrer@nsf.gov

http://www.nsf.gov/funding/pgm_summ.jsp?pims_id=501026\&org=CBET\&from=home 
Funding Source

NSF

Sponsoring Program/Office

Channel of Influence

NSF

Project Title

Basic and Applied Research and Development

Brief Description

CHE-DMR-DMS Solar Energy Initiative (SOLAR)

Supports research on the processes by which energy in diverse forms is generated by the Sun, transported to the Earth, and ultimately deposited in the terrestrial environment.

Objectives

The intent is to encourage new collaborations in which the mathematical sciences are linked in a synergistic way with the chemical and materials sciences to develop novel, potentially transformative approaches in an area of much activity but largely incremental advances. Successful proposals will offer potentially transformative projects, new concepts, and interdisciplinary education through research involvement based on the integrated expertise and synergy from the three disciplinary communities.

End Use

All

Product Type Focus

Type of Building

Stage

Status

Primary Contact

Weblinks

ID

Funding Source

Sponsoring Program/Office

Channel of Influence

Project Title

Brief Description

Objectives

End Use

Product Type Focus

Type of Building

Stage

Status

Primary Contact

Weblinks
Distributed generation

Non-Specific

Applied research \& technology development

Ongoing

cbessel@nsf.gov

http://www.rurdev.usda.gov/rbs/busp/REAPEA.htm

175

NSF

NSF

Basic and Applied Research and Development

Control Systems (CS)

The CS program supports innovative research on control theory and control technology driven by real life applications

The program accepts proposals on transformative research in established topic areas such as model-based control. However, the program emphasis is on paradigm-shifting ideas for control strategies that may be inspired by nature, unconventional applications, and the combined role of feedback and uncertainty in systems that incorporate large numbers of sensors and actuators. New sensor and actuator concepts that integrate feedback and signal processing to achieve a sensing or actuation objective are also funded.

All

Supervisory and system integration (Sensor-Control)

Non-Specific

Basic Research

Ongoing

sjayasur@nsf.gov

http://www.nsf.gov/funding/pgm_summ.jsp?pims_id=13352 
Funding Source

Sponsoring Program/Office

Channel of Influence

Project Title

Brief Description

Objectives

End Use

Product Type Focus

Type of Building

Stage

Status

Primary Contact

Weblinks

ID

Funding Source

Sponsoring Program/Office

Channel of Influence

Project Title

Brief Description

Objectives

End Use

Product Type Focus

Type of Building

Stage

Status

Primary Contact

Weblinks
185

US Congress

Regulatory

EPA 2005

Each electric utility shall make available upon request net metering service to any electric consumer that the electric utility serves. For purposes of this paragraph, the term 'net metering service' means service to an electric consumer under which electric energy generated by that electric consumer from an eligible on-site generating facility and delivered to the local distribution facilities may be used to offset electric energy provided by the electric utility to the electric consumer during the applicable billing period.

Enable all utility customers to have access to net metering.

Smart Grid

Distributed generation

Non-Specific

Market transformation \& deployment

http://www.usps.com/suppliers/supplychain.htm

184

US Congress

Regulatory

EISA - TITLE XIII--SMART GRID

It is the policy of the United States to support the modernization of the Nation's electricity transmission and distribution system to maintain a reliable and secure electricity infrastructure that can meet future demand growth and to achieve each of the following, which together characterize a Smart Grid:

\section{Smart Grid}

Generic Energy-Reduction Goal

Non-Specific

Market transformation \& deployment

Ongoing

http://www.rurdev.usda.gov/rbs/busp/9006grant.htm 
Funding Source

Sponsoring Program/Office

Channel of Influence

Project Title

Brief Description

Objectives

End Use

Product Type Focus

Type of Building

Stage

Status

Primary Contact

Weblinks

ID

Funding Source

Sponsoring Program/Office

Channel of Influence

Project Title

Brief Description

Objectives

End Use

Product Type Focus

Type of Building

Stage

Status

Primary Contact

Weblinks
186

USDA

Environmental Programs

Internal Federal Agency Efforts

Sustainable and High Performance Buildings

Buildings are major consumers of energy in this country. Sustainable building designs aim to lessen the negative impact on the environment through energy and resource efficiency. Sustainable building is defined as the creation and responsible management of a healthy built environment based on resource efficient and ecological principles. Buildings that are healthy for the environment are healthy for people, as well.

Employment of integrating design principles, optimization of of energy efficiency and use renewable energy, protection and conservation of water, enhancement of indoor environmental quality, and reduction of environmental impacts of materials

All

Whole Building Systems

Government Buildings

Analysis

Ongoing

http://www.greening.usda.gov/performance.htm

187

USDA

Rural Development

Internal Federal Agency Efforts

Rural Energy for America Program Grants/Energy Audit and Renewable Energy Development Assist (

The REAP/RES/EEI Grants Program will provide grants for energy audits and renewable energy development assistance. It also provides funds to agricultural producers and rural small businesses to purchase and install renewable energy systems and make energy efficiency improvements.

Eligible entities include a unit of State, tribal, or local government; institutions of higher education; rural electric cooperatives; or a public power entity. The program is design to assist farmers, ranchers, and rural small businesses.

\section{Smart Grid}

Distributed generation

Commercial (all)

Market transformation \& deployment

http://www.rurdev.usda.gov/recd_map.html

http://ase.org/content/article/detail/3289 
Funding Source

USDA

Sponsoring Program/Office

Channel of Influence

Rural Development

Project Title

Brief Description

Internal Federal Agency Efforts

Rural Energy For America Program Grants/Renewable Energy Systems/Energy Efficiency Improveme

The REAP/RES/EEI Grants Program will provide grants for energy audits and renewable energy development assistance. It also provides funds to agricultural producers and rural small businesses to purchase and install renewable energy systems and make energy efficiency improvements.

Objectives

The program is designed to assist farmers, ranchers and rural small businesses that are able to demonstrate financial need. All agricultural producers, including farmers and ranchers, who gain $50 \%$ or more of their gross income from the agricultural operations are eligible. Small businesses that are located in a rural area can also apply. Rural electric cooperatives may also be eligible to apply.

End Use

\section{Smart Grid}

Product Type Focus

Distributed generation

Type of Building

Stage

Commercial (all)

Market transformation \& deployment

Status

Primary Contact

Weblinks

http://money.cnn.com/news/newsfeeds/articles/globenewswire/181098.htm

ID

Funding Source

Sponsoring Program/Office

Channel of Influence

Project Title

Brief Description

Objectives

End Use

Product Type Focus

Type of Building

Stage

Status

Primary Contact

Weblinks
189

USPS

USPS

Internal Federal Agency Efforts

Green Purchasing Plan

Building a Sustainable Supply Chain is a central component of the Postal Service's corporate-wide sustainability program. In December 2008 the Postal Service issued our national Green Purchasing Plan. The plan provides environmentally preferable criteria for consideration when making purchasing decisions. We look to purchase products that are made from recycled content materials, carry an independent Eco-label Certification, are made from renewable resources, are energy and water efficient, support alternative fuel use, and are free of targeted hazardous chemicals and help to ensure a safe workplace.

All

Whole Building Systems

Medium commercial

Market transformation \& deployment

Ongoing

C-107

Page 107 of 137 
Funding Source

Sponsoring Program/Office

Channel of Influence

Project Title

Brief Description

Objectives

End Use

Product Type Focus

Type of Building

Stage

Status

Primary Contact

Weblinks

ID

Funding Source

Sponsoring Program/Office

Channel of Influence

Project Title

Brief Description

Objectives

End Use

Product Type Focus

Type of Building

Stage

Status

Primary Contact

Weblinks

190

USPS

USPS-California

Internal Federal Agency Efforts

California Building Efficiency

Since 1995 the USPS, with the assistance of Lawrence Berkeley National Laboratory (LBNL) through the Federal Energy Management Program, has implemented an innovative, comprehensive energy management program throughout California that has contributed significantly to a 22 percent reduction in the USPS's energy use nationally, and paved the way for further significant improvements in energy efficiency and environmental stewardship at USPS facilities nationwide.

\section{All}

Whole Building Systems

Government Buildings

Market transformation \& deployment

Ongoing

William Golove (LBNL, unclear what role is, however)

http://www.whitehouse.gov/the_press_office/President-Obama-signs-an-Executive-Order-Focused-

191

USPS

USPS

Internal Federal Agency Efforts

Contract with Lime Energy

Lime Energy will investigate energy efficiency projects at postal facilities in seven designated regions that include Southern New Jersey and Delaware, Philadelphia, District Columbia, Eastern Maryland, Eastern Shore of Maryland and Virginia, Northern Virginia, Greater Virginia, North Carolina and South Carolina. The contracts provide a fast-track efficient method for design and execution of more than 1,800 pre-determined items related to energy efficiency. Upon approval from the USPS, Lime will perform surveys, develop energy solutions, and install new energy efficient lighting and mechanical equipment.

All

Whole Building Systems

Government Buildings

Market transformation \& deployment

Ongoing 
Funding Source

Sponsoring Program/Office

Channel of Influence

Project Title

Brief Description

Objectives

End Use

Product Type Focus

Type of Building

Stage

Status

Primary Contact

Weblinks

ID

Funding Source

Sponsoring Program/Office

Channel of Influence

Project Title

Brief Description

Objectives

End Use

Product Type Focus

Type of Building

Stage

Status

Primary Contact

Weblinks
193

White House

Internal Federal Agency Efforts

Federal Leadership in Environmental, Energy, and Economic Performance

Establishes sustainability goals for facilities operated by the federal government and its agencies.

Implementation of the 2030 net-zero-energy building requirement; Development of guidance for sustainable Federal building locations in alignment with the Livability Principles put forward by the Department of Housing and Urban Development, the Department of Transportation, and the Environmental Protection Agency.

All

Generic Energy-Reduction Goal

Government Buildings

Market transformation \& deployment

Ongoing

http://www.bpa.gov/Energy/n/esgprogram.cfm

192

White House

Internal Federal Agency Efforts

Executive Order 13423

Executive Order 13423 requires Federal agencies to reduce energy intensity by $3 \%$ annually through the end of fiscal year 2015 , or $30 \%$ by the end of fiscal year 2015 , relative to a fiscal year 2003 baseline. This requirement includes laboratories and industrial facilities.

(a) improve energy efficiency and reduce greenhouse gas emissions of the agency, through reduction of energy intensity by (i) 3 percent annually through the end of fiscal year 2015, or (ii) 30 percent by the end of fiscal year 2015, relative to the baseline of the agency's energy use in fiscal year 2003;

All

Generic Energy-Reduction Goal

Government Buildings

Analysis

Ongoing

http://www.bpa.gov/Energy/N/tech/index.cfm 
Funding Source

Sponsoring Program/Office

Channel of Influence

Project Title

Brief Description

Objectives

End Use

Product Type Focus

Type of Building

Stage

Status

Primary Contact

Weblinks

ID

Funding Source

Sponsoring Program/Office

Channel of Influence

Project Title

Brief Description

Objectives

End Use

Product Type Focus

Type of Building

Stage

Status

Primary Contact

Weblinks
226

xState Utility

NYSERDA

Targeted Deployment Programs

Energy Efficiency Improvements for New York's Farms

NYSERDA provides energy audits and feasibility studies that identify cost effective energy efficiency improvements that will lower energy bills, increase productivity and reduce environmental impacts. In addition, NYSERDA provides incentives to farmers who implement the energy audit recommendations through our Enhanced Commercial/Industrial Performance Program and/or a reduced interest rate through our Loan Fund Program

An energy feasibility study provides the farmer with a detailed energy analysis to determine the cost effective savings, energy reductions, and improved efficiencies on more complex systems. NYSERDA will cost-share these studies and provide a pre-qualified Flex Tech Engineering firm who has expertise in the specific area or the farmer can choose their own consultant to perform the study.

All

Generic Energy-Reduction Goal

Large commercial

Market transformation \& deployment

Ongoing

http://www.nyserda.org/highered/default.asp

225

xState Utility

NYSERDA

Basic and Applied Research and Development

Green Building Services

NYSERDA provides computer modeling, design charrette coordination, assistance in obtaining LEED $^{\circledR}$ certification, Executive Order 111 assistance, New York State Green Buildings Tax Credit assistance, green materials recommendations, commissioning and life cycle costing analysis to building design teams to help make new and rehabilitated commercial, industrial, and institutional buildings green. Green Building services are offered under the New Construction program PON 1501.

All

Whole Building Systems

Government Buildings

Market transformation \& deployment

Ongoing

http://www.nyserda.org/programs/New_Construction/default.asp 
Funding Source

Sponsoring Program/Office

Channel of Influence

Project Title

Brief Description

Objectives

End Use

Product Type Focus

Type of Building

Stage

Status

Primary Contact

Weblinks

ID

Funding Source

Sponsoring Program/Office

Channel of Influence

Project Title

Brief Description

Objectives

End Use

Product Type Focus

Type of Building

Stage

Status

Primary Contact

Weblinks
224

xState Utility

NYSERDA

Targeted Deployment Programs

Innovations in Demand Response, Load Management, and Dynamic Pricing

NYSERDA seeks proposals for the development, demonstration or technical (paper) study of innovative and cost effective technologies and techniques that can greatly expand the amount of NYS electric customers' loads ( $\mathrm{kW}$ ) being managed for facility peak load reduction, participating in a demand response market or program and/or responding to a dynamic electric (kWh) price.

\section{Smart Grid}

Supervisory and system integration (Sensor-Control)

Non-Specific

Field testing \& demonstration

Ongoing

mailto:nsm@nyserda.org

http://www.powernaturally.org/programs/solar/incentives.asp
XState Utility

\section{NYSERDA}

Targeted Deployment Programs

RENEWABLE, CLEAN ENERGY and ENERGY EFFICIENCY PRODUCT MANUFACTURING INCENTIVE PRO

The New York State Energy Research and Development Authority (NYSERDA) seeks to expand the level of manufacturing of renewable, clean, and energy-efficient products in New York. This program is designed to provide New York electricity consumers with greater access to renewable, clean-energy, and energy-efficient products by providing financial assistance for developing manufacturing facilities to manufacture these eligible products in New York State. This program invites proposals requesting funding to develop or expand a facility to manufacture eligible products. Incremental additions or modifications to existing manufacturing lines will not be considered.

renewable or clean-energy products that produce or support the production of renewable or clean electricity; (2) energy-efficient end-use technologies that use electricity as a principal input and result in a substantial increase in the efficient use and or conservation of electricity compared to the status quo; or (3) electric storage technologies for grid-connected applications. In order to be eligible, products should be beyond the prototype stage and mature enough to warrant designing and building or expanding a commercial manufacturing facility.

All

Whole Building Systems

Medium commercial

Market transformation \& deployment

Ongoing

http://www.nyserda.org/programs/Commissioning/default.asp 
Funding Source

Sponsoring Program/Office

Channel of Influence

Project Title

Brief Description

Objectives

End Use

Product Type Focus

Type of Building

Stage

Status

Primary Contact

Weblinks

ID

Funding Source

Sponsoring Program/Office

Channel of Influence

Project Title

Brief Description

Objectives

\section{End Use}

Product Type Focus

Type of Building

Stage

Status

Primary Contact

Weblinks
227

xState Utility

NYSERDA

Targeted Deployment Programs

PV Incentives

It's an innovative program from the New York State Energy Research and Development Authority (NYSERDA) that provides cash incentives for the installation of new Solar Electric or Photovoltaic (PV) systems by Eligible Installers. Funding of approximately $\$ 13.8$ million in incentives, through 2009, for the Solar Electric Incentive Program ("Program") has been allocated by the New York State Renewable Portfolio Standard. Additional funding may be made available based on customer demand and program success. Incentives are granted on a first-come, first-served basis.

Applications will be accepted through December 31, 2009, or until funds are fully committed, whichever comes first.

Renewable Energy

Distributed generation

Commercial (all)

Market transformation \& deployment

Ongoing

http://www.nyserda.org/programs/Existing_Facilities/default.html

229

xState Utility

NYSERDA

Targeted Deployment Programs

Focus on Colleges and Universities (C\&U)

The New York State Energy Research and Development Authority's (NYSERDA's) Focus on Colleges and Universities (C\&U) identifies incentives for public and private institutions to reduce their energy usage. In an age of rising energy costs and increased calls for reduc-ing greenhouse gases, energy efficiency is a high priority. How does an institution formulate and fund a practical and effective plan that fits its philosophy and its budget? Through practical, technical assistance and financial incentives, Focus on C\&U is designed to help New York State colleges and universities fund their energy and environmental objectives and maintain a healthy bottom line.

NYSERDA has funding available for energy efficiency improvements on college and university campuses for new construction, renovations, or equipment upgrades. Focus on $C \& U$ will work to identify the range of NYSERDA incentives available for all qualified improvements. Additional funding could also be identified from city, State, federal, and non-governmental sources.

All

Building Commissioning

Large commercial

Market transformation \& deployment

Ongoing

HigherEd@nyserda.org

http://www.nyserda.org/programs/energyaudit.asp 
Funding Source

Sponsoring Program/Office

Channel of Influence

Project Title

Brief Description

Objectives

End Use

Product Type Focus

Type of Building

Stage

Status

Primary Contact

Weblinks

ID

Funding Source

Sponsoring Program/Office

Channel of Influence

Project Title

Brief Description

Objectives

End Use

Product Type Focus

Type of Building

Stage

Status

Primary Contact

Weblinks
228

xState Utility

NYSERDA

Targeted Deployment Programs

New Construction Program

The New Construction Program (NCP) can provide assistance to incorporate energy-efficiency measures into the design, construction, and operation of new and substantially renovated buildings. These measures are designed to save energy through reduced electric demand, and therefore reduce building operating costs.

Technical Assistance is available to help evaluate energy-efficiency measures and provide guidance to your design team on incorporating new and emerging energy-efficient technologies into your building. Funding is available to offset the additional costs associated with the purchase and installation of approved equipment. Assistance may also be available for commissioning services, advanced solar, day lighting technologies, and green building opportunities.

All

Whole Building Systems

Commercial (all)

Market transformation \& deployment

Ongoing

http://www.nyserda.org/programs/flextech.asp

223

xState Utility

NYSERDA

Basic and Applied Research and Development

Distributed Generation/ Combined Heat and Power (DG/CHP)

NYSERDA promotes innovative DG applications -- the on-site generation of electricity by means of technologies such as micro turbines and fuel cells. In particular, the program promotes CHP -electric generation where heat is recaptured from the process and used for space or domestic water heating, which improves the overall efficiency of the system. The success of CHP is dependent up appropriate application within the various end user markets. The industrial and residential sectors require different generation needs according to their thermal loads. Multifamily housing is often seen as a good candidate for CHP systems.

\section{Plug Loads}

Distributed generation

Non-Specific

Field testing \& demonstration

Ongoing

http://www.nyserda.org/ContactInformation/builstaf.asp

http://www.nyserda.org/Programs/Agricultural/default.asp 
Funding Source

Sponsoring Program/Office

Channel of Influence

Project Title

Brief Description

Objectives

End Use

Product Type Focus

Type of Building

Stage

Status

Primary Contact

Weblinks
230

xState Utility

NYSERDA

Targeted Deployment Programs

Existing Facilities Program

The New York State Energy Research and Development Authority's (NYSERDA) Existing Facilities Program offers incentives for a variety of energy projects including Pre-Qualified Measures and Performance-Based Incentives. Applicants can receive incentives (\$/unit) for pre-qualified energyefficiency and conservation measures. Projects can receive up to $\$ 30,000$ through pre-qualified incentives. For national fuel gas, pre-qualified incentives are limited to a cap of $\$ 25,000$. To apply for Pre-Qualified incentives, download and complete the Main Program Application and the appropriate Measure Application(s).

\section{All}

Building Commissioning

Commercial (all)

Market transformation \& deployment

Ongoing

http://www.nyserda.org/funding/1176pon.asp 
Funding Source

xState Utility

Sponsoring Program/Office NYSERDA

Channel of Influence

Project Title

Brief Description

Objectives

End Use

Product Type Focus

Type of Building

Stage

Status

Primary Contact

Weblinks
Basic and Applied Research and Development

Advanced Buildings

This program focuses on the development and demonstration of high-performance (significantly above commercial practice) single and attached residential buildings. The Program seeks to discover solutions that will increase construction productivity while delivering high performance and increase adoptability. It will transfer advances in building science and energy conversion systems into commercial practice by New York's residential construction industry. The program will support two broad paths: discrete components and integrated whole buildings. The development and demonstration of discrete components will focus on advanced building envelope technologies, on-site energy conversion, energy controls and thermal storage. The integrated whole-building component will work with low-volume and production developers to produce exemplary complete buildings that incorporate the advanced features enabling high-performance. Solicitations, suitable for the building industry, including contractors, designers, suppliers, educators and associations will be offered periodically, to both develop and demonstrate all aspects of this program.

All

Whole Building Systems

Non-Specific

Field testing \& demonstration

Ongoing

http://www.nyserda.org/funding/1501pon.asp 
Funding Source

Sponsoring Program/Office

Channel of Influence

Project Title

Brief Description

Objectives

End Use

Product Type Focus

Type of Building

Stage

Status

Primary Contact

Weblinks

ID

Funding Source

Sponsoring Program/Office

Channel of Influence

Project Title

Brief Description

Objectives

End Use

Product Type Focus

Type of Building

Stage

Status

Primary Contact

Weblinks
231

xState Utility

NYSERDA

Targeted Deployment Programs

FlexTech Program

NYSERDA's FlexTech Program provides New York State commercial, industrial, institutional, government, and not-for-profit sectors with objective and customized information to help customers make informed energy decisions. FlexTech's goal is to increase productivity and economic competitiveness of participating facilities by identifying and encouraging the implementation of cost-effective energy efficiency, carbon reduction measures, peak-load curtailment, and combined heat \& power (CHP) and renewable generation projects

All

Building Commissioning

Large commercial

Market transformation \& deployment

Ongoing

http://www.nyserda.org/resloanfund.asp

232

xState Utility

NYSERDA

Targeted Deployment Programs

Energy Audit Program Lower Energy Bills and Improved Energy Performance

Industrial and commercial facilities, State and local governments, not-for-profit and private institutions, colleges and universities, K-12 schools, and non-residential facilities. Facilities must have less than $\$ 75,000$ in annual electric bills to be eligible.

This program will provide energy audits to small businesses and other facilities to help them make informed electrical energy decisions and implement energy-efficiency strategies. Audits help identify economically viable improvements that yield substantial annual energy savings

All

Building Commissioning

Medium commercial

Market transformation \& deployment

Ongoing

http://www.nyserda.org/cre/static/index.html 
Funding Source

Sponsoring Program/Office

Channel of Influence

Project Title

Brief Description

Objectives

End Use

Product Type Focus

Type of Building

Stage

Status

Primary Contact

Weblinks

ID

Funding Source

Sponsoring Program/Office

Channel of Influence

Project Title

Brief Description

Objectives

End Use

Product Type Focus

Type of Building

Stage

Status

Primary Contact

Weblinks
234

xState Utility

NYSERDA

Targeted Deployment Programs

Residential Loan Fund Program

The Residential Loan Fund Program is a component of New York Energy \$martSM, a public benefit program designed to lower electricity costs by encouraging energy efficiency. One of the goals of the Residential Loan Fund is to demonstrate to financial institutions the economics of lending for energy efficiency and renewable energy projects.

The Residential Loan Fund currently offers Eligible Borrowers an Interest Rate Reduction of up to $4.0 \%$ or 400 basis points less than a Participating Lender's normal market interest rate on Loans up to $\$ 20,000$, except up to $\$ 30,000$ for customers in the Consolidated Edison service territory, for a term of up to ten (10) years. Eligible Borrowers must use funds for the purchase and installation of certain eligible energy efficiency improvements. The Interest Rate Reduction may be capped by NYSERDA so the interest rate charged to the Borrower is not lower than $3.0 \%$

All

Building Commissioning

Residential (all)

Market transformation \& deployment

Ongoing

http://www.nyserda.org/Programs/SWP/nationalfuel.asp

235

xState Utility

NYSERDA

Targeted Deployment Programs

Commercial Real Estate (CRE)

Focus on Commercial Real Estate (CRE) is New York State's new business-focused solution to translate energy efficiency into higher asset value. Conceived in partnership with the real estate industry, Focus on CRE recognizes that commercial building owners are in the occupancy business, not the energy business. Through a simple, re-engineered process, Focus on CRE enables commercial building owners and tenants to achieve their financial and environmental objectives

All

Building Commissioning

Commercial (all)

Market transformation \& deployment

Ongoing

http://www.getenergysmart.org/Lowlncome/HomeOwners.aspx 
Funding Source

Sponsoring Program/Office

Channel of Influence

Project Title

Brief Description

Objectives

End Use

Product Type Focus

Type of Building

Stage

Status

Primary Contact

Weblinks

ID

Funding Source

Sponsoring Program/Office

Channel of Influence

Project Title

Brief Description

Objectives

End Use

Product Type Focus

Type of Building

Stage

Status

Primary Contact

Weblinks
xState Utility

\section{TVA}

Targeted Deployment Programs

energy right HVAC Program

Qualified heat pump contractors that participate in the energy right Program are members of the Quality Contractor Network, a cooperative effort on the part of power companies, contractors, and TVA to promote heat pump systems for residential and small business customers

\section{Heating \& Cooling}

HVAC

Residential Single Family

Market transformation \& deployment

Ongoing

236

xState Utility

\section{NYSERDA}

Targeted Deployment Programs

Retro-Commissioning Existing Buildings in New York State

The commissioning of existing buildings, referred to as "Retro-commissioning" (RCX), has gained prominence as a cost-effective strategy for improving energy performance. It is an independent process that takes place after construction, and is applied to buildings that have not previously been commissioned. RCx is a systematic process intended not only to optimize how equipment and systems operate, but also to optimize how the systems function together.

Building owners and property management firms interested in retro-commissioning their buildings may choose one of NYSERDA's participating RCx Service Providers or FlexTech Contractors familiar with retro-commissioning. Those seeking technical assistance through NYSERDA's FlexTech program must choose from the list of participating FlexTech contractors. If you choose to work with a contractor that is not listed as a participating FlexTech contractor, you may receive $50-50$ costshared assistance through the Technical Assistance Program

Heating \& Cooling

Building Commissioning

Commercial (all)

Market transformation \& deployment

Ongoing

http://www.nyserda.org/programs/Environment/muniwaterwwt.asp 
Funding Source

xState Utility

Sponsoring Program/Office

Channel of Influence NYSERDA

Project Title

Brief Description

Objectives

End Use

Product Type Focus

Type of Building

Stage

Status

Primary Contact

Weblinks

Targeted Deployment Programs

National Fuel's Conservation Incentive Program

National Fuel's Conservation Incentive Program (CIP) offers customers valuable information on energy conservation and real-time savings opportunities, including rebates for both residential and small non-residential customers and no-cost natural gas energy efficiency services for low-income customers. With the CIP, residential and small non-residential customers in National Fuel's western New York service area can receive rebates for buying an ENERGY STAR ${ }^{\circledR}$ rated programmable thermostat or replacing specified appliances with new energy efficient models. Lowincome customers with high natural gas usage may be provided with insulation or other energy saving measures at no cost. The CIP represents a partnership between National Fuel and the New York State Energy Research and Development Authority ("NYSERDA") and is the first of its kind in New York State. Some of the program features are being implemented by NYSERDA, as indicated below.

Rebates are available for small, non-residential customers whose facilities use less than $12,000 \mathrm{Mcf}$ (thousand cubic feet) of natural gas per year for upgrading to more energy-efficient equipment. $T$

Heating

HVAC

Commercial (all)

Market transformation \& deployment

Ongoing

http://www.tva.gov/abouttva/energy_management/energy.htm 
Funding Source

Sponsoring Program/Office

Channel of Influence

Project Title

Brief Description

Objectives

End Use

Product Type Focus

Type of Building

Stage

Status

Primary Contact

Weblinks

ID

Funding Source

Sponsoring Program/Office

Channel of Influence

Project Title

Brief Description

Objectives

End Use

Product Type Focus

Type of Building

Stage

Status

Primary Contact

Weblinks
221

xState Utility

NYSERDA

Targeted Deployment Programs

Controls and Monitoring

This program supports development and demonstration of innovative control, sensor, and monitoring technologies for residential and commercial building systems. Technologies seek to improve power quality, reliability, and efficiency, as well as the indoor environment, such as variable speed air conditioners, wireless sub meters, remote HVAC diagnostic equipment, advanced indoor environmental quality monitors, web-enabled systems for price sensitive load management, and power quality and conditioning equipment. A solicitation for these projects is typically offered each year.

\section{Smart Grid}

Supervisory and system integration (Sensor-Control)

Non-Specific

Field testing \& demonstration

Ongoing

http://www.nyserda.org/demandside/default.asp

243

xState Utility

TVA

Targeted Deployment Programs

Heat Pump Program

There's a lot to consider when you're buying a heating-and-cooling system. One of the benefits of the energy right Heat Pump Program is access to contractors who can give you expert advice on the right system for you.

Provide rebates, financing, and connect experts with customers looking to utilize residential heat pumps

Heating \& Cooling

HVAC

Residential (all)

Market transformation \& deployment

Ongoing

http://www.energyrightpartners.com/network.htm 
Funding Source

Sponsoring Program/Office

Channel of Influence

Project Title

Brief Description

Objectives

End Use

Product Type Focus

Type of Building

Stage

Status

Primary Contact

Weblinks

ID

Funding Source

Sponsoring Program/Office

Channel of Influence

Project Title

Brief Description

Objectives

End Use

Product Type Focus

Type of Building

Stage

Status

Primary Contact

Weblinks
195

xState Utility

BPA

Targeted Deployment Programs

BPA EnergySmart Grocery Program

Participation under this new contract mechanism streamlines the utility reporting process because $\mathrm{PECl}$ will now track activity in the Planning Reporting and Tracking (PTR) system and cut checks, relieving utilities of this task. Participating utilities will still receive 75 percent credit toward the adjustment of their Conservation High Water Mark (CHWM) calculation, unless they fund incentives with their own utility funds. In cases of utility self funding, utilities will receive 100 percent credit toward the adjustment of their CHWM. In addition, BPA has made a determination not to apply the decrement policy for participation in this program under DA. Implementation and coordination between $\mathrm{PECl}$ and participating utilities will not change under this modified delivery approach.

\section{Plug Loads}

Generic Energy-Reduction Goal

Commercial (all)

Market transformation \& deployment

Ongoing

http://northwest-lighting.org/about.aspx
242

xState Utility

TVA

Targeted Deployment Programs

Preferred Partners Network

The Preferred Partners Network (PPN) is a master list of trade allies and energy services companies. These partners are qualified to supply technologies and equipment that deliver high-quality energy efficiency and demand response results. TVA maintains this list and makes the network available as an independent service for power distributors to share with their customers. The PPN can be a valuable asset when project assistance is needed for equipment purchases, design and implementation.

Commercial trade alliance to create a forum for contractors to connect with energy efficiency projects in need of labor, parts and/or expertise.

All

Building Commissioning

Commercial (all)

Market transformation \& deployment

Ongoing

http://www.energyrightpartners.com/heatpump.htm 
Funding Source

Sponsoring Program/Office

Channel of Influence

Project Title

Brief Description

Objectives

End Use

Product Type Focus

Type of Building

Stage

Status

Primary Contact

Weblinks

ID

Funding Source

Sponsoring Program/Office

Channel of Influence

Project Title

Brief Description

Objectives

End Use

Product Type Focus

Type of Building

Stage

Status

Primary Contact

Weblinks
241

xState Utility

TVA

Targeted Deployment Programs

Campbell Creek Energy Efficient Homes Project

The Campbell Creek research project is a unique test facility that will enable TVA and its partners, Oak Ridge National Laboratory (ORNL) and EPRI, to evaluate the effectiveness of residential construction and efficiency technologies in a controlled environment

TVA will use the results to develop the best, most cost-effective residential energy efficiency and demand-response tools to educate builders, developers and consumers. "Demand response" refers to approaches that encourage consumers to reduce their energy use during periods of peak demand.

All

Supervisory and system integration (Sensor-Control)

Residential (all)

Field testing \& demonstration

Ongoing

http://www.energyrightpartners.com/builders.htm

240

xState Utility

\section{TVA}

Internal Federal Agency Efforts

Internal Energy Management

Laws and requirements for energy efficiency in TVA building design, equipment procurement, and operations

All

Whole Building Systems

Medium commercial

Market transformation \& deployment

Ongoing

http://www.energyright.com/heatpump/index.htm 
Funding Source

Sponsoring Program/Office

Channel of Influence

Project Title

Brief Description

Objectives

End Use

Product Type Focus

Type of Building

Stage

Status

Primary Contact

Weblinks

ID

Funding Source

Sponsoring Program/Office

Channel of Influence

Project Title

Brief Description

Objectives

End Use

Product Type Focus

Type of Building

Stage

Status

Primary Contact

Weblinks

xState Utility

NYSERDA

Targeted Deployment Programs

Municipal Water and Wastewater Treatment: Energy Efficiency

Water and wastewater treatment facilities in New York State consume more than 3 billion kWh of electricity per year. With rising infrastructure demands, increasingly-stringent regulatory requirements, and decreasing resources, municipalities are looking for cost-saving measures to reduce operating costs. Municipalities are also actively pursuing ways in which to reduce their carbon footprint.

Through a variety of cost-shared technical assistance, research, demonstration, and outreach programs, NYSERDA encourages municipalities in New York State to adopt commercially-available and innovative technologies that improve the energy efficiency and economics of their treatment facilities, while also meeting or exceeding regulatory requirements and reducing the overall environmental impacts of these facilities.

All

Generic Energy-Reduction Goal

Small commercial

Market transformation \& deployment

Ongoing

http://www.tva.gov/ppn/index.htm

238

xState Utility

NYSERDA

Targeted Deployment Programs

Assistance for Low and Moderate Income Households

Assisted Home Performance with ENERGY STAR ${ }^{\circledR}$ brings a whole-house building performance approach to energy efficiency improvements. The objective of the program is to reduce energy costs of low- and moderate-income households by providing affordable energy efficiency improvements. The program will cover up to $50 \%$ of the costs associated with the energy-efficiency improvements, up to a maximum of $\$ 5,000$ per household or $\$ 10,000$ for a 2 - 4 family building.

Use approximately $30 \%$ less energy than conventionally built homes by building a New York ENERGY STAR Labeled Home. Receive a $\$ 500$ cash incentive if your household income is less than or equal to these guidelines.

All

Building Commissioning

Residential (all)

Market transformation \& deployment

Ongoing

http://www.tva.gov/campbellcreekresearchhomes/ 
Funding Source

Sponsoring Program/Office

Channel of Influence

Project Title

Brief Description

Objectives

End Use

Product Type Focus

Type of Building

Stage

Status

Primary Contact

Weblinks

ID

Funding Source

Sponsoring Program/Office

Channel of Influence

Project Title

Brief Description

Objectives

End Use

Product Type Focus

Type of Building

Stage

Status

Primary Contact

Weblinks
245

xState Utility

TVA

Targeted Deployment Programs

New Homes Plan

The energy right Program uses the industry-accredited Home Energy Rating System (HERS) software to rate the efficiency of new homes going through the program. Home energy ratings are similar to the fuel mileage ratings posted on new cars. Both predict efficiency based on the product's performance under standardized conditions.

All

Whole Building Systems

Residential Single Family

Market transformation \& deployment

Ongoing

\begin{tabular}{|r|}
\hline \\
\hline
\end{tabular}

xState Utility

\section{CEC}

Basic and Applied Research and Development

Buildings End-Use Energy Efficiency Program

The program seeks to decrease building energy use through research that will develop or improve energy efficient technologies, strategies, tools, and building performance evaluation methods.

Identification and implementation of market linkages including linkages to the building community, manufacturers, utilities, codes and standards groups, and other implementers of building efficiency market actions.

All

Whole Building Systems

Non-Specific

Market transformation \& deployment

Ongoing

http://phev.ucdavis.edu/ 
Funding Source

Sponsoring Program/Office

Channel of Influence

Project Title

Brief Description

Objectives

End Use

Product Type Focus

Type of Building

Stage

Status

Primary Contact

Weblinks

ID

Funding Source

Sponsoring Program/Office

Channel of Influence

Project Title

Brief Description

Objectives

End Use

Product Type Focus

Type of Building

Stage

Status

Primary Contact

Weblinks
202

xState Utility

BPA

Targeted Deployment Programs

Appliances and consumer electronics

ENERGY STAR appliances have been a successful program offer for many BPA utility customers and are expected to continue to perform well. Increasing plug loads from consumer electronics has emerged as a new priority and opportunity. BPA is working with Northwest Energy Efficiency Alliance (NEEA) to identify and maximize upstream opportunities in consumer electronics to leverage manufacturer and retail resources to transform the market.

Plug Loads

Generic Energy-Reduction Goal

Residential (all)

Market transformation \& deployment

Ongoing

mailto:cllindstrom-steele@bpa.gov

http://www.bpa.gov/Energy/n/DHP.cfm

201

xState Utility

BPA

Targeted Deployment Programs

Residential products promotion

To assure energy savings goals are met now and in the future, BPA is replacing its regional residential CFL program with an expanded opportunity that includes CFLs, light fixtures, showerheads and other measures delivered through retail markdown, builder channel promotions, direct install and more. This change is being made in response to new opportunities outlined in the Northwest Power and Conservation Council's (Council) draft Sixth Power Plan. The Council's draft plan includes opportunities for compact fluorescent light bulbs (CFLs) as eligible measures for 20102012 and also includes a high target for low flow showerheads (2.4 million units over the next five years).

Lighting

Lighting Equipment

Residential (all)

Market transformation \& deployment

Ongoing

Sarah Moore, 503-230-4157

http://www.bpa.gov/Energy/n/projects/PTCS/index.cfm 
Funding Source

Sponsoring Program/Office

Channel of Influence

Project Title

Brief Description

Objectives

End Use

Product Type Focus

Type of Building

Stage

Status

Primary Contact

Weblinks

ID

Funding Source

Sponsoring Program/Office

Channel of Influence

Project Title

Brief Description

Objectives

End Use

Product Type Focus

Type of Building

Stage

Status

Primary Contact

Weblinks
200

xState Utility

BPA

Targeted Deployment Programs

Commercial New Construction and Building Design

Incentives for the Energy Smart Design ${ }^{\mathrm{TM}}$ - Office (ESD Office) Prescriptive Packages are structured to reduce the incremental cost of this package of measures, without requiring building energy performance modeling. ESD Office buildings will be more efficient and help build a better environment.

All

Whole Building Systems

Existing Buildings

Market transformation \& deployment

Ongoing

http://www.bpa.gov/Energy/n/residential.cfm

199

xState Utility

BPA

Basic and Applied Research and Development

Commercial HVAC

Effectively correcting inefficiencies in existing packaged rooftop HVAC units is widely recognized as a potential source of significant energy savings. The Northwest Power and Conservation Council estimates 75 aMW of cost-effective savings could be realized, most of it in reduced cooling energy.

Heating \& Cooling

HVAC

Existing Buildings

Market transformation \& deployment

Complete

http://www.bpa.gov/Energy/n/consumerelectronics.cfm 
Funding Source

Sponsoring Program/Office

Channel of Influence

Project Title

Brief Description

Objectives

End Use

Product Type Focus

Type of Building

Stage

Status

Primary Contact

Weblinks

ID

Funding Source

Sponsoring Program/Office

Channel of Influence

Project Title

Brief Description

Objectives

End Use

Product Type Focus

Type of Building

Stage

Status

Primary Contact

Weblinks
198

xState Utility

BPA

Targeted Deployment Programs

Northwest Trade Ally Network (Commercial and Industrial Lighting)

The Northwest Trade Ally Network helps trade allies grow their businesses through participation in public utility lighting efficiency incentive programs. The Trade Ally Network helps trade allies find utility incentive programs, offers valuable trainings and industry news, and provides useful forms and resources.

Energy efficient lighting is one of the largest and most cost-effective ways a business can reduce its energy costs

Lighting

Lighting Equipment

Commercial (all)

Market transformation \& deployment

Ongoing

http://www.bpa.gov/Energy/n/residential_pro.cfm

197

xState Utility

BPA

Targeted Deployment Programs

Commercial Kitchen and Food Service Equipment

BPA offers incentive reimbursements to customer utilities for installation of an expanded suite of high efficiency kitchen and food service measures to commercial customers. Measures include refrigerators, freezers, ice makers, steamers, high-efficiency electric fryers, hot food holding cabinets and pre-rinse spray wash valves.

Plug Loads

Generic Energy-Reduction Goal

Commercial (all)

Market transformation \& deployment

Ongoing

http://www.bpa.gov/Energy/n/projects/ESD/index.cfm 
Funding Source

Sponsoring Program/Office

Channel of Influence

Project Title

Brief Description

Objectives

End Use

Product Type Focus

Type of Building

Stage

Status

Primary Contact

Weblinks

ID

Funding Source

Sponsoring Program/Office

Channel of Influence

Project Title

Brief Description

Objectives

End Use

Product Type Focus

Type of Building

Stage

Status

Primary Contact

Weblinks
196

xState Utility

BPA

Internal Federal Agency Efforts

The Commercial and Industrial Lighting Roadmap is created for utilities participating in Bonneville Power Administration's (BPAs) Conservation Acquisition Agreement (CAA) or Conservation Rate Credit (CRC) reimbursement programs.

Provide tools for educating or training staff, vendors and end users along with tips utilities can use to enhance or establish a $\mathrm{C} / \mathrm{I}$ lighting program in their service territory.

Lighting

Lighting Equipment

Commercial (all)

Market transformation \& deployment

Ongoing

http://www.bpa.gov/Energy/n/pdf/RTU-Pilot_BPA-EE_announcement_01-20-09.pdf

247

xState Utility

TVA

Targeted Deployment Programs

Quality Contractor Network (QCN)

The Quality Contractor Network (QCN) is a cooperative effort among local power companies, local HVAC contractors, and TVA to promote the design, installation, and servicing of quality heat pump systems for residential and small commercial customers. Contractors in the QCN can offer: Expert analysis of home heating and cooling needs, Equipment recommendations for maximum efficiency and comfort, Information on operating costs, Equipment warranties.

\section{Heating \& Cooling}

HVAC

Residential Single Family

Market transformation \& deployment

Ongoing 
Funding Source

Sponsoring Program/Office

Channel of Influence

Project Title

Brief Description

Objectives

End Use

Product Type Focus

Type of Building

Stage

Status

Primary Contact

Weblinks

ID

Funding Source

Sponsoring Program/Office

Channel of Influence

Project Title

Brief Description

Objectives

End Use

Product Type Focus

Type of Building

Stage

Status

Primary Contact

Weblinks
194

xState Utility

BPA

Basic and Applied Research and Development

\section{GridWise}

The integration of the utility electrical system, telecommunications system, and the energy market to optimize loads on the electrical network, reduce costs to consumers and utilities, facilitate the integration of renewable resources, increase electrical system reliability and reduce environmental impacts of load growth

\section{Smart Grid}

Generic Energy-Reduction Goal

Non-Specific

Field testing \& demonstration

Ongoing

http://www.bpa.gov/Energy/n/commercial_kit.cfm

\section{3}

XState Utility

BPA

Targeted Deployment Programs

Weatherization

While weatherization measures have been a core BPA utility focus for decades, market research indicates that too many homes still have poor insulation, single pane windows and major air leakage. Over the next five years BPA will aggressively target these leaky homes with new program approaches designed to empower our utilities to work more effectively with their trade allies and end customers.

Heating \& Cooling

Insulating Materials

Residential (all)

Market transformation \& deployment

Ongoing

http://www.bpa.gov/Energy/n/HPWH.cfm 
Funding Source

Sponsoring Program/Office

Channel of Influence

Project Title

Brief Description

Objectives

End Use

Product Type Focus

Type of Building

Stage

Status

Primary Contact

Weblinks

ID

Funding Source

Sponsoring Program/Office

Channel of Influence

Project Title

Brief Description

Objectives

End Use

Product Type Focus

Type of Building

Stage

Status

Primary Contact

Weblinks

205

xState Utility

BPA

Basic and Applied Research and Development

Ductless Heat Pump pilot program

BPA Energy Efficiency will continue to support ductless heat pumps in residential applications during fiscal year 2010. BPA's involvement with the collection of pilot data for the Northwest Energy Efficiency Alliance (NEEA) Ductless Heat Pump Single Family Evaluation pilot program is on track to deliver significant installations in order conduct a pilot program evaluation scheduled to be completed early in 2011. Ductless heat pumps are provisionally deemed measures by the Regional Technical Forum (RTF) until data and evaluation from NEEA's pilot has been completed and evaluated by the RTF.

Heating \& Cooling

HVAC

Residential (all)

Field testing \& demonstration

Ongoing

http://www.energy.ca.gov/research/buildings/description.html

204

xState Utility

BPA

Basic and Applied Research and Development

Performance Tested Comfort SystemTM

BPA has invested in the development of a residential HVAC infrastructure aimed at increasing the market penetration of high efficiency air source heat pumps. The Performance Tested Comfort Systems (PTCS) protocol is now delivering solid returns on this investment. With ongoing support BPA expects the PTCS program to continue delivering yearly increases in energy savings over the next five years

Heating \& Cooling

HVAC

Residential (all)

Market transformation \& deployment

Ongoing 
Funding Source

Sponsoring Program/Office

Channel of Influence

Project Title

Brief Description

Objectives

End Use

Product Type Focus

Type of Building

Stage

Status

Primary Contact

Weblinks

ID

Funding Source

Sponsoring Program/Office

Channel of Influence

Project Title

Brief Description

Objectives

End Use

Product Type Focus

Type of Building

Stage

Status

Primary Contact

Weblinks
207

xState Utility

BPA

Targeted Deployment Programs

Energy Smart Industrial

The ESI program works with industrial facility customers through their local public utility to deliver cost-effective energy efficiency in all industrial sectors. There are a wide variety of program options for industrial users of all sizes and budget levels. By participating, businesses in the industrial sector can save money and energy, and may increase productivity and profitability.

Plug Loads

Generic Energy-Reduction Goal

Commercial (all)

Market transformation \& deployment

Ongoing

http://www.energy.ca.gov/appliances/

\section{0}

xState Utility

\section{NYSERDA}

Targeted Deployment Programs

Building Envelope

This program offers assistance for developing new building construction products, such as advanced windows, panelized wall systems, and industrialized construction methods. Other projects include integrated systems to optimize building energy/ environmental impacts, such as building-integrated solar technologies and advanced indoor air quality systems. A regular solicitation is available to help fund the development of these projects.

All

Whole Building Systems

Non-Specific

Applied research \& technology development

Ongoing

mailto:rmc@nyserda.org

http://www.nyserda.org/Programs/IABR/BuildingsProgramAreas.asp\#DGCHP 
Funding Source

Sponsoring Program/Office

Channel of Influence

Project Title

Brief Description

Objectives

End Use

Product Type Focus

Type of Building

Stage

Status

Primary Contact

Weblinks

ID

Funding Source

Sponsoring Program/Office

Channel of Influence

Project Title

Brief Description

Objectives

End Use

Product Type Focus

Type of Building

Stage

Status

Primary Contact

Weblinks
xState Utility

CEC

Basic and Applied Research and Development

Energy Systems Integration - Demand Response

The CPUC and the CAISO are now developing and implementing these pricing mechanisms in order to facilitate demand response to wholesale prices and system contingencies. The goal of this research focus area is to develop new tools and technologies to complement the implementation of these pricing mechanisms.

Plug Loads

Supervisory and system integration (Sensor-Control)

Non-Specific

Market transformation \& deployment

Ongoing

http://www.energy.ca.gov/efficiency/brightschools/

210

xState Utility

CEC

Regulatory

California's Appliance Efficiency Program

California's Appliance Efficiency Regulations were established in 1976 in response to a legislative mandate to reduce California's energy consumption. The regulations are updated periodically to allow consideration and possible incorporation of new energy efficiency technologies and methods.

Plug Loads

Supervisory and system integration (Sensor-Control)

Non-Specific

Market transformation \& deployment

Ongoing

http://www.energy.ca.gov/efficiency/partnership/index.html 
Funding Source

Sponsoring Program/Office

Channel of Influence

Project Title

Brief Description

Objectives

End Use

Product Type Focus

Type of Building

Stage

Status

Primary Contact

Weblinks

ID

Funding Source

Sponsoring Program/Office

Channel of Influence

Project Title

Brief Description

Objectives

End Use

Product Type Focus

Type of Building

Stage

Status

Primary Contact

Weblinks
211

xState Utility

CEC

Basic and Applied Research and Development

Plug-in Hybrid Electric Vehicle (PHEV) Research Center

The center will serve as a magnet for innovative research on consumer response, environmental impacts, and vehicle technology. Its goals are to provide technology and policy guidance to the state, and to help solve research questions and address commercialization issues for PHEVs. The Center will achieve these goals in two ways: by administering research funding for UC Davis and outside research organizations, and by coordinating an external Advisory Council that will oversee the development of a PHEV Research Roadmap for the Energy Commission. The Advisory Council will be comprised of academics, government and non-governmental organizations, PHEV advocates and industry representatives from the electric utility, fuel provider and automotive manufacturing sectors.

The PHEV Center will conduct or administer funding for research in five distinct areas: Modeling alternative PHEV designs, Impacts of PHEVs on the electrical Grid, Consumers and PHEVs, environmental impacts of PHEVs, Lifecycle costs of PHEVs

Plug Loads

Whole Building Systems

Residential (all)

Analysis

Ongoing

http://www.commerce.state.il.us/dceo/Bureaus/Energy_Recycling/Energy/Energy+Efficiency/

212

xState Utility

\section{CEC}

Targeted Deployment Programs

The Bright Schools Program

You can change that by lowering your school's energy bills using readily available, energy efficient lighting and HVAC systems. Installing energy efficient equipment can reduce annual maintenance costs, conserve finite resources, and improve indoor air quality. Administrators confirm that our recommendations and assistance led to better learning environments. Savings from these systems are proven - typically reducing annual utility costs by an average of 20 percent.

Plug Loads

Generic Energy-Reduction Goal

School

Market transformation \& deployment

Delayed

mailto:Kperrin@energy.state.ca.us

http://www.getenergysmart.org/GreenBuilding.aspx 
Funding Source

Sponsoring Program/Office

Channel of Influence

Project Title

Brief Description

Objectives

End Use

Product Type Focus

Type of Building

Stage

Status

Primary Contact

Weblinks

ID

Funding Source

Sponsoring Program/Office

Channel of Influence

Project Title

Brief Description

Objectives

End Use

Product Type Focus

Type of Building

Stage

Status

Primary Contact

Weblinks
213

xState Utility

CEC

Targeted Deployment Programs

Energy Partnership Program

Costs for facility operations keep going up. Typical energy costs are three to ten percent of annual operating expenses. For the largest facilities, that can exceed \$1 million per year! One way to save money is by reducing your energy costs. The Energy Partnership Program offers services to help find ways for you to become more energy wise. Do you need help identifying the most cost effective energy saving opportunities? The Energy Partnership Program can help, usually at no cost to you. Savings are proven to typically reduce annual utility costs by an average of 20 percent.

\section{Plug Loads}

\section{Generic Energy-Reduction Goal}

Commercial (all)

\section{Market transformation \& deployment}

Delayed

pubprog@energy.state.ca.us

http://www.nyserda.org/Programs/IABR/BuildingsRD.asp

\section{4}

xState Utility

Illinois Department of Energy

Targeted Deployment Programs

Public Sector Electric Efficiency

Provides grants and rebates to public sector entities for electric system efficiency improvements including lighting, motors, variable frequency drive controls, HVAC equipment, traffic signals, among others

\section{Plug Loads}

Supervisory and system integration (Sensor-Control)

Non-Specific

Market transformation \& deployment

Ongoing

http://www.nyserda.org/programs/transportation/powersystems.asp 
Funding Source

Sponsoring Program/Office

Channel of Influence

Project Title

Brief Description

Objectives

End Use

Product Type Focus

Type of Building

Stage

Status

Primary Contact

Weblinks

ID

Funding Source

Sponsoring Program/Office

Channel of Influence

Project Title

Brief Description

Objectives

End Use

Product Type Focus

Type of Building

Stage

Status

Primary Contact

Weblinks
215

xState Utility

NYSERDA

Targeted Deployment Programs

Green Residential Building Program (GRBP)

In September 2008, Section 1872 of the Public Authorities Law (PAL) was enacted, authorizing NYSERDA to establish and administer a Green Residential Building Program (GRBP or "Program"). The Program is to provide incentives to owners of new and substantially renovated residential buildings that receive a Certificate of Occupancy or Certificate of Completion on or after January 1, 2010. The Program applies to single family homes and multifamily buildings with fewer than twelve dwelling units.

The Program will promote green design and building practices throughout New York State. Green design and construction practices can lower energy costs and reduce production of greenhouse gases, reduce waste, pollution and use of natural resources, and improve indoor air quality.

All

Whole Building Systems

Residential (all)

Market transformation \& deployment

Ongoing

http://www.nyserda.org/Programs/IABR/BuildingsProgramAreas.asp\#heatingcooling

216

xState Utility

NYSERDA

Basic and Applied Research and Development

BUILDINGS RESEARCH AND DEVELOPMENT

The Buildings R\&D program works through partnerships and collaborations with small-to-medium sized New York businesses, technical universities, U.S. DOE national laboratories, industry trade groups, and other organizations. During the last decade, the Buildings R\&D group helped small businesses introduce 40 new products, create 334 jobs, increase New York product sales by $\$ 238$ million, and achieve energy savings of about $\$ 161$ million.

Improve the energy and environmental efficiency of New York State residential and commercial buildings through development and application of energy-efficient building-related technologies: Building Envelope, Controls and Metering, Distributed Generation, Heating and cooling, Lighting

All

Whole Building Systems

Non-Specific

Market transformation \& deployment

Ongoing

http://www.nyserda.org/Programs/IABR/BuildingsProgramAreas.asp\#lighting 
Funding Source

Sponsoring Program/Office

Channel of Influence

Project Title

Brief Description

Objectives

End Use

Product Type Focus

Type of Building

Stage

Status

Primary Contact

Weblinks

ID

Funding Source

Sponsoring Program/Office

Channel of Influence

Project Title

Brief Description

Objectives

End Use

Product Type Focus

Type of Building

Stage

Status

Primary Contact

Weblinks
217

xState Utility

NYSERDA

Targeted Deployment Programs

Power Systems Research, Technology and Product Development

These new technologies include electricity power storage; management, communication, and interface technologies that supply the electricity grid; and supplying building or industrial loads with reliable, high quality power. The program undertakes projects designed to improve technology performance and reduce non-technical impediments and regulatory barriers to the widespread deployment of these new technologies.

The program will continue to focus on technologies that offer consumers environmentally superior electrical power options and plans to begin addressing emerging distribution grid capacity and reliability problems.

\section{Smart Grid}

Supervisory and system integration (Sensor-Control)

Non-Specific

Market transformation \& deployment

Ongoing

http://www.nyserda.org/Programs/IABR/BuildingsProgramAreas.asp\#buildingenvelope

218

xState Utility

\section{NYSERDA}

Basic and Applied Research and Development

Heating and Cooling

NYSERDA helps New York State manufacturers to develop and commercialize innovative, energy efficient, and environmentally-friendly heating and cooling technologies for the home and business. New products include a high-efficiency, pulse combustion, gas-fired, commercial boiler; a $95 \%$ efficient, aluminum, gas-fired residential boiler; fluorescent leak detection technologies for air conditioning systems; and an electric heat pump water heater. A yearly solicitation is available to help develop new heating and cooling technologies for buildings.

\section{Heating \& Cooling}

HVAC

Non-Specific

Applied research \& technology development

Ongoing

mailto:nar@nyserda.org

http://www.nyserda.org/Programs/IABR/BuildingsProgramAreas.asp\#controls 
Funding Source

Sponsoring Program/Office

Channel of Influence

Project Title

Brief Description

Objectives

End Use

Product Type Focus

Type of Building

Stage

Status

Primary Contact

Weblinks

ID

Funding Source

Sponsoring Program/Office

Channel of Influence

Project Title

Brief Description

Objectives

End Use

Product Type Focus

Type of Building

Stage

Status

Primary Contact

Weblinks
219

xState Utility

NYSERDA

Basic and Applied Research and Development

Lighting

NYSERDA teams with New York lighting manufacturers to develop quality, energy-efficient lighting products. An annual solicitation supports development of new products, such as fixtures to accommodate high efficiency light sources, fiber-based plasma display panels, photovoltaicpowered exterior fixtures, and ultraviolet germicidal systems. NYSERDA also partners with the Rensselaer Polytechnic Institute's Lighting Research Center (LRC), assisting manufacturers with programs such as the National Lighting Product Information Program (NLPIP), Design and Evaluation of Lighting Technologies and Applications (DELTA), the Hybrid Skylight Program, and numerous training seminars

Lighting

Lighting/daylighting (Sensor-Controls)

Non-Specific

Applied research \& technology development

Ongoing

mailto:mlw@nyserda.org

http://www.nyserda.org/Programs/IABR/BuildingsProgramAreas.asp\#advancedbuildings

206

xState Utility

BPA

Basic and Applied Research and Development

Heat Pump Water Heaters

The BPA focus includes coordinating lab testing and a technology demonstration in order to document performance, provide information to the region and deliver feedback to manufacturers. BPA lab testing began in October 2009 with evaluation results expected during the summer of 2010. A field-technology demonstration, partially funded by BPA and in partnership with the Electric Power Research Institute (EPRI), is also underway. The purpose of this demonstration pilot is to test units in the field at 40 sites in various climate zones throughout the Pacific Northwest region. Results from EPRI on this demonstration pilot are expected in early 2012.

Water Heating

Water Heat

Residential (all)

Applied research \& technology development

Ongoing

http://www.energy.ca.gov/research/esi/pricing/research_plan.html 





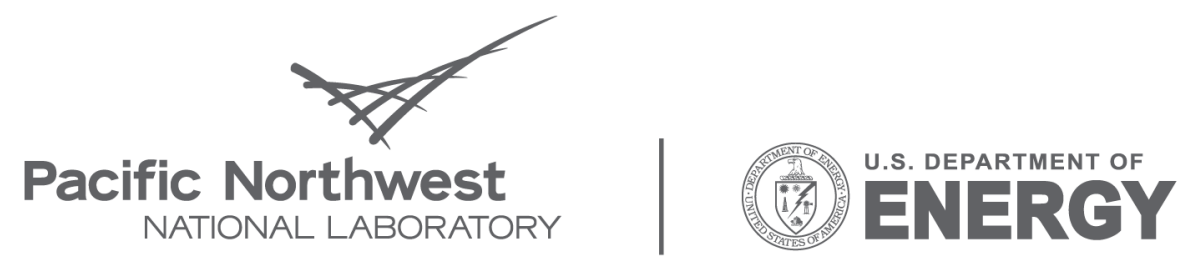

Proudly Operated by Battelle Since 1965

902 Battelle Boulevard

P.O. Box 999

Richland, WA 99352

1-888-375-PNNL (7665)

www.pnl.gov 